\title{
Cellular mechanisms of effects of sphingosine 1 -phosphate on vascular endothelial barrier
}

Mei Xu

West Virginia University

Follow this and additional works at: https://researchrepository.wvu.edu/etd

\section{Recommended Citation}

$\mathrm{Xu}, \mathrm{Mei}$, "Cellular mechanisms of effects of sphingosine 1 -phosphate on vascular endothelial barrier" (2008). Graduate Theses, Dissertations, and Problem Reports. 4432.

https://researchrepository.wvu.edu/etd/4432

This Dissertation is protected by copyright and/or related rights. It has been brought to you by the The Research Repository @ WVU with permission from the rights-holder(s). You are free to use this Dissertation in any way that is permitted by the copyright and related rights legislation that applies to your use. For other uses you must obtain permission from the rights-holder(s) directly, unless additional rights are indicated by a Creative Commons license in the record and/ or on the work itself. This Dissertation has been accepted for inclusion in WVU Graduate Theses, Dissertations, and Problem Reports collection by an authorized administrator of The Research Repository @ WVU.

For more information, please contact researchrepository@mail.wvu.edu. 
Cellular Mechanisms of Effects of Sphingosine 1-Phosphate on

Vascular Endothelial Barrier

\author{
Mei Xu
}

\begin{abstract}
Dissertation Submitted to the School of Medicine at West Virginia University

In Partial Fulfillment of the Requirements for the Degree of Doctor of Philosophy in Cellular and Integrative Physiology
\end{abstract}

Fred Minnear, Ph.D., Chair Matthew Boegehold, Ph.D. Scott Weed, Ph.D. Robert Wysolmerski, Ph.D. Yong Qian, Ph.D.

Cellular and Integrative Physiology

Morgantown, West Virginia

2008

Keywords: S1P, VE-cadherin, endocytosis, recycling, human umbilical vein endothelial cell, endothelial barrier, electrical resistance, adherens junction. 


\section{ABSTRACT \\ Cellular Mechanisms of Effects of Sphingosine 1-Phosphate on Vascular Endothelial Barrier}

\section{Mei Xu}

Sphingosine 1-phosphate (S1P), a biologically active lipid, induces a myriad of cellular events including enhancement of the endothelial barrier and assembly of adherens junction proteins, VE-cadherin and catenins. The over all goal in this set of studies was to investigate what cellular mechanisms contribute to S1P-induced enhancement of the vascular endothelial barrier.

Since VE-cadherin contributes to the stabilization of the endothelial barrier, I determined in the first study if the rapid, barrier-enhancing activity of S1P requires VEcadherin. $\mathrm{Ca}^{2+}$-dependent, homophilic VE-cadherin binding of endothelial cells, derived from human umbilical veins and grown as monolayers, was disrupted with EGTA, an antibody to the extracellular domain of VE-cadherin, or gene silencing of VE-cadherin with small interfering RNA (siRNA). All three protocols caused a reduction in the immunofluorescent localization of VE-cadherin at intercellular junctions, the separation of adjacent cells, and a decrease in basal, endothelial electrical resistance. In all three conditions, S1P rapidly increased endothelial electrical resistance. These findings demonstrate that S1P enhances the endothelial barrier independently of homophilic VEcadherin binding. Junctional localization of VE-cadherin, however, was associated with the sustained activity of S1P. Imaging with phase-contrast and differential interferencecontrast (DIC) optics revealed that S1P induced cell spreading and closure of intercellular gaps. Pretreatment with Latrunculin B, an inhibitor of actin polymerization, or Y-27632, a Rho kinase inhibitor, attenuated cell spreading and the rapid increase in electrical resistance induced by S1P. I conclude that S1P rapidly closes intercellular gaps, resulting in an increased electrical resistance across endothelial cell monolayers, via cell spreading and Rho kinase and independently of VE-cadherin.

Based on the previous observation that S1P increases the localization of junctional VE-cadherin as early as $10 \mathrm{~min}$, I determined in the second study what cellular mechanisms contributed to this increase. Because VE-cadherin dynamically traffics between cell surface and cytoplasmic vesicles, I hypothesized that S1P can regulate VE-cadherin trafficking. Immunofluorescence microscopy and a biotinylated cell impermeable reagent were used to demonstrate internalized and cell surface VEcadherin. Endocytosis of VE-cadherin was induced by EGTA or VEGF. S1P decreased EGTA-induced endocytosis and co-localization of internalized VE-cadherin with EEA 1, a marker of early endosomes, and prevented and reversed the effect of VEGF. S1P also increased the recovery of cell surface VE-cadherin after endocytosis by EGTA or VEGF and increased the co-localization of internalized VE-cadherin with Rab11, a marker of the recycling endosome. Bafilomycin A1, an inhibitor of recycling, and microtubule inhibitors, taxol and colchicine, blocked the increase in junctional VEcadherin and the sustained increase in endothelial electrical resistance induced by S1P, 
the latter using the $\mathrm{Ca}^{2+}$-switch protocol. Bafilomycin $\mathrm{A} 1$ also prevented the increase in recovery of cell surface VE-cadherin induced by S1P. When co-treated or post-treated with VEGF, S1P blocked or reversed the increased interaction of VE-cadherin with $\beta$ arrestin2, an endocytic adapter protein. I conclude that S1P stabilizes homophilic VEcadherin binding by decreasing endocytosis and increasing recycling of VE-cadherin, the latter requiring microtubules.

In the third study, I investigated the cellular mechanisms contributing to the regulatory effects of S1P on VE-cadherin trafficking. S1P increased co-localization and interaction of p120 with VE-cadherin and increased biotinylated, cell surface VEcadherin and p120 with or without EGTA pretreatment. In addition, S1P enhanced the co-localization of p120 with EGFP-tagged Rab11, a maker of recycling endosomes. VEGF decreased the interaction of VE-cadherin with p120, and co-treatment or posttreatment with S1P blocked or reversed, respectively, this effect of VEGF. Interestingly, S1P increased the interaction of p120 with kinesin, a motor protein that moves along microtubules to transport vesicles.

In summary, I conclude that S1P enhances the endothelial barrier through multiple ways: the rapid increase in endothelial barrier function is independent of VEcadherin, but requires Rho kinase and actin cytoskeleton-based cell spreading; sustained enhancement of the barrier is related to an increase in junctional VE-cadherin on which S1P has a novel effect—regulation of VE-cadherin trafficking, i.e. decreasing endocytosis and increasing recycling of VE-cadherin. p120 possibly is involved in this novel regulatory effect of S1P. Augmented interaction of p120 with kinesin by S1P may facilitate transport of recycling VE-cadherin via microtubules. 


\section{ACKNOWLEDGEMENTS}

First and foremost I would like to thank my advisor, Dr. Fred Minnear. His patience, kindness, knowledge, guidance and pleasantries always create a nice ambience which pushes me to do research. From him, I have learned how to think as a scientist and become an independent researcher. I would not finish my study without his dedication. I am eternally grateful.

I would like to thank my committee, Dr. Matthew, Boegehold, Dr. Scott Weed, Dr. Robert Wysolmerski, Dr. Yong Qian and Dr. Chuan Hu for all of their support and suggestions. I also want to thank Christopher Waters and people in the department of physiology for all of their help and teaching.

I deeply appreciate my parents, my husband and my son for their love and support. 


\section{TABLE OF CONTENTS}

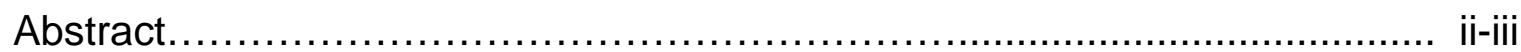

Acknowledgement $\ldots \ldots \ldots \ldots \ldots \ldots \ldots \ldots \ldots \ldots \ldots \ldots \ldots \ldots \ldots \ldots \ldots \ldots \ldots \ldots \ldots$ iv

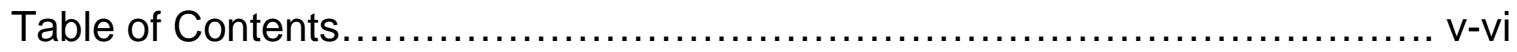

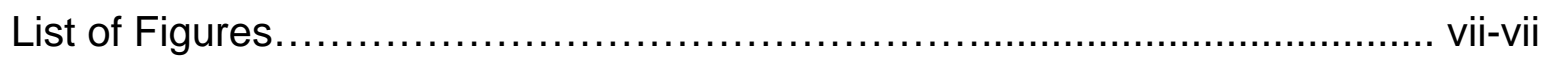

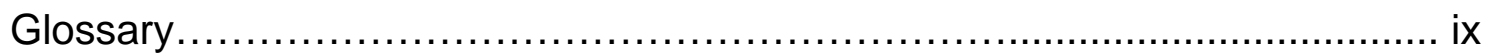

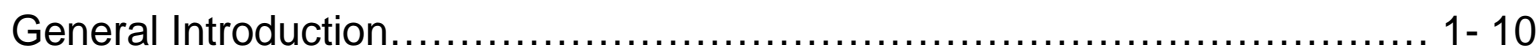

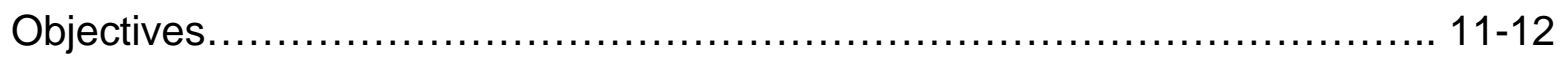

Study 1: Sphingosine 1-phosphate rapidly increases endothelial barrier function independent of VE-cadherin but requires cell spreading and Rho kinase.

Abstract

Introduction

Materials and Methods

Results

Discussion

References

Study 2: Sphingosine 1-phosphate regulates membrane trafficking of

VE-cadherin i. e. decreasing endocytosis and increasing recycling of VE-cadherin

Abstract

Introduction

Materials and Methods

Results

Discussion

References

Study 3: p120 is potentially involved in the regulated trafficking of

VE-cadherin by S1P

Abstract

Introduction

Materials and Methods

Results

Discussion

References 


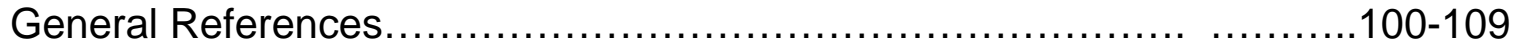




\section{LIST OF FIGURES}

General Introduction

1. Structure of adherens junctions.

2. Structure of sphingosine 1-phosphate and its bio-activities.

3. S1P increases electrical resistance of bovine pulmonary arterial endothelial cells.

4. S1P increases electrical resistance of human umbilical vein endothelial cells.

5. Cadherin trafficking pathway.

6. ECIS monitors the resistance between cells.

7. Biotinylation protocol.

Study 1

1. S1P rapidly increased endothelial electrical resistance after chelation of extracellular $\mathrm{Ca}^{2+}$ with EGTA.

2. S1P enhanced the junctional localization of vascular endothelial (VE)-cadherin and peripheral actin.

3. S1P rapidly increased endothelial electrical resistance in presence of antibody to extracellular domain of VE-cadherin.

4. S1P increased endothelial electrical resistance after gene silencing of VEcadherin.

5. S1P induced cell spreading.

6. Inhibitor of actin polymerization attenuated S1P-induced increases in endothelial electrical resistance and cell spreading.

7. Inhibitor of Rho kinase attenuated S1P-induced increases in endothelial electrical resistance and cell spreading.

Study 2

1. S1P increased VE-cadherin and p120 at cell-cell contacts.

2. S1P influenced trafficking of VE-cadherin.

3. S1P decreased and reversed effects of VEGF.

4. S1P increased co-localization of Rab11 with VE-cadherin.

5. S1P augmented recycling of VE-cadherin

6. Inhibition of recycling blocked sustained activity of S1P and recovery of cell surface VE-cadherin..

7. S1P decreased endocytosis of VE-cadherin and blocked increase in colocalization of VE-cadherin with EEA 1.

8. Microtubule inhibitors blocked effects of S1P.

Study 3

1. S1P increased interaction of $p 120$ with VE-cadherin.

2. S1P enhanced interaction of p120 with recycled, cell surface VE-cadherin.

3. S1P increased co-localization of p120 with recycled VE-cadherin. 
4. S1P increased co-localization of p120 with Rab11.

5. S1P increased interaction of $\mathrm{p} 120$ with kinesin.

6. S1P inhibited and reversed decrease in interaction of VE-cadherin with p120 by VEGF. 


\section{GLOSSARY}

S1P

HUVEC

VE-cadherin

EGTA

ECIS

ER

E/B

SiRNA

DMSO

PBS

TBS

BSA

SDS-PAGE

DIC

Lat

$Y$

E-cadherin

BPAEC

VEGF

Sulfo-NHS-SS-Biotin

PMSF

Baf

EEA 1

$\mathrm{N}$-cadherin

EGF

PDGF

GPCR

Edg

p120

PKC

ICRAC
Sphingosine 1-phosphate

Human umbilical vein endothelial cell

Vascular endothelial cadherin

Ethylene glycol-bis(2-amino-ethylether)-

$\mathrm{N}, \mathrm{N}, \mathrm{N}$ ',N'-tetra-acetic acid

Electric Cell-substrate Impedance Sensing

Electrical resistance

Electrical resistance/basal value

Small interference RNA

Dimethyl sulfoxide

Phosphate-buffered saline

Tris-buffered saline

Bovine serum albumin

Sodium dodecyl sulfate-polyacrylamide-gel

electrophoresis

Differential interference-contrast

Latrunculin B

Y-27632

Epithelial cadherin

Bovine pulmonary arterial endothelial cell

Vascular endothelial growth factor

Sulfosuccinimidyl 2-(biotinamido) ethyl-

dithioproprionate

Phenylmethanesulfonyl fluoride

Bafilomycin A1

Early endosome antigen 1

Neuronal cadherin

Epithelial growth factor

Platelet-drived growth factor

G-protein coupled receptor

Endothelial differentiation gene

p120-catenin

Protein kinase $\mathrm{C}$

Calcium release-activated calcium current 


\section{GENERAL INTRODUCTION}

Endothelia adhere to each other through junctional structures to constitute a selective semipermeable barrier. Disruption of vascular barrier integrity leads to increases of fluid, solutes and proteins across endothelia, resulting in raised permeability which is linked to normal biological processes, such as protein and fluid transport, inflammation, white cell emigration, vasogenesis, as well as to many pathological processes, for example, cancer metastasis and tumor angiogenesis. Two pathways, paracellular and intracellular (vesicular), can account for the increased permeability. However, the paracellular pathway is considered main pathway that contributes to the increased permeability (45). However, the cellular mechanisms are unclear. Suggested mechanisms that regulate the endothelial barrier include alterations in the integrity of the junctions, the cytoskeleton, focal adhesions and cellular retraction/contraction and relaxation. There are two main intercellular junctions between endothelial cells, tight junctions and adherens junctions $(5,6,16,31)$. Distribution of tight junctions varies along different segments of the vascular tree; tight junctions are well developed in arteries and arterioles, but less organized in veins and postcapillary venules, which are the primary sites for the extravasation of proteins and leukocytes (5). Adherens junctions (Figure 1) are formed by trans-membrane adhesion proteins of the cadherin family, especially vascular endothelial (VE) cadherin, whose cytoplasmic tail is linked to the actin cytoskeleton through $\beta$ - and $\alpha$-catenin. p120 catenin stabilizes VE-cadherin at the junctional site by binding to the juxtamembrane domain of VE-cadherin $(28,63)$. VEcadherin consists of an extracellular domain with five homologous $\mathrm{Ca}^{2+}$-binding repeats (EC1-EC5) that binds homophilically with VE-cadherin on an adjacent cell. It is known that VE-cadherin is related to endothelial cell migration, survival, contact-induced growth inhibition, vascular integrity and most notably, angiogenesis (17, 18, 42, 61). Targeting the extracellular domain of VE-cadherin by specific antibodies, resulting in the inhibition of angiogenesis, tumor growth and metastasis, is being developed as a potential tool for cancer therapy $(13,14,38)$. Interestingly, the loss of VE-cadherin expression is related to a variety of pathologies, e. g. inflammation, angiogenesis and endothelial-mesenchymal transdifferentiation $(1,10,62)$. Thereby, the regulated 
changes in VE-cadherin level have important consequences on endothelial function and pathophysiology. However, the cellular mechanisms that regulate cell surface expression of VE-cadherin are poorly characterized.

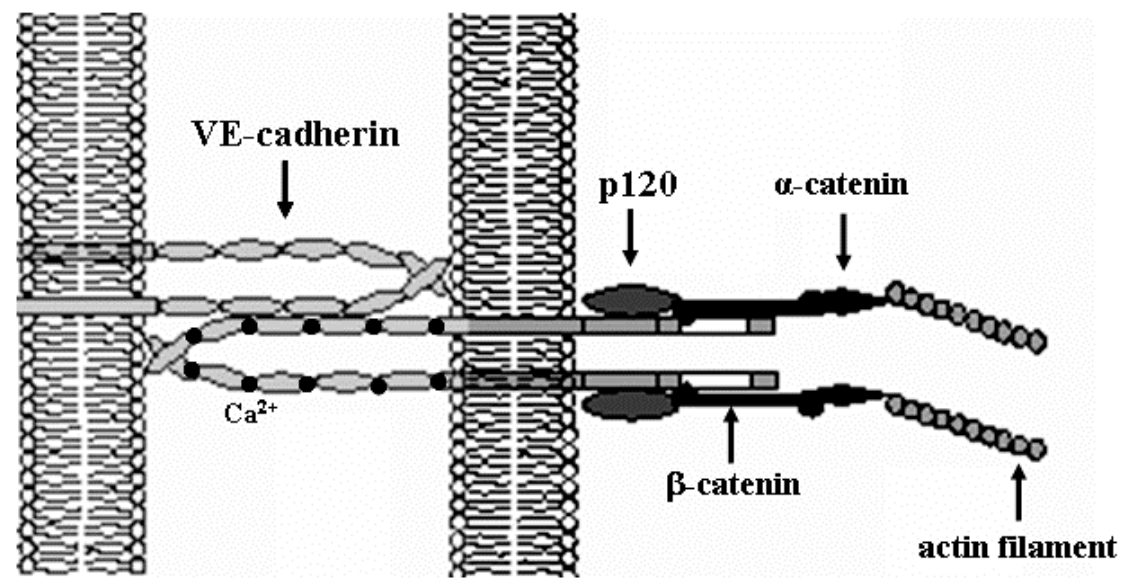

Figure 1. Structure of adherens junctions (see text for details).

Adherens junctions are extensively investigated and are considered as a primary regulated site by many endogenous and exogenous factors. Sphingosine 1-phosphate (S1P) is a biologically active lipid growth factor (Figure 2) produced in many cells mainly from platelets by the phosphorylation of sphingosine $(55,57)$, and also from erythrocytes in a stimulus-independent manner (27). S1P exists in the circulation from nanomolar to micromolar concentration, and its activities are regulated by association with HDL (active form) or LDL (inactive form) (4). S1P distributes throughout the whole cardiovascular system and plays a role in regulation of vascular tone. It is known that S1P can induce a myriad of cellular events, such as cellular locomotion, vascular maturation, and angiogenesis, as well as enhance the endothelial barrier (45, 46, 57). S1P ligates G-protein coupled receptors, known are at least five S1P receptors of the endothelial differentiation gene (Edg) family, and elicits a wide variety of intracellular signals. Vascular endothelial cells express predominantly S1P-1 (Edg-1) and S1P-3 


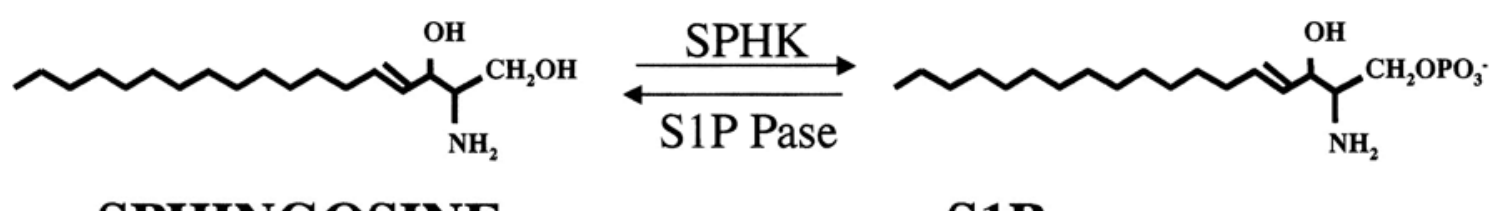

\section{SPHINGOSINE}

Growth arrest

Enhances apoptosis

Inhibits PKC

Inhibits ICRAC

Decreases thermotolerance

Regulates endocytosis

Role in cytoskeletal rearrangements
S1P

Stimulates growth

Suppresses apoptosis

Regulates motility

Regulates calcium

Increases thermotolerance

GPCR ligand

Role in cytoskeletal rearrangements

Figure 2. Structure of S1P and its bio-activities.

(Edg-3) receptors $(26,37,45,46,51)$. S1P induces a rapid and dose-dependent increase in vascular endothelial barrier function as recorded by increases in transendothelial monolayer electrical resistance (20). For example, S1P induces a dosedependent increase in electrical resistance on bovine pulmonary arterial endothelial cell (BPAEC) monolayers and a sustained increase in electrical resistance on human umbilical vein endothelial cell (HUVEC) monolayers (Figures 3 and 4). S1P activates a number of Rho family GTPases, such as Rac 1 , Cdc42 and Rho A (20, 22, 35). S1Pelicited Rac 1 has been studied more extensively and has been linked to S1P-enhanced barrier function $(20,58)$. However, we found that inhibition of Rho-kinase, a downstream target of Rho A, also suppresses the S1P-increased electrical resistance in both human and bovine cell lines. Therefore, the role of Rho A in S1P effects needs more study. It is known that S1P organizes actin filaments into a strong cortical ring (45) and assembles VE-cadherin and $\beta$-catenin at adherens junctions $(20,36,47)$. How the actin cytoskeleton or VE-cadherin contributes to the whole process of S1P effects is still unclear. Furthermore, what cellular mechanisms contribute to S1P-assembled membrane VE-cadheren have not yet been investigated. S1P and other lysophospholipids elevate intracellular calcium and trigger exocytosis in non-endothelial and endothelial cells $(36,44,47)$. S1P induces the exocytosis of Weibel-Palade bodies, 
and increases glutamate secretion in hippocampal neurons $(29,44)$. Possibly, S1P is able to regulate exocytosis of internalized proteins.

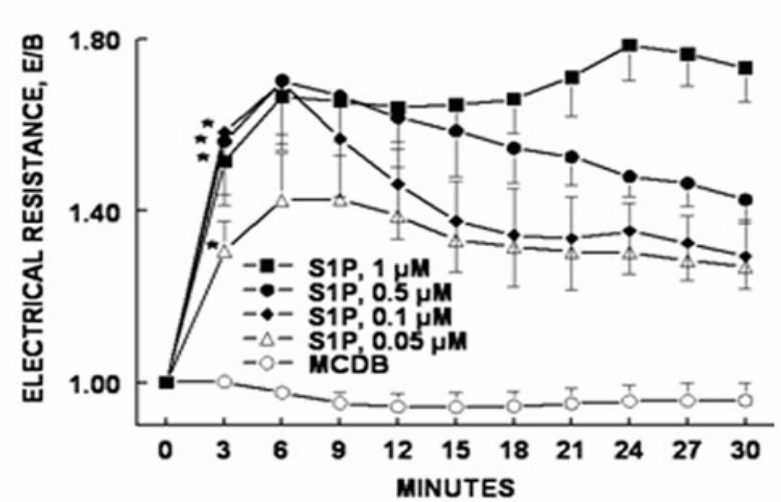

Unpublished from Dr. Fred Minnear

Figure 3. S1P increases electrical resistance of BPAECs (see text for details).

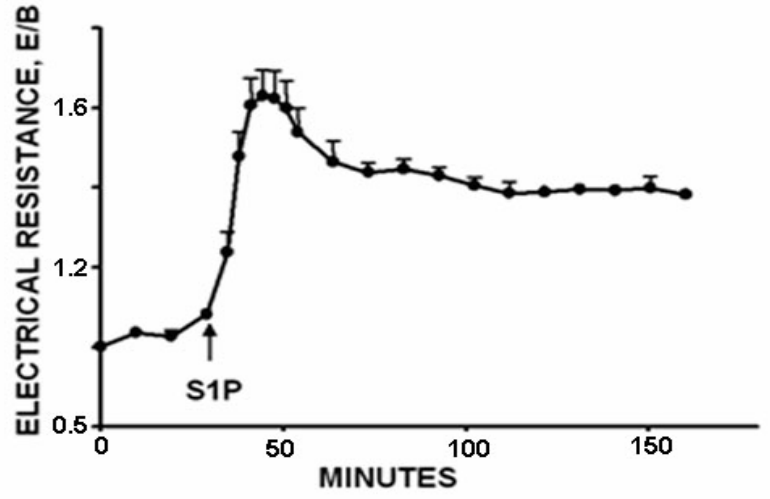

Figure 4. S1P increases electrical resistance of HUVECs. (see text for details).

The cadherin family of proteins consists of epithelial $(E)-$, placental $(P)-$, neuronal $(\mathrm{N})-$, muscle (M)-, and VE-cadherin and constitutively traffics between cell surface and cytoplasm. Expression of cadherin at the plasma membrane is dynamically regulated by cadherin turnover, which involves the processes of endocytosis, degradation, and recycling. Cadherin first sorts into early endosomes, then goes through later endosomes to be degraded by lysosomes, or recycled back to the cell surface via recycling endosomes (Figure 5). Endocytosis of cadherins can be mediated through clathrindependent and clathrin-independent (caveolin-mediated) pathways and has been observed during development, during epithelial to mesenchymal transition, and in response to growth factors and tumorigenic signals $(8,9,34,65)$. The endocytosis and recycling of E-cadherin, a member of the cadherin family expressed mainly on epithelial cells, have been studied intensively by Stow et al. $(8,9,33,34)$. They found that $13 \%$ of E-cadherin traffics dynamically. Depletion of extracellular calcium disrupted cell-cell 
contacts and induced endocytosis of E-cadherin, and repletion of calcium recovered surface E-cadherins, which was inhibited by bafilomycin A1, an inhibitor of recycling (34). They suggested that the pool of cell surface E-cadherin is constantly trafficking through endocytic and recycling pathways. The trafficking of VE-cadherin may be similar to that of E-cadherin. Endocytosis of VE-cadherin is an important regulated mechanism that accounts for the amount of cell surface VE-cadherin. Down-regulation of VE-cadherin initiates endothelial-mesenchymal transdifferentiation and is related to atherogenesis $(7,19)$. Alexander et al. $(2,34)$ reported that a decrease in extracellular calcium reduced cell surface $\mathrm{VE}$-cadherin and

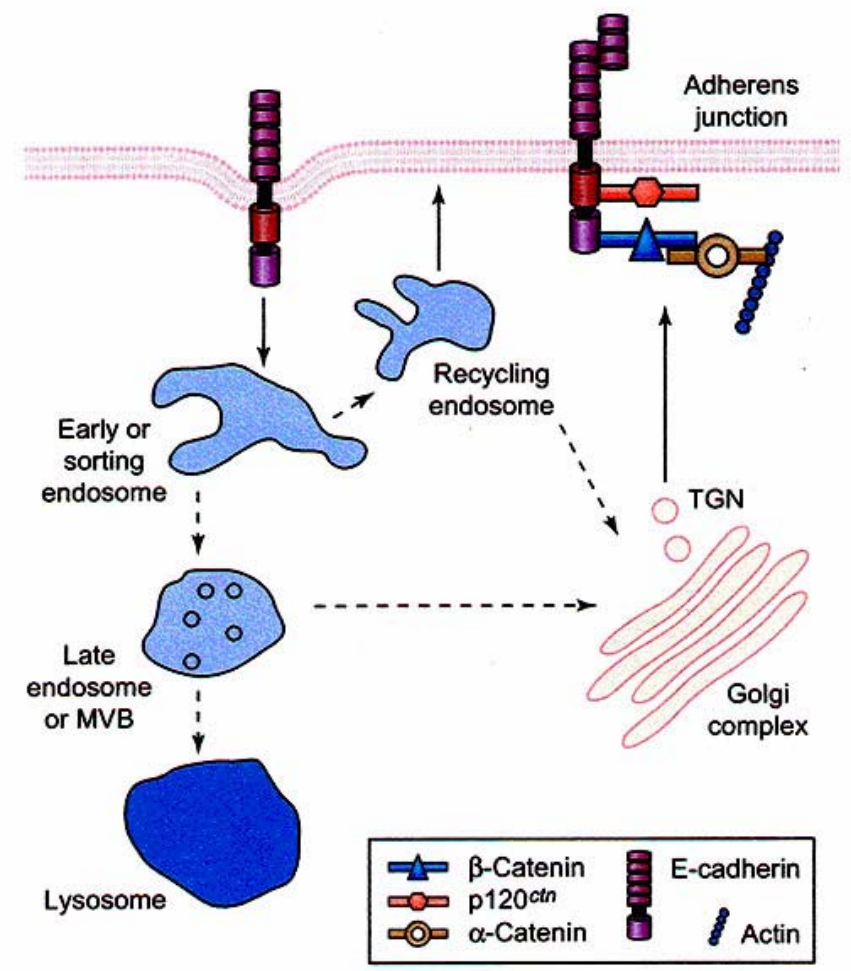

Bryant and Stow, TICB $200414: 427$

Figure 5. Trafficking pathway of E-cadherin (see text for details).

induced endocytosis of VE-cadherin in which protein kinase C is involved. Gavard and Gutkind (21) reported that VEGF induces endocytosis of VE-cadherin through a $\beta$ arrestin2, an adaptor protein for endocytosis, -dependent pathway which may contribute to the increased permeability by VEGF. Furthermore, endocytosis of VE-cadherin facilitates VEGF receptor2 internalization and its downstream signaling (32). However, 
the mechanisms related to regulation of trafficking of VE-cadherin are unclear, and which endogenous factors that regulate VE-cadherin trafficking have not been investigated. Interestingly, S1P at low concentration stabilized the vascular endothelial barrier through regulation of $\mathrm{N}$-cadherin trafficking (52), but whether S1P has capacity to regulate VE-cadherin trafficking that contributes to S1P-induced enhancement of endothelial barrier function is not clear. Our study is designed to investigate the cellular mechanisms for the regulation of endothelial barrier function induced by S1P.

Recently, p120 was reported to play a core function for regulation of VEcadherin. p120 catenin, a member of the armadillo family of proteins and originally identified as a substrate for Src and other tyrosine kinases, interacts with VE-cadherin through its ARM domain and binds to the juxtamembrane domain (3). lyer et al. (28) reported that the interaction of VE-cadherin with p120 is crucial for stabilization of the endothelial barrier, and p120 plays a major role in this stabilization; either a decrease or increase in expression level of p120 results in disruption of the endothelial barrier. Xiao et al. $(15,63-65)$ reported that p120 acts as a set point for cadherin expression in mammalian endothelial cells. The loss of p120 causes the internalization of E-cadherin and delivery to lysosomes for proteolytic degradation. Contrastingly, over-expression of p120 strongly inhibited clathrin-dependent endocytosis of VE-cadherin. Interestingly, there is a reported interaction of $\mathrm{p} 120$ with kinesin, a motor protein, via a segment of the $\mathrm{N}$-terminus of $\mathrm{p} 120$ that binds to kinesin heavy chain. Based on this interaction, p120kinesin regulates $\mathrm{p} 120$ localization and function, and furthermore facilitates the transport of the cadherin-catenin complex to intercellular junctions $(12,67)$. However, p120 is not necessary for proper delivery of new biosynthesized VE-cadherin to the cell membrane (63). One goal of my studies is to investigate whether or not p120 is involved in VEcadherin trafficking induced by S1P.

Rab proteins, a large family of monomeric small GTPases, distribute to distinct intracellular compartments, and in their active form, coordinate with their effectors to regulate vesicle sorting, transportation, and fusion with membranes $(53,59,60,68)$. As mentioned above, cadherin turnover mainly includes endocytosis, recycling, as well as 
degradation of which, respectively, are related to early endosomes, recycling endosomes, and later endosomes and lysosomes. Rab5, works together with its effector, EEA1 (early endosome antigen 1) to regulate the transportation of clathrincoated-vesicles from the plasma membrane to early endosomes as well as homotypic fusion of early endosomes. Rab7 localizes at later endosomes and Rab11 and Rab4 regulate the recycling process. Papers by Moore and Stow $(41,48)$ have reported that Rab11 works as an intermediate compartment for regulation of recycling of beta2adrenergic receptors and the post-Golgi trafficking and exocyotosis of E-cadherin. Accordingly, Rab proteins are used as markers for specialization of distinct endosomes. Other proteins, such as soluble NSF attachment receptors (SNAREs), Vamp3, etc. also work in partnership with the function of Rab GTPases.

Vascular endothelial growth factor (VEGF), formerly known as a vascular permeability factor, is essential for vasculogenesis and angiogenesis through ligating to its receptor, VEGFR-2. Dejana and co-workers (32) reported that VEGF induced the internalization of VEGFR-2, which was facilitated in the absence of cell surface VEcadherin. Furthermore, engaged homophilic binding of VE-cadherin retained VEGFR-2 at the cell membrane and prevented its internalization into signaling compartments. Recently, it was reported that the VEGF-induced increase in vascular permeability is related to VEGF-induced endocytosis of VE-cadherin $(21,32)$. These studies outline the following sequence of events: VEGF binds to VEGFR-2 and activates Src which activates Rac then p21-activated kinase (PAK), which phosphorylates a highly conserved motif within the intracellular tail of VE-cadherin, followed by recruitment of $\beta$ arrestin2 to the serine-phosphorylated VE-cadherin, thereby promoting clathrindependent endocytosis of VE-cadherin. Interestingly, S1P is a vascular barrier enhancer. Based on the opposite role of S1P, I hypothesize that S1P is able to suppress the VEGF-induced increase in vascular permeability by regulating the interaction of $\beta$-arrestin2 with VE-cadherin, which in turn modulates the endocytosis of VE-cadherin. 
Protein trafficking transports via actin cytoskeletons or microtubules or both (25, 49). Microtubules, together with the microtubule-based motor proteins, kinesin and dynein, play an essential role in membrane trafficking events involved in endocytosis, transcytosis, etc. $(25,39,40,43,50,66)$. As aforementioned, p120-kinesin interaction facilitates the transport of the cadherin-catenin complex to cell-cell contacts via microtubules in living fibroblasts (43). Interestingly, S1P was reported to increase polymerization of microtubules and facilitate $\mathrm{N}$-cadherin trafficking along it $(52,66)$. However, if trafficking of VE-cadherin goes through microtubules, it has not been characterized. In this dissertation, two types of microtubule inhibitors, taxol (inhibits depolymerization) and colchicine (inhibits polymerization), were used to investigate the effects of microtubules on VE-cadherin trafficking.

As stated above, S1P enhances endothelial barrier function as assessed as an increase in electrical resistance by using Electric Cell-substrate Impedance Sensing (ECIS) technology (Figure 6). This patented technique, invented by Drs. Ivar Giaever and Charles R. Keese (Applied Biophysics, Inc), is one of the main techniques used in my dissertation and now is widely applied to measure, in real time, cell motility, cell growth, cell spreading, wound healing and barrier function via constantly monitoring the changes in impedance of a small electrode to $A C$ current flow $(11,23,24,54,56)$. The current flows between a small electrode and a larger counter electrode using normal culture medium as the electrolyte. Cells are seeded on a gold-coated small electrode (250 $\mu \mathrm{m}$ diameter) in ECIS culture wells. The electrical resistance measured is that of those cells. When cells attach to the culture wells, the current flows in the spaces under and between the cells, as the cell membranes are essentially insulators. A constant current of $1 \mu \mathrm{A}$ is supplied by a $1-\mathrm{V}, 4,000-\mathrm{Hz}$ alternating current through a $1-\mathrm{M} \Omega$ resistor. Finally, changes in voltage between the small electrode and the large counter are monitored by the lock-in amplifier, stored, and then calculated as resistance by the computer. On confluent endothelial monolayers, an increase in electrical resistance indicates cell-cell contacts becoming tighter, i. e. enhancing endothelial barrier. In contrast, decreased electrical resistance means loosened cell-cell contacts. 
To study protein trafficking, quantitative measurements of internalized and
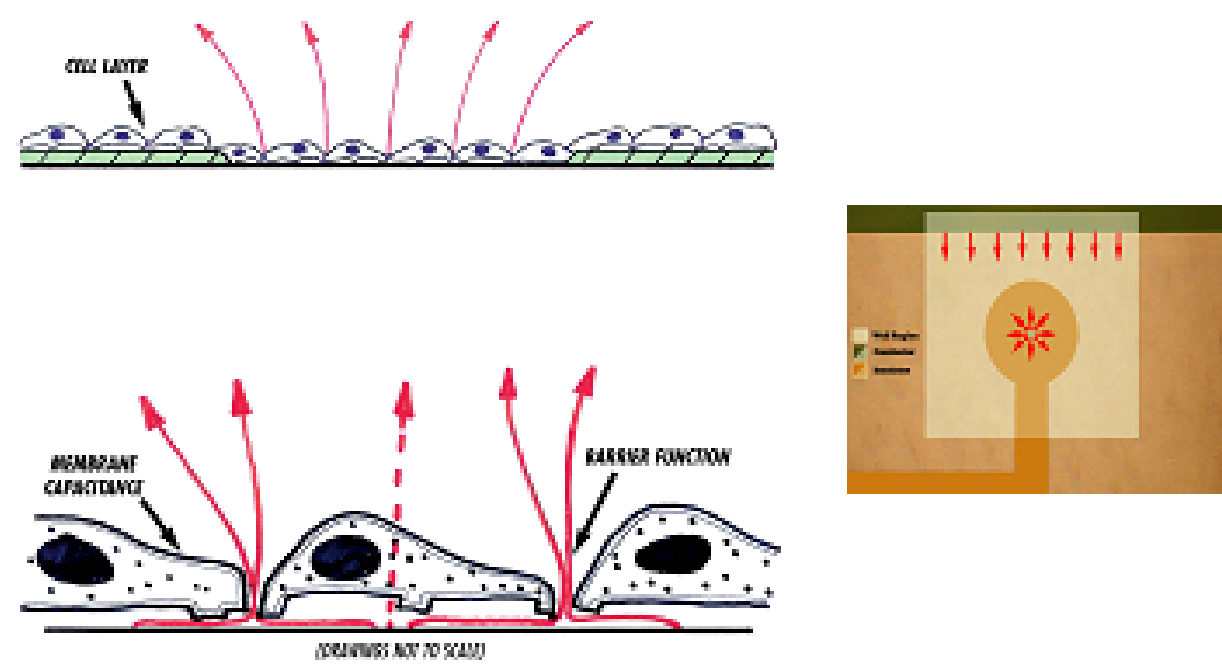

Figure 6. ECIS monitors the resistance between cells (see text for details).

cell surface VE-cadherin are essential. A biotinylation protocol (Figure 7) was adopted to measure internalized and cell surface proteins and has been frequently used by Stow et al. in their studies on trafficking of E-cadherin $(8,33,34)$. Sulfo-NHS-SS-biotin is a water-soluble, membrane impermeable and cleavable biotin reagent that binds to primary amines (lysine) through its NHS ester. Since biotin forms a strong non-covalent bond when it interacts with avidin or streptavidin, sulfo-NHS-SS-biotin is good for purification and extraction of proteins. For measurement of internalized proteins, labeling cell surface proteins with sulfo-NHS-SS-biotin is the first step, followed by designated treatments to induce endocytosis. Glutathione disrupts S-S bonds in sulfoNHS-SS-biotin and removes biotin from the cell surface. Internalized proteins resistant to the glutathione wash and still bound to sulfo-NHS-SS-biotin are collected by streptavidin beads. However, the measurement of cell surface proteins is somewhat different. After treatments, whole cell surface proteins are labeled with sulfo-NHS-SSbiotin and then collected by streptavidin. Comparing these two methods, the glutathione wash is the pivotal step. 
In summary, the cellular mechanisms of the effects of S1P on endothelial barrier function were investigated through measurements of changes in endothelial electrical resistance, function of homophilic VE-cadherin binding, junctional localization of VEcadherin, cell spreading, interaction of VE-cadherin with other proteins, and trafficking of VE-cadherin.

\section{Biotinylation Method}

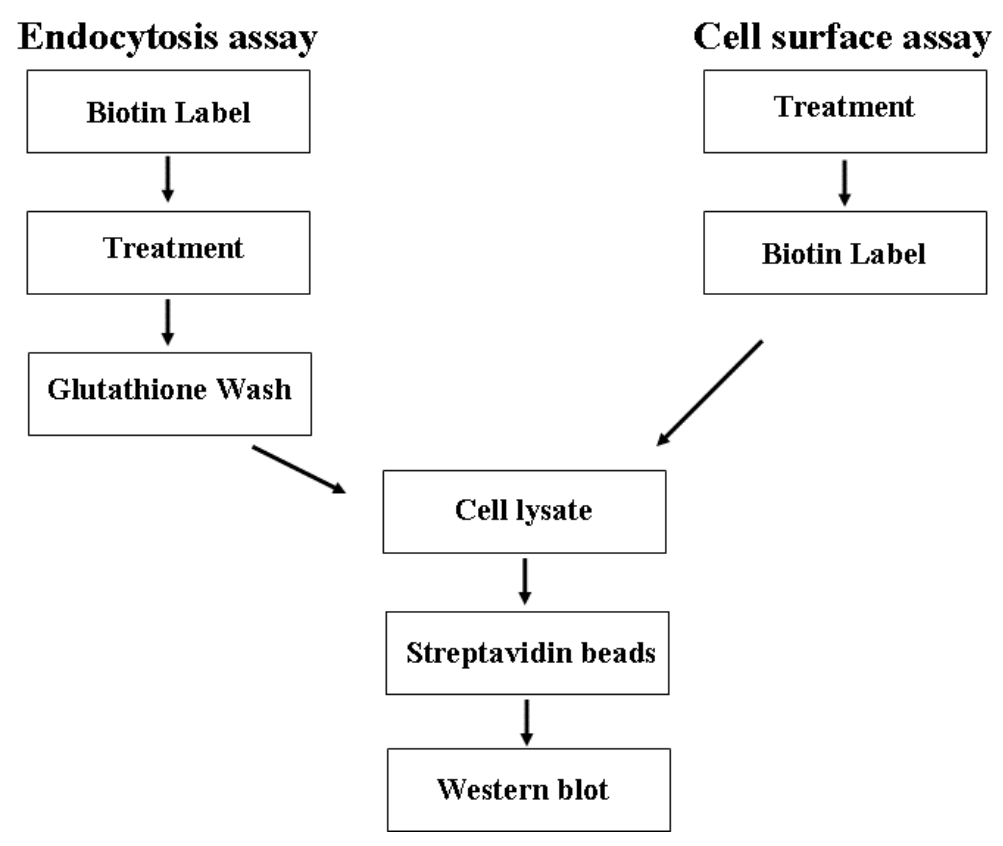

Figure 7. Biotinylation protocol (see text for details). 


\section{OBJECTIVES}

Endothelia lining the inner surface of blood vessels constitute a selective semipermeable barrier. Changes of barrier integrity are linked to many physiological and pathological processes. For example, disruption of the vascular barrier by inflammatory stimuli increases vascular permeability to fluid and solutes, which can result in edema (30). Angiogenesis also requires physiological changes of the endothelial barrier $(6,31)$. The cellular mechanisms that regulate the endothelial barrier are not completely clear and may involve a number of cellular processes. Adherens junctions containing vascular endothelial (VE)-cadherin, other cadherins and catenins $(\alpha, \beta, \gamma$ and $p 120)$ have been studied extensively and have been considered as primary regulated sites by various endogenous and exogenous factors. Calcium-dependent VEcadherin mediates cell-cell contacts and plays an essential role in stabilization of the vascular barrier. It has been recognized that sphingosine 1-phosphate (S1P), a biologically active lipid released mainly by active platelets, enhances barrier function as measured by an increase in trans-endothelial electrical resistance (20), and increases the localization of VE-cadherin and $\beta$-catenin at the adherens junctions $(36,46)$. However, the cellular mechanisms that contribute to S1P effects on endothelial barrier function, especially on regulating VE-cadherin, are not fully clear.

The goal of my research is to identify what cellular mechanisms contribute to the S1P-induced enhancement of barrier function.

Study 1. To determine if VE-cadherin is involved in the S1P-induced enhancement of electrical resistance.

- The primary objective is delineate the involvement of homophilic VE-cadherin binding and cell spreading in the enhancement of endothelial barrier function induced by S1P.

Study 2. To investigate S1P effects on the maintenance of endothelial barrier function through regulating trafficking of VE-cadherin. 
- Hypothesis 1. S1P enhances the localization of VE-cadherin at adherens junctions by increasing recycling and decreasing endocytosis of VE-cadherin. By these processes, S1P stabilizes the localization of VE-cadherin.

- Hypothesis 2. S1P rescues the VEGF-induced decrease in membrane VEcadherin by blocking the VEGF-induced $\beta$-arrestin2-related endocytosis of VEcadherin.

Study 3. To investigate if $\mathrm{p} 120$ is involved in regulated VE-cadherin trafficking by S1P.

- Hypothesis. Increased interaction of p120 with VE-cadherin by S1P facilitates VE-cadherin trafficking. 


\section{Study 1}

Sphingosine 1-phosphate rapidly increases endothelial barrier function independent of VE-cadherin but requires cell spreading and Rho kinase

Keywords: permeability, microscopy, electric cell-substrate impedance sensing, human umbilical endothelial cell. 


\section{ABSTRACT}

Sphingosine 1-phosphate (S1P) rapidly increases endothelial barrier function and induces the assembly of adherens junction proteins, VE-cadherin and catenins. Since VE-cadherin contributes to the stabilization of the endothelial barrier, I determined if the rapid, barrier-enhancing activity of S1P requires VE-cadherin. $\mathrm{Ca}^{2+}$-dependent, homophilic VE-cadherin binding of endothelial cells, derived from human umbilical veins and grown as monolayers, was disrupted with EGTA, an antibody to the extracellular domain of VE-cadherin, or gene silencing of VE-cadherin with small interfering RNA (siRNA). All three protocols caused a reduction in the immunofluorescent localization of VE-cadherin at intercellular junctions, the separation of adjacent cells, and a decrease in basal, endothelial electrical resistance. In all three conditions, S1P rapidly increased endothelial electrical resistance. These findings demonstrate that S1P enhances the endothelial barrier independently of homophilic VE-cadherin binding. Junctional localization of VE-cadherin, however, was associated with the sustained activity of S1P. Imaging with phase-contrast and differential interference-contrast (DIC) optics revealed that S1P induced cell spreading and closure of intercellular gaps. Pretreatment with Latrunculin B, an inhibitor of actin polymerization, or Y-27632, a Rho kinase inhibitor, attenuated cell spreading and the rapid increase in electrical resistance induced by S1P. I conclude that S1P rapidly closes intercellular gaps, resulting in an increased electrical resistance across endothelial cell monolayers, via cell spreading and Rho kinase and independently of VE-cadherin. 


\section{INTRODUCTION}

Vascular endothelia act as a restrictive barrier and as such regulate many biological processes such as protein and fluid transport, inflammation, white cell emigration, and angiogenesis. Disruption of the endothelial barrier leads to accumulation of fluid and macromolecules in the interstitial space, resulting in edema and dysfunction of tissues and organs $(1,11,14)$. The cellular mechanism(s) that regulates the endothelial barrier is not known and may involve a number of cellular processes. Proposed mechanisms include alterations in the integrity of the junctions, the cytoskeleton, and focal adhesions and cellular retraction/contraction and relaxation $(1,11,14)$. Tight junctions comprised of occludins, claudins, ZO-1, etc. impart the barrier characteristics of epithelial cells; however, their importance with respect to endothelial barrier function requires further study (1). The endothelial adherens junction, containing vascular endothelial (VE)-cadherin, other cadherins, and catenins, has been studied extensively, and modifications to VE-cadherin profoundly affect the integrity of the endothelial barrier. For example, antibodies directed toward the extracellular domain of VE-cadherin increased the permeability of endothelial cell monolayers (4) and the vascular permeability in heart and lungs of mice (5).

Sphingosine 1-phosphate (S1P) is a biologically active lipid released from a number of cells, notably platelets, and is present in blood and serum at nanomolar to micromolar concentrations. S1P enhances the barrier function of cell monolayers (8), prevents the increase in hydraulic conductivity induced by platelet-activating factor in single venular microvessels (17), and attenuates the increase in pulmonary edema in mice and dogs subjected to intra-tracheal endotoxin $(12,19)$. In addition, S1P enhances the localization of VE-cadherin and the catenins, $\alpha, \beta$, and $\gamma$, at endothelial junctions within 30 to 60 min of treatment $(9,13)$. S1P has also been shown to induce membrane ruffling and cell spreading of single endothelial cells $(6,18)$ and lamellipodia formation and cell spreading at the leading edge of wounded, endothelial cell monolayers (25). Cell spreading is also induced by cAMP-enhancing agents that are well known to rapidly tighten the endothelial barrier $(15,22)$. 
Therefore, the primary objective of the study was to delineate the involvement of homophilic VE-cadherin binding and cell spreading in the enhancement of endothelial barrier function induced by S1P. VE-cadherin binding was disrupted by using three different methodologies, addition of EGTA to the cell culture medium to lower extracellular $\mathrm{Ca}^{2+}$, addition of an antibody to the extracellular domain of VE-cadherin, and gene silencing of VE-cadherin with small interfering RNA (siRNA). Imaging of live cells by phase-contrast and differential interference-contrast (DIC) optics documented changes in cell shape. Evidence of closure of intercellular gaps, induced by the treatment of EGTA, was demonstrated microscopically and by an increase in endothelial electrical resistance. Since actin polymerizes at the leading edge of spreading cytoplasm (21), S1P reorganizes actin to the cell periphery (8), and activation of the small GTPase Rho has been implicated in the spreading of single endothelial cells by S1P (18), I further determined if inhibitors of actin polymerization and Rho kinase, an effector of Rho, would impede the spreading of endothelial cells by S1P. 


\section{MATERIALS AND METHODS}

Materials. S1P was purchased from Avanti Polar Lipids (Alabaster, AL). Gentamicin sulfate was from ICN Biomedicals, Inc. (Aurora, $\mathrm{OH}$ ). Newborn calf serum and bovine brain extract were from Cambrex Corporation (East Rutherford, NJ). Prolong Gold antifade reagent, Alexa Fluor-labeled secondary antibodies and Alexa Fluor-labeled phalloidin were from Invitrogen Molecular Probes (Eugene, OR). Gold-coated ECIS (Electrode Cell-substrate Impedance Sensing) electrodes were from Applied Biophysics (Troy, NY). Rabbit anti-human VE-cadherin antibodies were purchased from USBiological (Swampscott, MS) and Axxora (San Diego, CA). Goat anti-human VEcadherin antibody and normal rabbit IgG were from Santa Cruz Biotechnology (San Diego, CA). Horseradish peroxidase conjugated secondary antibodies were purchased from Chemicon International (Temecula, CA). Control (scrambled) siRNA and VEcadherin siRNA (Smartpool) were from Dharmacon (Chicago, IL). Nitrocellulose membranes and ECL (enhanced chemiluminescence) Western blotting detection reagents were from Amersham Biosciences (Buckinghamshire, England). All other chemicals were from Sigma-Aldrich (St. Louis, MO).

Cell Culture. Endothelial cells were isolated from human umbilical veins (HUVEC) with $1 \mathrm{mg} / \mathrm{ml}$ of type I collagenase and grown in MCDB-131 (MCDB) culture medium containing 5\% (v/v) human serum, 20\% (v/v) newborn calf serum, $7.5 \mu \mathrm{g} / \mathrm{ml}$ of endothelial cell growth supplement, $4.5 \mu \mathrm{g} / \mathrm{ml}$ of bovine brain extract, $25 \mu \mathrm{g} / \mathrm{ml}$ of porcine intestinal heparin, and $50 \mu \mathrm{g} / \mathrm{ml}$ of gentamicin sulfate. HUVECs (passages 2-8) were grown to confluence $(2 \mathrm{~d})$ in a humidified incubator maintained at $37^{\circ} \mathrm{C}$ and $5 \%$ $\mathrm{CO}_{2}$. Before treatment with S1P, MCDB containing 25\% serum was replaced with serum-free MCDB, and the cells monolayers were allowed to equilibrate for $2 \mathrm{~h}$ in an incubator.

Transendothelial electrical resistance. To assess changes in endothelial barrier function, electrical resistance was measured continuously across HUVEC monolayers 
by ECIS $(7 ; 16)$. Briefly, HUVECs $(80,000-100,000$ cells) were seeded onto ECIS cultureware $\left(0.8 \mathrm{~cm}^{2} /\right.$ well $)$ precoated with $0.2 \%$ gelatin. The measured electrical resistance was of those cells located on the small gold electrode $\left(5 \times 10^{-4} \mathrm{~cm}^{2}\right)$ in each of the wells. The culture medium was the electrolyte, and the small gold electrode, covered by confluent endothelial cells, and a larger gold counter-electrode $\left(\sim 2 \mathrm{~cm}^{2}\right)$ were connected to a phase-sensitive, lock-in amplifier. A constant current of $1 \mu \mathrm{A}$ was supplied by a $1-\mathrm{V}, 4000-\mathrm{Hz}$ alternating current through a $1-\mathrm{M} \Omega$ resistor. Changes in voltage between the small electrode and the large counter electrode were monitored by the lock-in amplifier, stored, and then calculated as resistance by the computer. The small size of the cell-seeded electrode is the critical feature of the system. When electrodes of $10^{-3} \mathrm{~cm}^{2}$ or smaller are used, the impedance at the small electrode dominates the system, allowing for assessment of the morphological changes of the cells located at this interface. Electrical resistance of the bare electrode is $\sim 2,000$ ohms and increases to 10,000 ohms or greater when HUVECs have become confluent. If the electrical resistance of the endothelial cell-covered electrode is 10,000 ohms, as depicted in Figure 4, and is corrected for electrical resistance of the bare electrode (2,000 ohms), then multiplying 8,000 ohms times the electrode surface area of $5 \times 10^{-4}$ $\mathrm{cm}^{2}$ yields a basal electrical resistance across the HUVEC monolayer of 4 ohms $\bullet \mathrm{cm}^{2}$, similar to 5 ohms $\bullet \mathrm{cm}^{2}$ as reported using a Ussing-type recording chamber (24).

EGTA Protocol ( $\mathrm{Ca}^{2+}$-switch protocol). HUVEC monolayers were treated with $2 \mathrm{mM}$ EGTA (ethylene glycol-bis(2-aminoethylether)-N,N,N',N'-tetraacetic acid) for $10 \mathrm{~min}$ to chelate extracellular $\mathrm{Ca}^{2+}$, followed by 1) no treatment, 2) adding $400 \mu \mathrm{l}$ of fresh MCDB containing $1.6 \mathrm{mM} \mathrm{Ca}^{2+}$ to restore extracellular $\mathrm{Ca}^{2+}, 3$ ) adding only $1 \mu \mathrm{M} \mathrm{S1P} \mathrm{(in} 1 \mu \mathrm{l}$ ) without restoring extracellular $\mathrm{Ca}^{2+}$ ), and 4) adding S1P and MCDB together. For treatments 1 and 3 above, EGTA was present in the cell culture medium for the entire experimental period. For treatments 2 and 4 above, culture medium was withdrawn at 10 min after the administration of EGTA and before the addition of fresh MCDB. S1P was solubilized in methanol with sonication and transferred to microcentrifuge tubes $(0.5 \mathrm{ml})$. Methanol was subsequently removed by nitrogen, and the tubes with S1P were stored at $-20^{\circ} \mathrm{C}$. S1P was reconstituted in TBS for experimentation. 
Immunofluorescence confocal microscopy. After the various treatments, HUVECs monolayers were rinsed with phosphate buffered saline containing $\mathrm{Ca}^{2+}$ and $\mathrm{Mg}^{2+}$ (PBS +++ ). Cells were fixed with $3.7 \%$ paraformaldehyde for $15 \mathrm{~min}$, permeabilized for 5 min in cytoskeletal buffer (10 mM PIPES at $\mathrm{pH} 6.8,3 \mathrm{mM} \mathrm{MgCl}, 100 \mathrm{mM} \mathrm{NaCl}$, and $300 \mathrm{mM}$ sucrose) containing $0.5 \%$ Triton $\mathrm{X}-100$, then incubated for $20 \mathrm{~min}$ with $5 \%$ BSA. Rabbit anti-human VE-cadherin polyclonal antibody was added to the cells for 60 min, followed by Alexa Fluor 488- or 594-labeled goat anti-rabbit IgG and Alexa Fluor 488-labeled phalloidin to identify actin filaments, and the cells were rinsed several times with PBS+/+. Cells were mounted with Prolong Gold anti-fade reagent. Images were generated by confocal laser scanning with a Zeiss LSM 510 confocal microscope. When comparing images, the fluorescent signals were measured at emission wavelengths of 488 and $594 \mathrm{~nm}$ with the same pinhole (less than $1 \mu \mathrm{m}$ ), the same detector gain, and the same amplifier offset.

RNA Interference. VE-cadherin siRNA was transiently transfected into HUVECs by electroporation with the Nucleofector I device (Amaxa Biosystems, Berlin, Germany). Briefly, $90 \%$ confluent cell monolayers were trypsinized and individual cells counted. After centrifugation, $1.5 \times 10^{6}$ cells were resuspended in $100 \mu \mathrm{l}$ of a Nucleofector solution (7.25 mM ATP, $12 \mathrm{mM} \mathrm{MgCl} \cdot 6 \mathrm{H}_{2} \mathrm{O}, 88 \mathrm{mM} \mathrm{KH} \mathrm{PO}_{4}, 14 \mathrm{mM} \mathrm{NaHCO}$, and $2 \mathrm{mM}$ glucose at pH 7.4) with 400 pmoles of VE-cadherin siRNA or control, scrambled siRNA. The cells in solution were transferred immediately to a cuvette and electroporated in the Nucleofector apparatus using the U-01 program. Transfected cells were recovered with warm, fresh MCDB for $5 \mathrm{~min}$, and seeded immediately on $0.2 \%$ gelatin-coated ECIS wells and monitored for electrical resistance or seeded on 24-well tissue culture plates and placed in an incubator for $2 \mathrm{~d}$ until used for microscopy or Western blot experiments. The protein level of VE-cadherin was quantified from Western blots by densitometry after normalization to $\beta$-actin as a protein loading control.

Immunoblotting. Cells were washed 2x in ice-cold PBS, lysed in RIPA buffer (15 mM $\mathrm{NaCl}, 50 \mathrm{mM}$ Tris, $1 \% \mathrm{NP}-40$, and $0.5 \%$ sodium deoxycholate) containing $2 \mathrm{mM}$ EGTA, 
phosphatase inhibitors ( $1 \mathrm{mM}$ sodium vanadate and $1 \mathrm{mM}$ phenylmethanesulfonyl fluoride), and proteinase inhibitors ( $5 \mu \mathrm{g} / \mathrm{ml}$ of aprotinin and $2 \mu \mathrm{g} / \mathrm{ml}$ of leupeptin). Samples were clarified by centrifugation at $14,000 \mathrm{rpm}$ for $10 \mathrm{~min}$ at $4^{\circ} \mathrm{C}$. Proteins were resolved by sodium dodecyl sulfate-polyacrylamide gel electrophoresis (SDSPAGE) and transferred to Nitrocellulose membrane using a mini-Protean electrophoresis system. Protein blots were probed with indicated primary antibodies, followed by the appropriate horseradish peroxidase-conjugated secondary antibody, and developed by enhanced chemiluminescence.

Cell Spreading. HUVECs were grown to confluence in $35-\mathrm{mm}$ glass bottom culture dishes or Delta T culture dishes. Cells were placed in serum-free MCDB with $20 \mathrm{mM}$ HEPES for $2 \mathrm{~h}$. For phase-contrast microscopy, 35-mm glass bottom dishes were inserted into a temperature $\left(37^{\circ} \mathrm{C}\right)$ and humidified controlled chamber mounted on the stage of a Zeiss AxioVert 200M microscope, and cells were viewed through a $20 \mathrm{X}$ phase-contrast objective, and 1.6X Optovart to increase magnification. For DIC microscopy, Delta T culture dishes, with a temperature-controlled bottom, were placed on the stage of a Nikon Eclipse TE 2000-5 microscope, and cells were viewed through a 20X DIC optical lens. Phase-contrast images were obtained using a Zeiss AxioCam camera and Axiovision software, and DIC images were processed using a Nikon camera and Metamorph software.

Statistics. All values are presented as means \pm SE. A minimum of three experiments was conducted for ECIS experiments and five for microscopy experiments. Data on electrical resistance were analyzed with a 2-way analysis of variance with repeated measures (26). Differences between treatments at specific time points were analyzed further with a Bonferroni post-test. Statistical significance was set at $P<0.05$. 


\section{RESULTS}

S1P rapidly increased endothelial electrical resistance independently of homophilic VE-cadherin binding. S1P has been reported to increase the localization of

a.

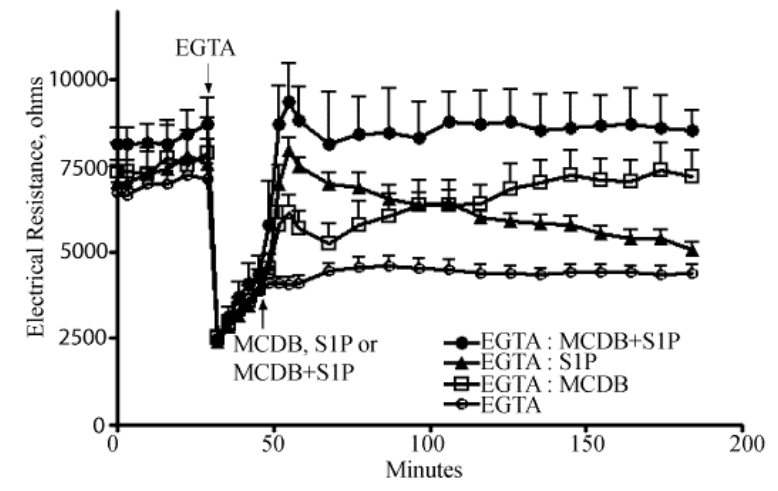

b.

c.

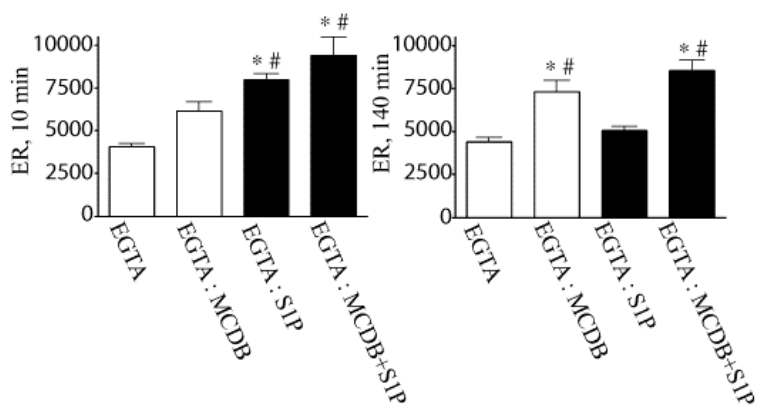

Figure 1. S1P rapidly increased endothelial electrical resistance after chelation of extracellular $\mathrm{Ca}^{2+}$ with EGTA. $\mathrm{Ca}^{2+}$ in culture media of cell monolayers, derived from human umbilical vein endothelial cells (HUVECs), was chelated with $2 \mathrm{mM}$ EGTA. Cells were then not treated (EGTA, open circles) or treated (arrow) with MCDB-131 (MCDB, open squares) to restore extracellular $\mathrm{Ca}^{2+}, \mathrm{S} 1 \mathrm{P}$ alone $(1 \mu \mathrm{M}$ in $1 \mu \mathrm{l}$, closed triangles), or S1P and MCDB (closed circles). EGTA-containing medium was removed before addition of MCDB without or with S1P but remained for cell monolayers not treated or treated with S1P alone. a) Continuous data recorded over 180-min time period; b) values at $10 \mathrm{~min}$ after treatments with MCDB, S1P, or MCDB+S1P; c) values at 140 min after treatments. Note that S1P rapidly increased endothelial electrical resistance (ER) without or with addition of $\operatorname{MCDB}(a, b)$, whereas sustained activity of $\mathrm{S} 1 \mathrm{P}$ required $\operatorname{MCDB}(\mathrm{a}, \mathrm{c})$. $n=6$ in each group; ${ }^{*} \mathrm{P}<0.05$ from EGTA; ${ }^{P}<0.05$ from EGTA:MCDB in (b) and EGTA:S1P in (c).

VE-cadherin at intercellular junctions $(9 ; 13)$. To determine whether this increase is responsible for the rapid increase in endothelial electrical resistance induced by S1P, 
a.
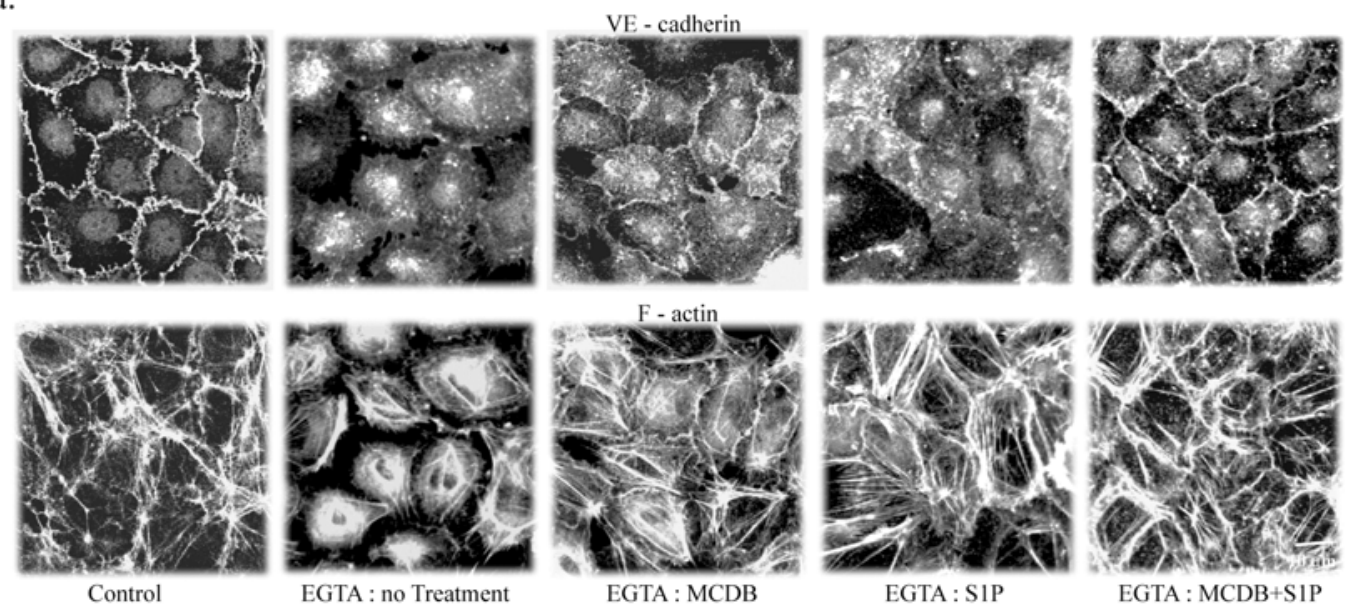

EGTA $10 \mathrm{~min}+10 \mathrm{~min}$ Post-treatment

b.

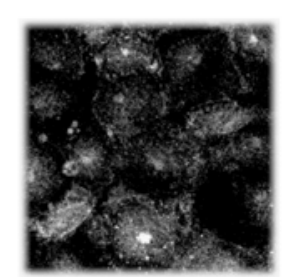

EGTA : no Treatment

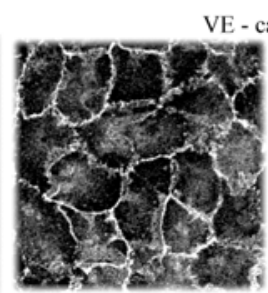

EGTA : MCDB
VE - cadherin

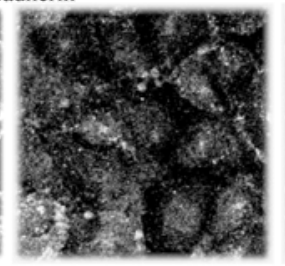

EGTA : SIP

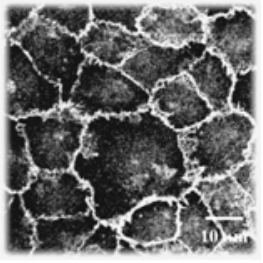

EGTA : $\mathrm{MCDB}+\mathrm{S} 1 \mathrm{P}$

EGTA $10 \mathrm{~min}+140 \mathrm{~min}$ Post-treatment

Figure 2. S1P enhanced the junctional localization of VE-cadherin and peripheral actin. EGTA protocol outlined in Figure 1 was repeated for visualization of VE-cadherin and filamentous actin (F-actin) at cell periphery of same cells. a,b) Representative micrographs depicted are of HUVEC monolayers at 10 min (a) or 140 min (b) after treatment with MCDB, S1P, or S1P plus MCDB. In fixed and permeabilized cell monolayers, VE-cadherin was visualized by incubation with rabbit anti-human VE-cadherin polyclonal antibody and Alexa Fluor 594-labeled goat antirabbit secondary antibody, and filamentous actin was visualized with Alexa Fluor 488-labeled phallodin. Note that treatment with S1P plus MCDB increased presence of VE-cadherin at intercellular junctions (a), that S1P alone and S1P plus MCDB reorganized actin to cell periphery (a), and that presence of junctional VE-cadherin was maintained for 140 min only after treatment with MCDB or S1P plus MCDB. Scale bars, $10 \mu \mathrm{m}$.

homophilic VE-cadherin binding was disrupted by three different protocols: 1) addition of $2 \mathrm{mM}$ EGTA to chelate extracellular $\left.\mathrm{Ca}^{2++}, 2\right)$ addition to the culture medium of an antibody to the extracellular domain of VE-cadherin, and 3) gene silencing of VEcadherin. In all three protocols, S1P (1 $\mu \mathrm{M})$ rapidly increased electrical resistance 
across endothelial cell monolayers in association with a reduction in the localization of VE-cadherin at intercellular junctions.

Addition of EGTA to the cell culture medium caused a precipitous decrease in endothelial electrical resistance (Fig. 1a) and a loss of VE-cadherin at intercellular junctions (Fig. 2a). After 10 min of incubation with EGTA, cell monolayers were either not treated or treated with MCDB (containing $1.6 \mathrm{mM}$ ) to replenish extracellular $\mathrm{Ca}^{2+}$, S1P alone $(1 \mu \mathrm{M}$ in $1 \mu \mathrm{l})$, or MCDB plus S1P. Therefore, cell monolayers not treated or treated with S1P alone were exposed to EGTA for the entire experimental period; whereas, those cell monolayers treat with MCDB or S1P+MCDB were exposed to concentrated EGTA for only $10 \mathrm{~min}$. Endothelial electrical resistance did not change with no treatment and increased slightly then slowly returned to the pre-EGTA level with the addition of MCDB (Fig. 1a, b). In contrast, electrical resistance increased rapidly within 10 min to the pre-EGTA level or above upon treatment, respectively, with S1P without (Fig. 1a, b) or with MCDB (Fig. 1a, b). The identical EGTA protocol was repeated to visualize VE-cadherin and filamentous actin by confocal microscopy (Fig. 2). A characteristic of the S1P response is a reorganization of actin to the cell periphery (8), which was also observed in the present study within $10 \mathrm{~min}$ of treatment with S1P or S1P plus MCDB subsequent to the addition of EGTA (Fig. 2a). In control cell monolayers, VE-cadherin appeared prominently at intercellular junctions. Twenty minutes (also $10 \mathrm{~min}$, data not shown) after EGTA treatment, there was a reduction in junctional VE-cadherin and an apparent increase in VE-cadherin in the cytoplasm (Fig. 2a, EGTA:no treatment). In addition, gaps were present between adjacent cells. After replacement of extracellular $\mathrm{Ca}^{2+}$ with the addition of fresh MDCB, VE-cadherin was observed to some extent at intercellular junctions and there was a reduction in cytoplasmic VE-cadherin within $10 \mathrm{~min}$ (Fig. 2a). The effect of S1P on junctional VEcadherin was dependent on whether MCDB was added to restore extracellular $\mathrm{Ca}^{2+}$. After treatment with S1P alone for 10 min, very little VE-cadherin was observed at intercellular junctions. Upon treatment with S1P plus MCDB, the intensity of immunofluorescent staining of VE-cadherin at cell borders was greater at 10 min than with treatment of MCDB alone and was similar to immunofluorescent staining of control 
cell monolayers. Both treatments, S1P alone and S1P plus MCDB, resulted in the closure of most of the intercellular gaps. These microscopy and functional findings provide correlative evidence that S1P rapidly closes preexisting gaps between cells and increases endothelial electrical resistance in association with an absence of VEcadherin at intercellular junctions.

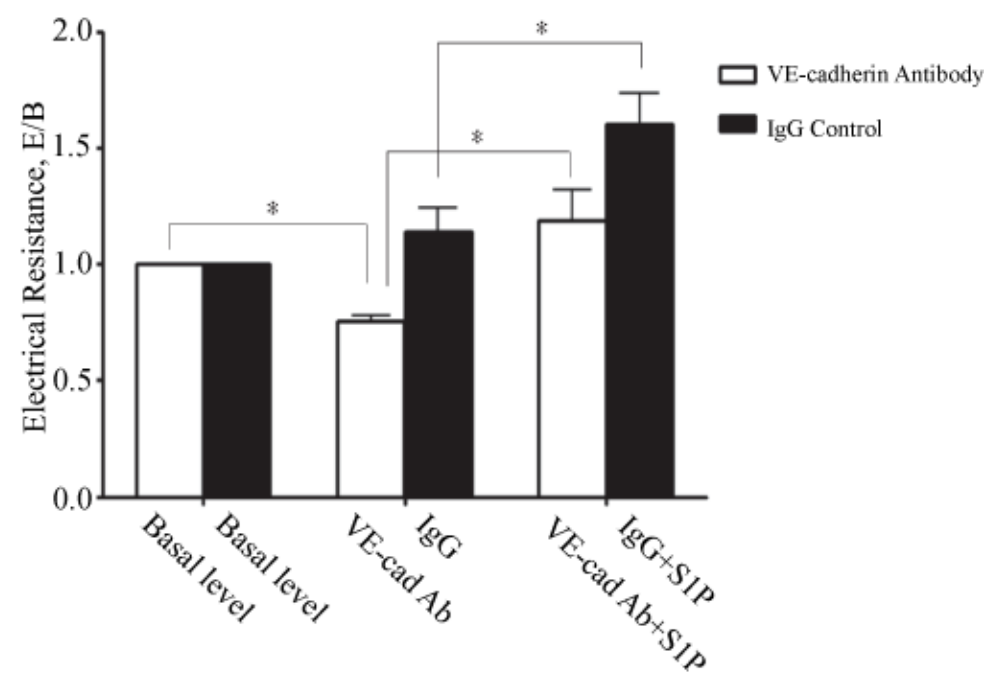

Figure 3. S1P rapidly increased endothelial electrical resistance in presence of antibody to extracellular domain of VE-cadherin. Homophilic VE-cadherin binding was also disrupted by incubation with an antibody (Ab, CD144) to extracellular domain of VE-cadherin. HUVEC monolayers were incubated for $60 \mathrm{~min}$ with VE-cadherin antibody or normal rabbit immunoglobulin ( $\mathrm{IgG})$, then treated with S1P. Note that endothelial electrical resistance decreased after 60-min administration of VE-cadherin antibody (open bar) and that S1P increased electrical resistance (peak response) in both treated groups (closed bars). $n=4$ in each group; * $\mathrm{P}<0.05$ vs. indicated group.

Similar results were obtained by the addition of an antibody to the extracellular domain of VE-cadherin (Fig. 3) or gene silencing of VE-cadherin (Fig. 4). Addition to the culture medium of an extracellular VE-cadherin antibody resulted in a decrease in basal, endothelial electrical resistance (Fig. 3) and a discontinuous appearance of VEcadherin at intercellular junctions (data not shown) as compared to the addition of normal rabbit immunoglobin $\mathrm{G}(\mathrm{lg} \mathrm{G})$. S1P rapidly and transiently increased electrical resistance of cell monolayers incubated with the VE-cadherin antibody as well as the control IgG (Fig. 3). Transient transfection of VE-cadherin siRNA reduced the protein 


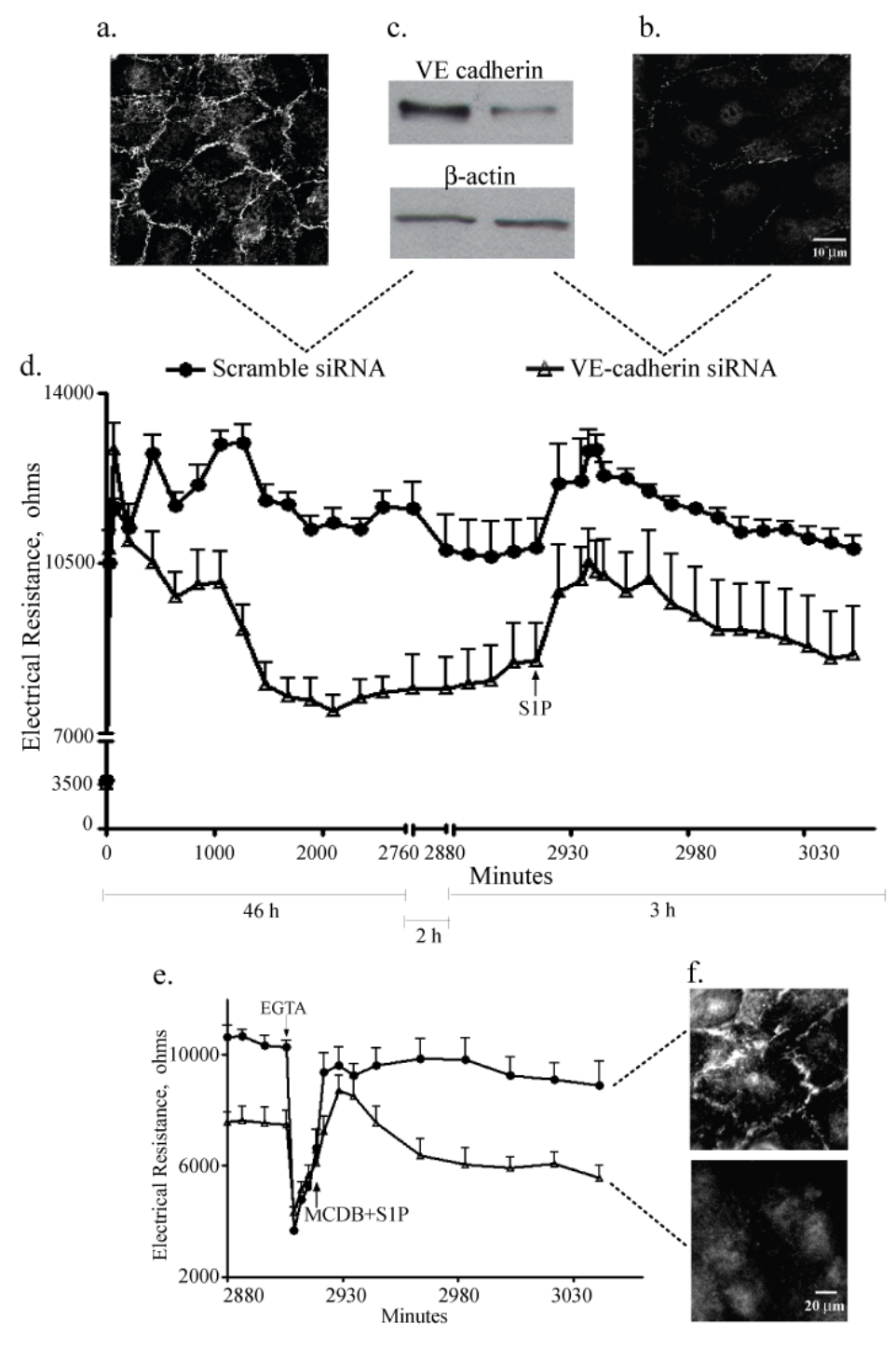

Figure 4. S1P increased endothelial electrical resistance after gene silencing of VE-cadherin. HUVEC monolayers ( $90 \%$ confluence) were transiently transfected by electroporation with VEcadherin siRNA or scrambled siRNA. Transfected cells were seeded on 24-well culture dishes and incubated for $2 \mathrm{~d}$ until used for microscopy $(a, b)$ or Western blot (c) experiments or seeded on ECIS wells for continuous measurement of electrical resistance (d). a,b) VEcadherin was visualized at $48 \mathrm{~h}$ by incubation with CD144 antibody to VE-cadherin and Alexa Fluor 594-labeled goat anti-rabbit secondary antibody. d) Continuous measurement of endothelial electrical resistance for $\sim 48 \mathrm{~h}$ after electroporation of VE-cadherin siRNA (open triangles) or scrambled siRNA (close circles) and after treatment with S1P (arrow); MCDB with $25 \%$ serum was replaced with serum-free MCDB at $46 \mathrm{~h}$. e) EGTA was administered for 10 min to cell monolayers already transfected with either VE-cadherin siRNA (open triangles) or scrambled siRNA (closed circles) then treated with S1P plus MCDB (arrow). f) Cells were viewed directly on ECIS wells at end of experiment by incubation with rabbit anti-human VEcadherin polyclonal antibody and Alexa Fluor 594-labeled goat anti-rabbit secondary antibody. Note that S1P increased endothelial electrical resistance in both transfected groups (d) and that increased electrical resistance was maintained only in scrambled siRNA group in which VE-cadherin was localized to cell borders (f, upper). $n=5$ in each group; ${ }^{*} P<0.05$ vs. control groups. Scale bars, $a, b=10 \mu \mathrm{m} ; f=20 \mu \mathrm{m}$. 
level of VE-cadherin by $\sim 90 \%$ (Fig. 4c) and the localization of VE-cadherin at intercellular junctions (Fig. 4a, scrambled siRNA, versus Fig. 4b, VE-cadherin siRNA) within $48 \mathrm{~h}$. As with the other two protocols, gene silencing of VE-cadherin caused a decrease in basal, endothelial electrical resistance (Fig. 4d), which was apparent within $24 \mathrm{~h}$, and did not affect the rapid increase in endothelial electrical resistance induced by S1P. Moreover, S1P was still active in those cell monolayers exposed to a combinatory protocol of reduction of VE-cadherin protein by gene silencing followed by chelation of extracellular $\mathrm{Ca}^{2+}$ with EGTA (Fig. 4e).

S1P augmented the junctional localization of VE-cadherin. Within $10 \mathrm{~min}$ of treatment, S1P was observed to increase the localization of VE-cadherin at intercellular junctions (Fig. 2a). This observation was made only when S1P was administered in the presence of extracellular $\mathrm{Ca}^{2+}$. Following the administration of EGTA (Fig. 2a), more VE-cadherin was present at intercellular junctions with the treatment of S1P and MCDB, the latter to restore extracellular $\mathrm{Ca}^{2+}$, as compared to the treatment of MCDB or S1P alone. This increased localization was also observed under normal, cell culture conditions (Fig. 6b).

Sustained increase in endothelial electrical resistance induced by S1P was associated with localization of VE-cadherin. Using the EGTA protocol, there was a sustained increase in endothelial electrical resistance (Fig. 1a,c; also Figs. 4e and 7b) and VE-cadherin was localized to intercellular junctions (Fig. 2b and $4 \mathrm{f}$ upper) at 140 min after S1P was administered in combination with MCDB. Endothelial electrical resistance was also maintained for $140 \mathrm{~min}$ by S1P+MCDB in cell monolayers transfected with a scrambled siRNA then administered EGTA (Fig. 4e); VE-cadherin was localized to intercellular junctions in those cell monolayers (Fig. $4 \mathrm{f}$ upper). In contrast, treatment with S1P alone, without the addition of MCDB, induced only a transient increase in electrical resistance, as electrical resistance returned to the EGTAonly treated value by $140 \mathrm{~min}$ (Fig. 1a,c), and at that time-point junctional localization of VE-cadherin was much reduced (Fig. 2b). The activity of S1P was also transient in cell monolayers pretreated with the VE-cadherin antibody, which was not removed during 
the course of the experiment (data not shown). Furthermore, S1P activity was transient in those cell monolayers reduced of VE-cadherin protein by gene silencing followed by chelation of extracellular $\mathrm{Ca}^{2+}$ with EGTA (Fig. 4e). Immunofluorescent staining of VEcadherin was much reduced at intercellular junctions at the end of the experiment in these cell monolayers (Fig. $4 \mathrm{f}$ lower). Therefore, the sustained increase in endothelial electrical resistance induced by S1P, using the EGTA protocol, appears to require VEcadherin.

S1P induced cell spreading. Imaging of live cells with phase-contrast and DIC optics revealed that endothelial cells within a monolayer spread following the administration of S1P (Fig. 5). Administration of EGTA for $10 \mathrm{~min}$ increased the birefringence, indicative of a change in cell shape, of the cell monolayers as viewed by phase-contrast optics (Fig. 5a) and caused gaps with connecting strands to form between cells as viewed with DIC optics (Fig. 5b). Subsequent treatment for $10 \mathrm{~min}$ with S1P alone or in combination with MCDB resulted in cellular changes indicative of cell spreading, i.e. reduction of the birefringence (Figs. 5a), reduction of the connecting strands between cells, closure of intercellular gaps (Figs. 5b), appearance of flatter cells (Figs. 5b), and ridges between adjacent cells (Fig. 5b, EGTA:S1P). Addition of MCDB alone to restore extracellular $\mathrm{Ca}^{2+}$ caused cell spreading and closure of intercellular gaps but to a much lesser extent than with S1P. These observations implicate cell spreading and the resultant closure of intercellular gaps as the mechanism for the S1Pinduced rapid increase in electrical resistance of endothelial cell monolayers.

Latrunculin B inhibited S1P effects on electrical resistance and cell spreading. S1P is known to reorganize actin filaments to the cell periphery (8). Visualization of actin filaments with phalloidin conjugated to Alexa Fluor 488 revealed in the present study that S1P also reorganized actin to the cell periphery in the presence of reduced VE-cadherin at intercellular junctions, resulting from administration of EGTA (Fig. 2a). To determine the role of actin in the barrier-enhancing activity of S1P, actin polymerization was blocked with Latrunculin B. Latrunculin B binds to actin monomers 

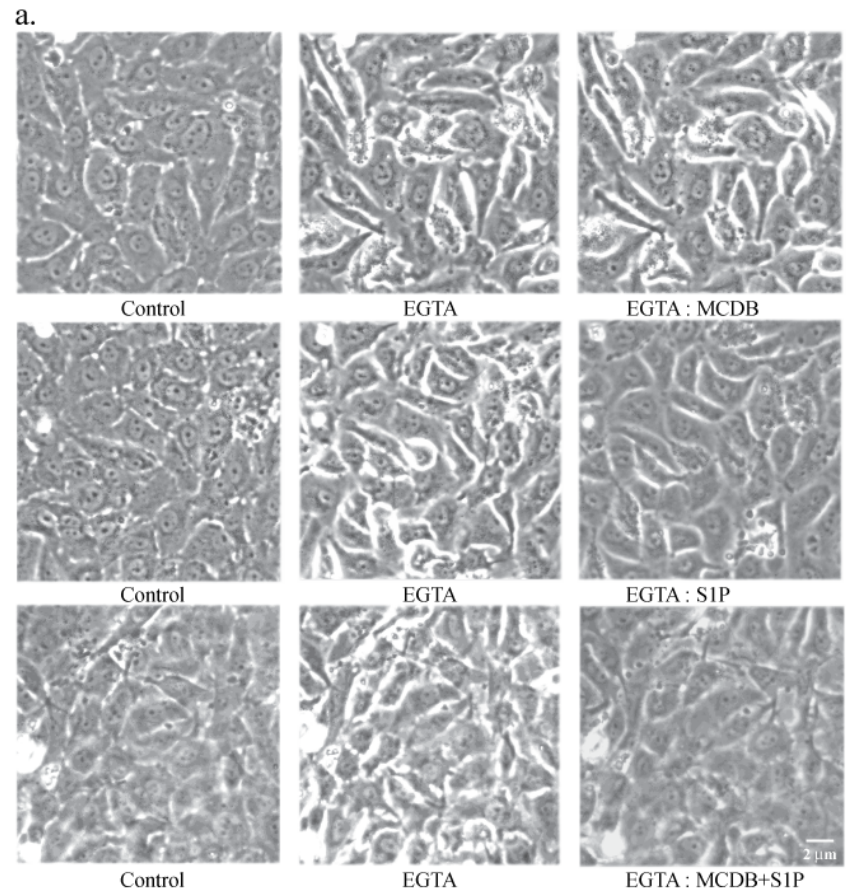

EGTA : SIP
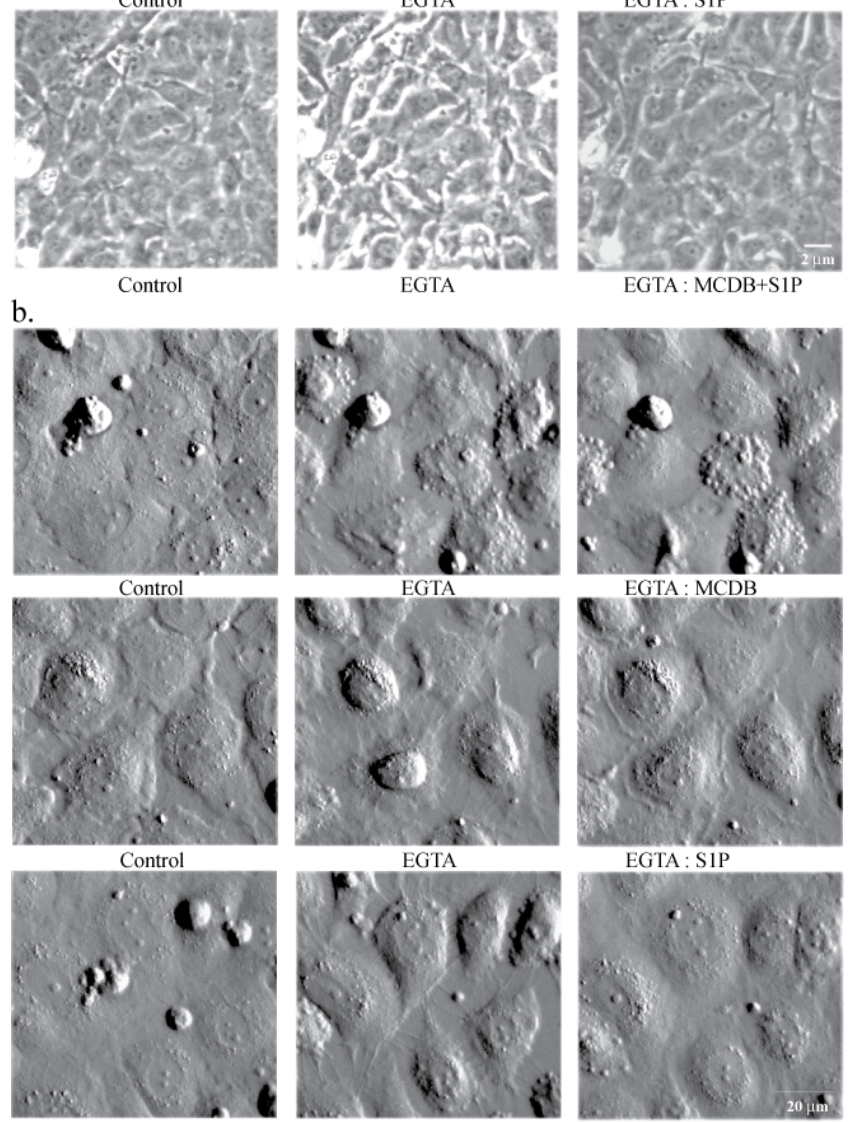

EGTA : SIP

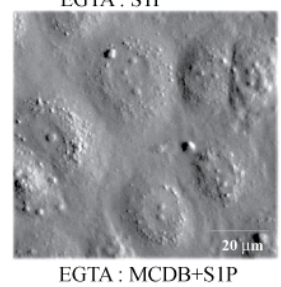

Figure 5. S1P induced cell spreading. Cell spreading and closure of intercellular gaps of HUVEC monolayers were visualized with phase-contrast (a) and differential interference-contrast (DIC, b) optics. Increased birefringence (a) and gaps (b) with connecting strands between adjacent cells (b) were induced by $10-\mathrm{min}$ incubation with EGTA $(2 \mathrm{mM})$ to culture medium. HUVEC monolayers were then treated for 10 min with MCDB or S1P alone or S1P+MCDB. Note that S1P treated without or with MCDB decreased birefringence (a) and induced cells to spread, resulting in closure of most of the intercellular gaps (b). Same group of cells are depicted in each row in (a) and (b). Scale bars, $a=2 \mu \mathrm{m} ; b=20 \mu \mathrm{m}$. 

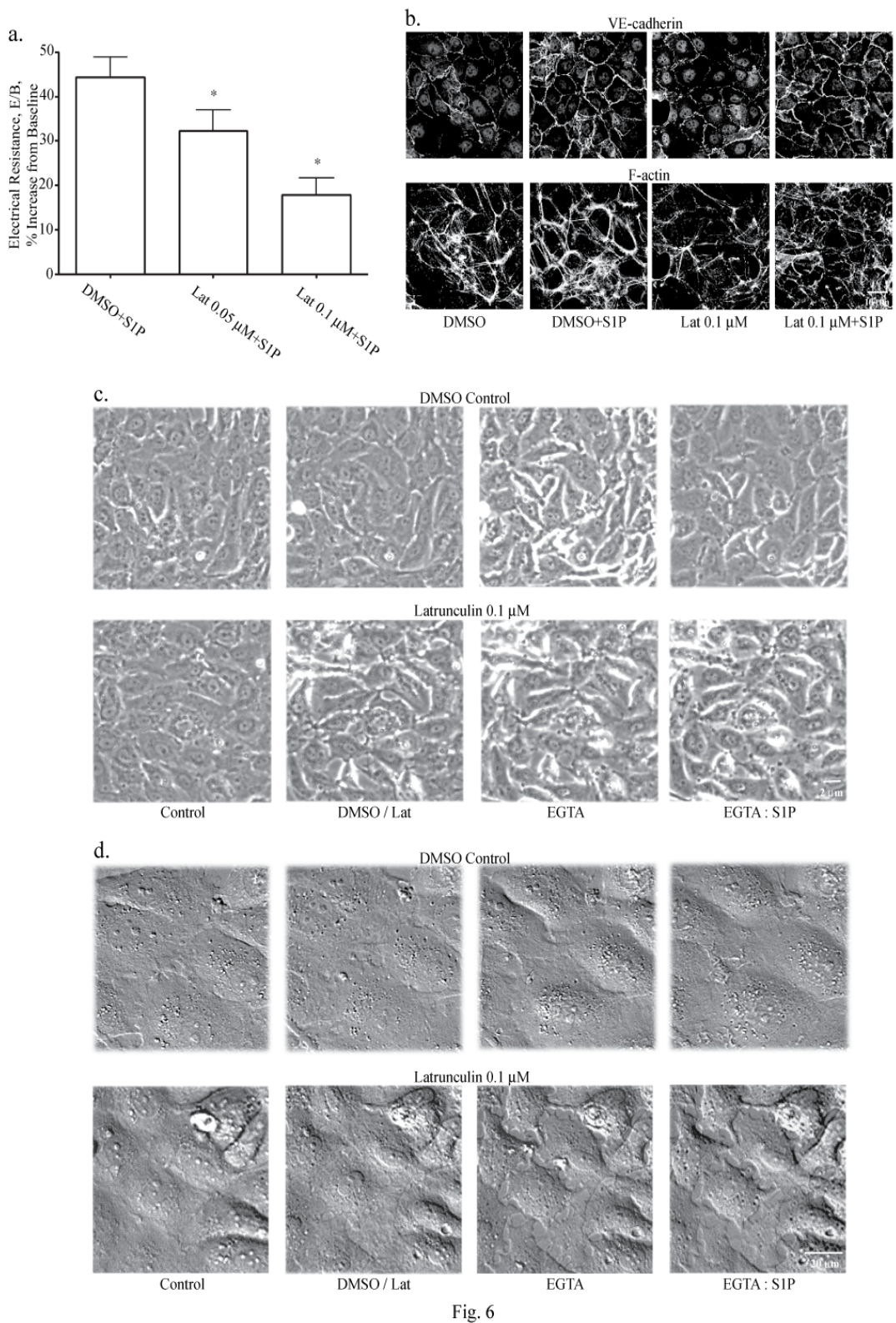

Figure 6. Inhibitor of actin polymerization attenuated S1P-induced increase in endothelial electrical resistance and cell spreading. HUVEC monolayers were pretreated for 30 min with Latrunculin B (Lat) to inhibit actin polymerization before treatment with S1P for 10 min. a) Depicts peak increases in electrical resistance, as normalized to basal values (E/B). b) VE-cadherin and actin were visualized, respectively, by incubation with rabbit anti-human VE-cadherin polyclonal antibody and Alexa Fluor 488-labeled goat anti-rabbit secondary antibody and Alexa Fluor 594-labeled phalloidin. Same group of cells are depicted in each column in (b). c,d) Same group of cells in each row were imaged with phase-contrast (c) and DIC (d) optics. EGTA was administered to disrupt homophilic VE-cadherin binding, resulting in formation of intercellular gaps. Note that Latrunculin $B$ attenuated increase in endothelial electrical resistance (a) and reorganization of filamentous actin (F-actin) to cell periphery (b), decrease in birefringence of cell monolayers (c), and cell spreading and closure of intercellular gaps (d) induced by S1P. Latrunculin B did not affect S1P-induced increase in localization of junctional VE-cadherin (b). $n=5$ in each group in (a); ${ }^{*} \mathrm{P}<0.05$ vs. DMSO+S1P group. Scale bars, $b=10 \mu \mathrm{m} ; \mathrm{c}=2 \mu \mathrm{m} ; \mathrm{d}=20 \mu \mathrm{m}$. 
that results in the inhibition of the actin nucleation during polymerization of actin filaments. Pre-treatment with Latrunculin B for $30 \mathrm{~min}$ attenuated the increase in endothelial electrical resistance (Fig. 6a) and reorganization of peripheral actin (Fig. 6b) but had no effect on the increase in junctional VE-cadherin induced by S1P (Fig. 6b). Latrunculin B also prevented cell spreading induced by S1P. S1P reversed the EGTAinduced increases in birefringence (Fig. 6c) and gap formation (Fig. 6d) in cell monolayers pretreated with the vehicle, dimethyl sulfoxide (DMSO), but not with Latrunculin B.

Visualization of actin filaments with phalloidin conjugated to Alexa Fluor 488 revealed in the present study that $\mathrm{S} 1 \mathrm{P}$ also reorganized actin to the cell periphery in the presence of reduced VE-cadherin at intercellular junctions, resulting from administration of EGTA (Fig. 2a). To determine the role of actin in the barrier-enhancing activity of S1P, actin polymerization was blocked with Latrunculin B. Latrunculin B binds to actin monomers that results in the inhibition of the actin nucleation during polymerization of actin filaments. Pre-treatment with Latrunculin B for $30 \mathrm{~min}$ attenuated the increase in endothelial electrical resistance (Fig. 6a) and reorganization of peripheral actin (Fig. 6b) but had no effect on the increase in junctional VE-cadherin induced by S1P (Fig. 6b). Latrunculin $B$ also prevented cell spreading induced by S1P. S1P reversed the EGTAinduced increases in birefringence (Fig. 6c) and gap formation (Fig. 6d) in cell monolayers pretreated with the vehicle, dimethyl sulfoxide (DMSO), but not with Latrunculin B.

Rho kinase inhibitor attenuated S1P effects on electrical resistance and cell spreading. Rho kinase and its downstream effectors influence cofilin, an actin severing protein (8). Inhibition of cofilin by activated Rho kinase has been proposed to be responsible for the reorganization of peripheral actin induced by S1P (8). Pre-treatment for 30 min with $5 \mu \mathrm{M}$ Y-27632, a pharmacological inhibitor of Rho kinase, decreased basal endothelial electrical resistance and significantly attenuated the rapid increase in electrical resistance induced by S1P when administered either under normal conditions (Fig. 7a) or after EGTA treatment (Fig. 7b); Y-27632 at $1 \mu \mathrm{M}$ had no effect in either 
a.

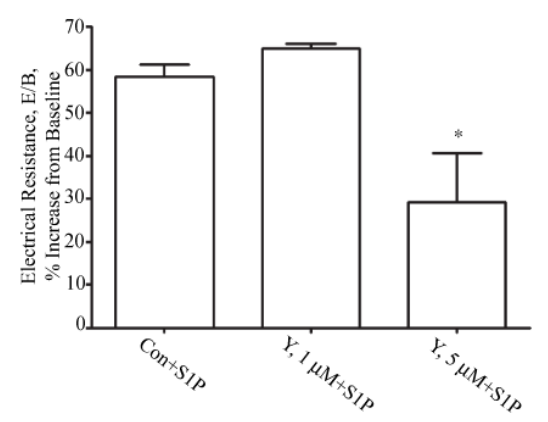

b.

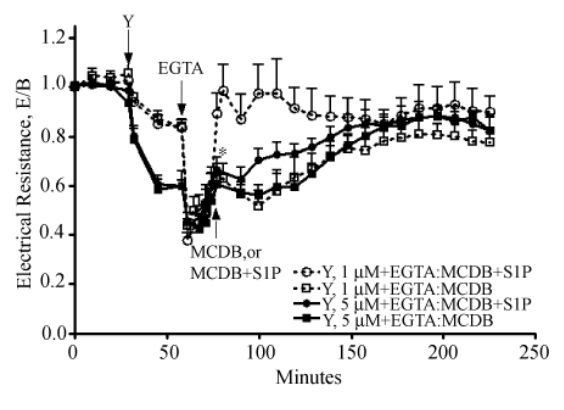

c.
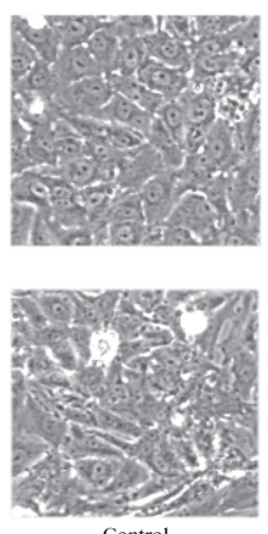

Control

d.
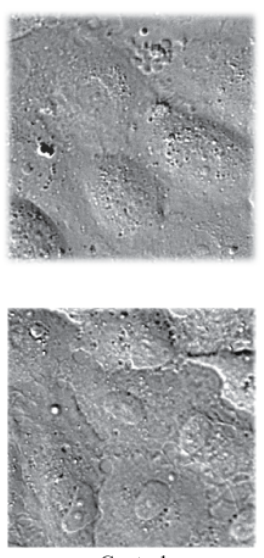

Control

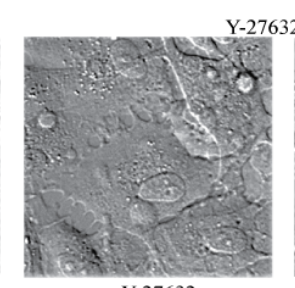

Y-27632
Control
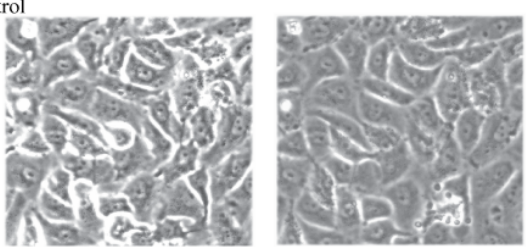

$\mathrm{Y}-27632,5 \mu \mathrm{M}$

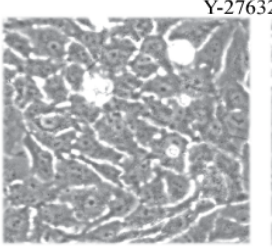

Y-27632

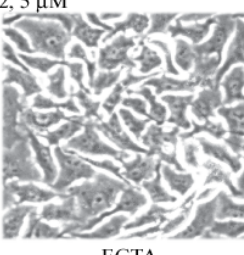

EGTA

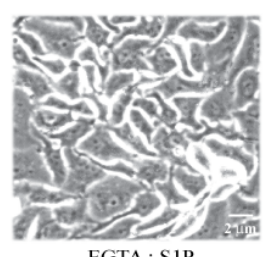

EGTA : SIP
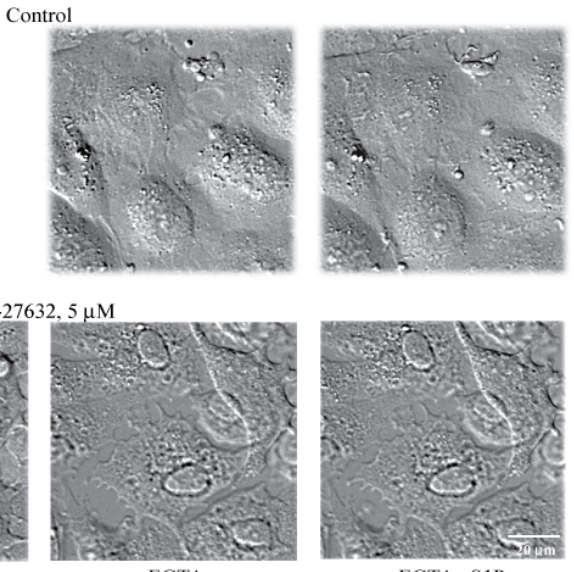

EGTA

Fig 7

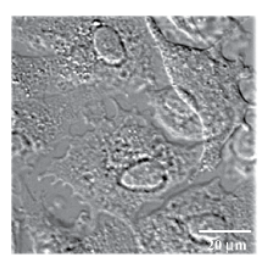

EGTA : S1P

Figure 7. Inhibitor of Rho kinase attenuated S1P-induced increase in endothelial electrical resistance and cell spreading. HUVEC monolayers were pretreated for 30 min with Y-27632 $(\mathrm{Y}, 1$ and $5 \mu \mathrm{M})$, an inhibitor of Rho kinase, before treatment with S1P (a,c,d), MCDB alone (b), or S1P+MCDB (b) . a) Depicts peak increases in electrical resistance, as normalized to basal values (E/B). b,c,d) EGTA was added to disrupt homophilic VE-cadherin binding and induce formation of intercellular gaps. Same group of cells in each row were imaged with phase-contrast (c) or DIC (d) optics. Note that Y-27632 at $5 \mu \mathrm{M}$ attenuated increase in endothelial electrical resistance $(a, b)$, decrease in birefringence of cell monolayers (c), and cell spreading and closure of intercellular gaps (d) induced by S1P. Y-27632 at $1 \mu \mathrm{M}$ had no effect on these parameters. $n=3$ in each group in (a) and $n=4$ in each group in (b); ${ }^{*}<<0.05$ vs. Control (Con)+S1P group (a) and Y, $1 \mu \mathrm{M}+\mathrm{EGTA}: M C D B+S 1 P$ (b). Scale bars, c = $2 \mu \mathrm{m}$; $\mathrm{d}=20 \mu \mathrm{m}$. 
condition (Fig. 7a,b). In the EGTA protocol, addition of MCDB caused a small increase in endothelial electrical resistance, which slowly increased to the pre-control level (Fig. 7b), an observation similar to that depicted in Fig. 1a. Pre-treatment with Y-27632 before the addition of EGTA also attenuated the decrease in birefringence, spreading of endothelial cells, and closure of intercellular gaps induced by S1P, as viewed by phasecontrast (Fig. 7c) and DIC (Fig. 7d) optics. Therefore, the findings with inhibitors of actin polymerizaton and Rho kinase suggest that S1P rapidly increases endothelial electrical resistance via an actin-dependent process that involves Rho kinase. 


\section{DISCUSSION}

Two publications have demonstrated that S1P enhances the localization of endothelial adherens junction proteins, VE-cadherin and catenins, within 30 to 60 min of treatment $(9,13)$. S1P, however, rapidly increases endothelial barrier function $(8,17)$, as noted by a peak increase in electrical resistance within 6-10 min. Whether VEcadherin plays a significant role in this rapid activity of S1P was an intriguing question especially after I observed that S1P enhanced the localization of VE-cadherin within 10 min of treatment. Based on experiments whereby homophilic VE-cadherin binding was disrupted by three different mechanisms, cell monolayers were imaged with phasecontrast and DIC optics, and inhibitors of actin polymerization and Rho kinase were administered, I conclude that the rapid increase in endothelial electrical resistance induced by S1P occurs independently of homophilic VE-cadherin binding and requires cell spreading and Rho kinase. However, our initial findings suggest that the sustained activity of S1P, demonstrated in the EGTA protocol, requires VE-cadherin.

S1P induces the assembly of adherens junctions via activation of the small GTPases, Rac1 and Rho $(9,13)$. Localization of VE-cadherin and the catenins, $\alpha, \beta$, and $\gamma$, to intercellular junctions increased markedly and more VE-cadherin was demonstrated in the Triton X-100 insoluble (actin associated fraction) within 60 min in HUVECs treated with S1P. Either inhibition of Rho with C3 exoenzyme or Rac1 with dominant-negative N17Rac1 diminished the increased immunofluorescent staining of VE-cadherin at intercellular junctions (9). Similar increases in VE-cadherin and $\beta$ catenin were also observed at intercellular junctions within 30 min of treatment of S1P (13). In the present study, I observed an increased immunofluorescent localization of VE-cadherin at intercellular junctions within 10 min of S1P treatment.

Since this 10 -min time point temporally aligns with the rapid activity of S1P, I determined if VE-cadherin is responsible for the rapid increase in endothelial electrical resistance induced by S1P. Homophilic VE-cadherin binding was disrupted by three different protocols, and all three protocols caused the reduction in immunofluorescent 
localization of VE-cadherin at intercellular junctions, separation of adjacent endothelial cells, and a decrease in basal, endothelial electrical resistance. The important finding was that S1P rapidly increased endothelial electrical resistance in all three protocols. Following the administration of EGTA, the rapid increase in electrical resistance occurred when S1P was administered either without or with restoration of extracellular $\mathrm{Ca}^{2+}$ with MCDB. VE-cadherin was present at intercellular junctions in monolayers treated with MCDB alone and was increased with treatment of S1P plus MCDB, but there was much less VE-cadherin observed at intercellular junctions following treatment with S1P alone. S1P was also effective in increasing endothelial electrical resistance after presumably interfering with homophilic VE-cadherin binding by incubation with an antibody to the extracellular domain of VE-cadherin or after VE-cadherin was reduced significantly by gene silencing. These findings support our conclusion that S1P rapidly increases endothelial electrical resistance independently of homophilic VE-cadherin binding.

The sustained increase in electrical resistance induced by S1P appears to require extracellular $\mathrm{Ca}^{2+}$ and the localization of VE-cadherin at intercellular junctions. Following the administration of EGTA, the increased electrical resistance induced by S1P was sustained in cell monolayers containing junctional VE-cadherin. After EGTA, the sustained increase in electrical resistance induced by S1P required restoration of extracellular $\mathrm{Ca}^{2+}$ with MCDB, which was associated with the presence of VE-cadherin at intercellular junctions. Similarly, S1P maintained electrical resistance in cell monolayers containing junctional VE-cadherin after transfection with scrambled siRNA and the subsequent administration of EGTA. In contrast, treatment with S1P without replenishment of extracellular $\mathrm{Ca}^{2+}$ following EGTA or after reduction of VE-protein coupled with EGTA resulted in only a transient increase in electrical resistance, and junctional VE-cadherin was much reduced at the 140-min time point.

I next determined if S1P induced cell spreading, because in the initial experiments S1P reorganized actin to the cell periphery and also appeared to reduce the width of intercellular gaps initially formed by EGTA. Cell spreading is also induced 
by cAMP-enhancing agents that are well known to rapidly tighten the endothelial barrier in association with reorganization of actin to the cell periphery $(15,22)$. S1P has been shown to induce membrane ruffling and cell spreading in single endothelial cells of human umbilical origin and to increase cell size $(6,18)$. S1P also formed lamellipodia and induced cell spreading of endothelial cells at the leading edge of wounded, HUVEC monolayers resulting in closure of the wound (25). In the present study, I observed by imaging with phase-contrast and DIC optics that S1P also induces spreading of endothelial cells grown as confluent monolayers. Treatment for 10 min with S1P without or with MCDB to restore extracellular $\mathrm{Ca}^{2+}$ caused cells to spread resulting in closure of intercellular gaps, initially formed by EGTA. These observations indicate that the rapid increase in electrical resistance across endothelial cell monolayers induced by S1P occurs via cell spreading and the subsequent closure of intercellular gaps. Although the above-mentioned formation of lamellipodia and subsequent closure of wounded HUVEC monolayers implicates the process of cell spreading, the conditions (injury versus EGTA-induced gap formation) and the signaling pathways are different. Wound closure by S1P was prevented by pre-treatment with inhibitors of Src (PP2) and mitogen-activated protein kinase (U0126); whereas, the increased endothelial electrical resistance induced by S1P was not affected by PP2 or U0126 (8). Similarly, it was shown previously that $\mathrm{U} 0126$ did not block the increase in endothelial electrical resistance induced by platelet-conditioned medium (7), of which S1P has been suggested as the barrier-enhancing factor (20).

Garcia et al. (8) initially demonstrated that S1P remodeled actin to the cell periphery and that Latrunculin B, an inhibitor of actin polymerization, or $\mathrm{Y}-27632$, an inhibitor of Rho kinase, attenuated the S1P-induced increase in endothelial electrical resistance. I confirmed these findings and, in addition, demonstrated that S1P reorganized actin to the cell periphery following disruption of homophilic VE-cadherin binding with EGTA and that pretreatment with Latrunculin B or Y-27632 $(5 \mu \mathrm{M})$ attenuated actin reorganization and the cell spreading induced by S1P. Y-27632 also lowered basal, endothelial electrical resistance in HUVEC monolayers. The preventative effects of Y-27632 may be explained by the ability of Rho kinase to 
inactivate cofilin, an actin-severing protein, via the phosphorylation of LIM kinase. Expression of wild-type cofilin has been reported to reduce the S1P-induced increases in peripheral actin and in endothelial electrical resistance (8). Rho kinase is also an effector for the small GTPase Rho, and activation of Rho has been implicated in the spreading of single endothelial cells by S1P (18) or of cells grown on type IV collagen (10). In these studies, inactivation of Rho with C3 exoenzyme blocked spreading of endothelial cells. The barrier-enhancing activity of S1P, therefore, appears to be dependent on the Rho-Rho kinase-signaling pathway.

Rho kinase has also been implicated in loosening of the endothelial barrier. Y27632 attenuated the activated neutrophil-induced increases in albumin permeability of porcine coronary venules and of cell monolayers derived from coronary venular endothelia and in cell tension of coronary venular endothelia (2). A similar attenuation of albumin permeability by Y-27632 was demonstrated in porcine coronary venules and coronary venular endothelia treated with vascular endothelial growth factor (23). Furthermore, transfection of constitutively active Rho kinase increased the permeability and endothelial cell tension in these two model systems (2). With regard to the effect of inhibition of Rho kinase on thrombin's ability to increase endothelial permeability, the findings are equivocal. In one study, Y-27632 prevented the increase in endothelial permeability (27), but not in another study (3). Y-27632 per se enhanced the barrier function of cell monolayers derived from bovine pulmonary artery endothelial cells, as assessed by a size-selective permeability assay (3). In contrast, I show herein that $Y$ 27632 decreased the endothelial barrier function of HUVEC monolayers, as assessed by a decrease in endothelial electrical resistance. From the findings of the above studies and the present study, it is apparent that the outcome of activation of the Rho kinase-signaling pathway is varied. One possibility is that the cellular targets downstream of Rho kinase are different for various mediators or for different cell types and that separate or parallel pathways differentially influence endothelial barrier function. 
REFERENCES

Reference List

1. Bazzoni G and Dejana E. Endothelial cell-to-cell junctions: Molecular organization and role in vascular homeostasis. Physiol Rev 84: 869-901, 2004.

2. Breslin JW, Sun H, Xu W, Rodarte C, Moy AB, Wu MH, Yuan SY. Involvement of ROCK-mediated endothelial tension development in neutrophil-stimulated microvascular leakage. Am J Physiol Heart Circ Physiol 290: H741-H750, 2006.

3. Carbajal JM, Gratrix ML, Yu C-H, Schaeffer Jr RC. ROCK mediates thrombin's endothelial barrier dysfunction. Am J Physiol Cell Physiol 279: C195-C204. 2000.

4. Corada M, Liao F, Lindgren M, Lampugnani MG, Breviario F, Frank R, Muller WA, Hicklin DJ, Bohlen P, Dejana E. Monoclonal antibodies directed to different regions of vascular endothelial cadherin extracellular domain affect adhesion and clustering of the protein and modulate endothelial permeability. Blood 97: 16791684, 2001.

5. Corada M, Mariotti M, Thurston G, Smith K, Kunkel R, Brockhaus M, Lampugnani MG, Martin-Padura I, Stoppacciaro A, Ruco L, McDonald DM, Ward PA, Dejana E. Vascular endothelial-cadherin is an important determinant of microvascular integrity in vivo. Proc Natl Acad Sci USA 96: 9815-9820, 1999.

6. Endo A, Nagashima K-I, Kurose H, Mochizuki S, Matsuda M, Mochizuki N. Sphingosine 1-phosphate induces membrane ruffling and increases motility of human umbilical vein endothelial cells via vascular endothelial growth factor receptor and Crkll. J Biol Chem 277: 23747-23754, 2002. 
7. Gainor JP, Morton CA, Roberts JT, Vincent PA, Minnear FL. Plateletconditioned medium increases endothelial electrical resistance independently of cAMP/PKA and cGMP/PKG. Am J Heart Circ Physiol 281: H1992-H2001, 2001.

8. Garcia JGN, Liu F, Verin AD, Birukova A, Dechert MA, Gerthoffer WT, Bamburg JR, English D. Sphingosine 1-phosphate promotes endothelial cell barrier integrity by Edg-dependent cytoskeletal rearrangement. J Clin Invest 108: 689-701, 2001.

9. Lee M-J, Thangada S, Claffey KP, Ancellin N, Liu CH, Kluk M, Volpi M, Sha'afi RI, Hla T. Vascular endothelial cell adherens junction assembly and morphogenesis induced by sphingosine-1-phosphate. Cell 99: 301-312, 1999.

10. Masiero L, Lapidos KA, Ambudkar I, Kohn EC. Regulation of the RhoA pathway in human endothelial cell spreading on type IV collagen: role of calcium influx. J Cell Sci 112: 3205-3213, 1999.

11. McVerry BJ and Garcia JG. Endothelial cell barrier regulation by sphingosine 1phosphate. J Cell Biochem 92: 1075-1085, 2004.

12. McVerry BJ, Peng X, Hassoun PM, Sammani S, Simon BA, Garcia JGN. Sphingosine 1-phosphate reduces vascular leak in murine and canine models of acute lung injury. Am J Respir Crit Care Med 170: 987-993, 2004.

13. Mehta D, Konstantoulaki M, Ahmmed GU, Malik AB. Sphingosine 1-phosphateinduced mobilization of intracellular $\mathrm{Ca}^{2+}$ mediates Rac activation and adherens junction assembly in endothelial cells. J Biol Chem 280: 17320-17328, 2005.

14. Mehta D and Malik AB. Signaling mechanisms regulating endothelial permeability. Physiol Rev 86: 279-367, 2006. 
15. Minnear FL, DeMichele MAA, Moon DG, Rieder CL, Fenton II JW. Isoproterenol reduces thrombin-induced pulmonary endothelial permeability in vitro. Am J Physiol Heart Circ Physiol 257: H1613-H1623, 1989.

16. Minnear FL, Patil S, Bell D, Gainor JP, Morton CA. Platelet lipid(s) bound to albumin increases endothelial electrical resistance: mimicked by LPA. Am J Lung Cell Mol Physiol 281, L1337-L1344. 2001.

17. Minnear FL, Zhu L, He P. Sphingosine 1-phosphate prevents platelet-activating factor-induced increase in hydraulic conductivity in rat mesenteric venules: pertussis toxin sensitive. Am J Physiol Heart Circ Physiol 289: H840-H844, 2005.

18. Paik JH, Chae S-S, Lee M-J, Thangada S, Hla T. Sphingosine 1-phosphateinduced endothelial cell migration requires the expression of EDG-1 and EDG-3 receptors and Rho-dependent activation of $a_{v} b_{3}$ - and $b_{1}$-containing integrins. J Biol Chem 276: 11830-11837, 2001.

19. Peng X, Hassoun PM, Sammani S, McVerry BJ, Burne MJ, Rabb H, Pearse D, Tuder RM, Garcia JGN. Protective effects of sphingosine 1-phosphate in murine endotoxin-induced inflammatory lung injury. Am J Respir Crit Care Med 169: 12451251, 2004.

20. Schaphorst KL, Chiang E, Jacobs KN, Zaiman A, Natarajan V, Wigley F, Garcia JG. Role of sphingosine-1 phosphate in the enhancement of endothelial barrier integrity by platelet-released products. Am J Lung Cell Mol Physiol 285: L258-L267, 2003. 
21. Shuster CB and Herman IM. The mechanics of vascular cell motility. Microcirculation 5: 239-257, 1998.

22. Stelzner TJ, Weil JV, O'Brien RF. Role of cyclic adenosine monophosphate in the induction of endothelial barrier properties. J Cell Physiol 139: 157-166, 1989.

23. Sun H, Breslin JW, Zhu J, Yuan SY, Wu MH. Rho and ROCK signaling in VEGFinduced microvascular endothelial hyperpermeability. Microcirculation 13: 237-247, 2006.

24. Tschugguel W, Zhegu Z, Gajdzik L, Maier M, Binder BR, Graf J. High precision measurement of electrical resistance across endothelial cell monolayers. Pfluger Arch 430: 145-147, 1995.

25. Vouret-Craviari V, Bourcier C, Boulter E, van Obberghen-Schilling E. Distinct signals via Rho GTPases and Src drive shape changes by thrombin and sphingosine-1-phosphate in endothelial cells. J Cell Sci 115: 2475-2484, 2002.

26. Wallenstein S, Zucker CL, Fleiss JL. Some statistical methods useful in circulation research. Circ Res 47: 1-9, 1980.

27. Wojciak-Stothard B, Potempa S, Eichholtz T, Ridley AJ. Rho and Rac but not Cdc42 regulate endothelial cell permeability. J Cell Sci 114: 1343-1355, 2001 
Study 2

Sphingosine 1-phosphate regulates membrane trafficking of VE-cadherin: decreasing endocytosis and increasing recycling of VE-cadherin

Keywords: S1P, Rab11, vascular endothelial growth factor, $\beta$-arrestin2, microscopy, electric cell-substrate impedance sensing, human umbilical vein endothelial cell, microtubule. 


\section{ABSTRACT}

The biologically active lipid, sphingosine 1-phosphate (S1P), induces a myriad of cellular events including enhancement of the endothelial barrier and an increase in vascular endothelial (VE) cadherin. Based on the latter observation, I hypothesized that S1P affects the trafficking of VE-cadherin between cell surface and cytoplasmic vesicles. Immunofluorescence microscopy and a biotinylated cell impermeable reagent were used to demonstrate internalized and cell surface VE-cadherin. Endocytosis of VE-cadherin was induced by EGTA or VEGF. S1P decreased EGTA-induced endocytosis and co-localization of internalized VE-cadherin with EEA 1, a marker of early endosomes, and prevented and reversed the effect of VEGF. S1P also increased the recovery of cell surface VE-cadherin after endocytosis by EGTA or VEGF and increased the co-localization of internalized VE-cadherin with Rab11, a marker of the recycling endosome. Bafilomycin $\mathrm{A} 1$, an inhibitor of recycling, and microtubule inhibitors, taxol and colchicine, blocked the increase in junctional VE-cadherin and the sustained increase in endothelial electrical resistance induced by S1P, the latter using the $\mathrm{Ca}^{2+}$-switch protocol. Bafilomycin A1 also prevented the increase in recovery of cell surface VE-cadherin induced by S1P. When co-treated or post-treated with VEGF, S1P blocked or reversed the increased interaction of VE-cadherin with $\beta$-arrestin2, an endocytic adapter protein. I conclude that S1P stabilizes homophilic VE-cadherin binding by decreasing endocytosis and increasing recycling of VE-cadherin, the latter requiring microtubules. 


\section{INTRODUCTION}

VE-cadherin, the major protein at endothelial adherens junctions, forms $\mathrm{Ca}^{2+}$ dependent homophilic adhesions between cells and is vital to the integrity of the endothelial barrier. A blocking antibody to VE-cadherin increased the vascular permeability in heart and lungs of mice (8), and antibodies directed to specific domains of the extracellular region of VE-cadherin increased the permeability of endothelial cell monolayers $(7,9)$ and/or prevented angiogenesis (21). Down-regulation of VE-cadherin initiates the transition from a normal endothelial phenotype to a mesenchymal phenotype as is seen in mature bovine systemic and pulmonary endothelial cells and is related to atherogenesis $(2,3,13)$. Induction of endocytosis of VE-cadherin by vascular endothelial growth factor (VEGF) has been hypothesized as the cellular mechanism for the VEGF-induced increase in vascular permeability (15). Therefore, alterations in the level of VE-cadherin have important consequences in endothelial function and pathophysiology.

Sphingosine 1-phosphate (S1P), released mainly from activated platelets and unstimulated erythrocytes, induces a myriad of cellular events, one of which is enhancement of the endothelial barrier $(14,27)$. S1P rapidly increases endothelial barrier function as assessed by a peak increase in endothelial electrical resistance within 6-10 min of treatment $(14,45)$, prevents the transient increase in hydraulic conductivity induced by platelet-activating factor in individually perfused microvessels of the rat mesentery (29), and reduces the increase in pulmonary edema in mice and dogs subjected to intratracheal endotoxin $(26,34)$. S1P also enhances the localization of VEcadherin at endothelial junctions and induces the assembly of endothelial adherens junctions within $10 \mathrm{~min}$ of treatment (45). This observation of an increase in junctional VE-cadherin prompted us to explore the cellular mechanisms for the apparent S1Pinduced stabilization of VE-cadherin.

Gene expression, decreased degradation, and or membrane stabilization could explain the increased junctional localization of VE-cadherin induced by S1P. Since S1P 
increases junctional VE-cadherin within 10 min, stabilization of membrane trafficking of VE-cadherin appeared most likely. VE-cadherin constitutively undergoes endocytosis via a clathrin-dependent pathway (42) and is degraded via a lysosomal pathway (41, 42). Furthermore, trafficking of VE-cadherin has been postulated to be involved in angiogenesis and regulation of endothelial barrier function (42, 43). VEGF, formerly known as vascular permeability factor, was recently shown to increase the endocytosis of VE-cadherin by a signaling pathway involving an enhanced interaction of VEcadherin with $\beta$-arrestin2, an endocytic adaptor protein involved in receptor internalization (15). Trafficking of epithelial (E)-cadherin has been extensively studied by Stow and co-workers $(4,5,19,20)$. These authors demonstrated that E-cadherin constitutively traffics from the cell surface to endocytic vesicles and either back to the surface or to late endosomes to be degraded. However, recycling of E-cadherin to the cell surface predominates over degradation, promoting stabilization of the barrier $(4$, 20). Further, endocytosis of E-cadherin is required for signals of fibroblast growth factor (FGF) receptors (FGFRs) (5).

In this study, I hypothesized that S1P stabilizes VE-cadherin at intercellular junctions by influencing the trafficking of VE-cadherin, i.e. by decreasing the endocytosis and increasing the recycling of VE-cadherin. Endocytosis of VE-cadherin was induced by EGTA and physiologically by VEGF and assessed by immunofluorescence microscopy and a biotinylated impermeable reagent. Recovery of cell surface VE-cadherin or recycling was assessed by the biotinylated reagent, colocalization of VE-cadherin with Rab11, a recycling endosomal marker, and bafilomycin $\mathrm{A} 1$, an inhibitor of recycling endosomes. The interaction of $\beta$-arrestin2 with VE-cadherin was identified by co-immunoprecipitation. Because active trafficking of intracellular vesicles involves microtubules $(22,44)$, inhibitors of microtubules were used to test the affect of VE-cadherin trafficking induced by S1P. 


\section{MATERIALS AND METHODS}

Materials. S1P was purchased from Avanti Polar Lipids (Alabaster, AL). Bovine pulmonary artery endothelial cells were purchased from Vec Technologies, Inc. (Rensselaer, NY). Gentamicin sulfate was from ICN Biomedicals, Inc. (Aurora, OH). Newborn calf serum and bovine brain extract were from Cambrex Corporation (East Rutherford, NJ). Sulfosuccinimidyl 2-(biotinamido) ethyl-dithioproprionate (sulfo-NHSSS-biotin) was purchased from Pierce (Rockford, IL). Recombinant human VEGF 165 was purchased from R\&D systems, Inc. (Minneapolis, MN). Prolong Gold anti-fade reagent and Alexa Fluor-labeled secondary antibodies were from Invitrogen Molecular Probes (Eugene, OR). Gold-coated electrodes for the measurement of electrical resistance by Electrical Cell-Substrate Impedance Sensing (ECIS) were from Applied Biophysics (Troy, NY). VE-cadherin antibodies were purchased from Axxora (San Diego, CA) and Beckman Coulter Company (Marseille Cedex, France). $\beta$-arrestin2 antibody was purchased from Novus Biologicals (Littleton, CO). $\beta$-catenin antibody was from BD Bioscience (San Jose, CA). p120-catenin antibody and protein A/G beads were from Santa Cruz Biotechnology (San Diego, CA). Horseradish peroxidase conjugated secondary antibodies were purchased from Chemicon International (Temecula, CA). Nitrocellulose membranes and ECL (enhanced chemiluminescence) Western blotting detection reagents were purchased from Amersham Biosciences (Buckinghamshire, England). Bafilomycin A1 was purchased from LC Laboratories (Woburn, MA). Cycloheximide was a gift from Dr. Chuan Hu. All other chemicals were from Sigma-Aldrich (St. Louis, MO).

Cell culture. Human umbilical vein endothelial cells (HUVEC) were isolated from fresh human placentas by $1 \mathrm{mg} / \mathrm{ml}$ of type I collagenase and grown in MCDB-131 (MCDB) culture medium containing $5 \%(\mathrm{v} / \mathrm{v})$ human serum, $20 \%(\mathrm{v} / \mathrm{v})$ newborn calf serum, 7.5 $\mu \mathrm{g} / \mathrm{ml}$ of endothelial cell growth supplement, $4.5 \mu \mathrm{g} / \mathrm{ml}$ of bovine brain extract, $25 \mu \mathrm{g} / \mathrm{ml}$ of porcine intestinal heparin, and $50 \mu \mathrm{g} / \mathrm{ml}$ of gentamicin sulfate at $37^{\circ} \mathrm{C}$ in $5 \% \mathrm{CO}_{2}$. HUVECs were used between passages 2 and 8 . Before treatments or ECIS experiments, HUVEC monolayers were serum-starved for $2 \mathrm{~h}$. Bovine pulmonary artery 
endothelial cells (BPAEC, passages 3-18) were cultured in MCDB medium containing $10 \%$ fetal bovine serum and $50 \mu \mathrm{g} / \mathrm{ml}$ of gentamicin sulfate. BPAEC monolayers were serum-starved for $4 \mathrm{~h}$ before treatments. HUVECs were used for all experiments except for experiments with VEGF.

Transendothelial electrical resistance. Electrical resistance across HUVEC and BPAEC monolayers was measured continuously with ECIS to assess changes in endothelial barrier function. Briefly, cells were seeded onto ECIS cultureware $\left(0.8 \mathrm{~cm}^{2} /\right.$ well $)$ precoated with $0.2 \%$ gelatin. The measured electrical resistance was of those cells located on the small gold electrode $\left(5 \times 10^{-4} \mathrm{~cm}^{2}\right)$ in each of the wells. The culture medium was the electrolyte, and the small gold electrode, covered by confluent endothelial cells, and a larger gold counter-electrode $\left(\sim 2 \mathrm{~cm}^{2}\right)$ were connected to a phase-sensitive, lock-in amplifier. A constant current of $1 \mu \mathrm{A}$ was supplied by a $1-\mathrm{V}$, $4000-\mathrm{Hz}$ alternating current through a $1-\mathrm{M} \Omega$ resistor. The computer controlled the output of the amplifier and switched the measurements to different electrodes in each of two 8-well arrays during the course of an experiment. Changes in voltage between the small electrode and the large counter electrode were monitored by the lock-in amplifier, stored, and then calculated as impedance by the computer. Data are presented as changes in the resistive portion of electrical impedance normalized to the initial value at time 0 .

$\mathrm{Ca}^{2+}$-switch protocol. Cell monolayers were treated with $2 \mathrm{mM}$ EGTA (ethylene glycolbis(2-amino-ethylether)-N,N,N',N'-tetra-acetic acid) for $10 \mathrm{~min}$ to chelate extracellular $\mathrm{Ca}^{2+}$, followed by (1) adding nothing, (2) adding fresh MCDB containing $1.6 \mathrm{mM} \mathrm{Ca}^{2+}$ to restore extracellular $\mathrm{Ca}^{2+}$, or (3) adding $1 \mu \mathrm{M}$ S1P and fresh MCDB.

Immunofluorescence microscopy. After treatments, cell monolayers were rinsed quickly with phosphate-buffered saline containing $\mathrm{Ca}^{2+}$ and $\mathrm{Mg}^{2+}(\mathrm{PBS}+/+)$. Cells were fixed, permeabilized, and incubated with 5\% BSA. Cells were then incubated with primary antibodies, followed by Alexa Fluor-labeled secondary antibodies, and rinsed several times with PBS+/+. Cells were mounted with Prolong Gold anti-fade reagent. Images 
were generated by confocal laser scanning with a Zeiss LSM 510 confocal microscope. For the same group of images, the fluorescent signals were measured at emission wavelengths of 488 and $594 \mathrm{~nm}$ with the same pinhole (less than $1 \mu \mathrm{m}$ ), the same detector gain, and the same amplifier offset.

To better visualize internalized VE-cadherin, cell surface (antibody labeled) VEcadherin was removed with an acid wash. Briefly, BPAECs were pre-incubated for $1 \mathrm{~h}$ with serum-free MCDB containing $20 \mathrm{mM}$ HEPES, a mouse anti-human VE-cadherin antibody (cad5; 1:50 dilution) against its extracellular domain, and $3 \% \mathrm{BSA}$ at $4{ }^{\circ} \mathrm{C}$, followed by several washes in PBS $+/+$ to remove extra antibody, and then cultured with MCDB for $30 \mathrm{~min}$ at $37^{\circ} \mathrm{C}$ in $5 \% \mathrm{CO}_{2}$. After indicated treatments, BPAECS were separated into two groups, one group was administered a mild acid wash (PBS, pH 2.7, containing $25 \mathrm{mM}$ glycine and $3 \% \mathrm{BSA}$ ) for $15 \mathrm{~min}$ at $4^{\circ} \mathrm{C}$ to remove cell surface bound antibody while retaining internalized antibody $(16,43)$, whereas the other group was washed with PBS. The cells were then processed for immunofluorescence microscopy.

Transfection. Enhanced GFP (EGFP)-tagged Rab11 was transfected into HUVECs by electroporation with the Nucleofector I device (Amaxa Biosystems, Berlin, Germany). Briefly, 90\% confluent HUVEC monolayers were trypsinized and counted. After centrifugation, $1.0 \times 10^{6}$ cells were resuspended in $100 \mu \mathrm{l}$ of Nucleofector solution (7.25 mM ATP, $12 \mathrm{mM} \mathrm{MgCl} \cdot 6 \mathrm{H}_{2} \mathrm{O}, 88 \mathrm{mM} \mathrm{KH}_{2} \mathrm{PO}_{4}, 14 \mathrm{mM} \mathrm{NaHCO}$, and $2 \mathrm{mM}$ glucose at $\mathrm{pH}$ 7.4) with EGFP-tagged Rab11 and transferred immediately to a cuvette and electroporated in the Nucleofector apparatus, using program U-001. Transfected cells were recovered with fresh medium at $37^{\circ} \mathrm{C}$ for $5 \mathrm{~min}$ and seeded on gelatin-coated glass cover-slips. Cells were placed in a humidified environment and maintained at $37^{\circ} \mathrm{C}$ and $5 \% \mathrm{CO}_{2}$ for $2 \mathrm{~d}$ until used for experimentation.

Immunoblotting. Cells were washed $2 x$ in ice-cold PBS, lysed in RIPA buffer (15 mM $\mathrm{NaCl}, 50 \mathrm{mM}$ Tris, $1 \% \mathrm{NP}-40,0.5 \%$ sodium deoxycholate) containing $2 \mathrm{mM}$ EGTA, 1 $\mathrm{mM}$ sodium vanadate, $1 \mathrm{mM}$ phenylmethanesulfonyl fluoride (PMSF), $5 \mu \mathrm{g} / \mathrm{ml}$ of aprotinin, and $2 \mu \mathrm{g} / \mathrm{ml}$ of leupeptin. Samples were clarified by centrifugation at 14,000 rpm for $10 \mathrm{~min}$ at $4^{\circ} \mathrm{C}$. Proteins were resolved by sodium dodecyl sulfate- 
polyacrylamide gel electrophoresis (SDS-PAGE) and transferred to Nitrocellulose membrane using a mini-Protean electrophoresis system. Protein blots were probed with indicated primary antibodies, followed by the appropriate horseradish peroxidaseconjugated secondary antibody, and developed by enhanced chemiluminescence.

Biotinylation assay for assessment of VE-cadherin trafficking. Internalized and cell surface VE-cadherin were quantified by using a biotinylation assay $(5,20)$. Cell surface proteins were covalently labeled with $1.0 \mathrm{mg} / \mathrm{ml}$ of sulfosuccinimidyl 2-(biotinamido) ethyl-dithioproprionate (sulfo-NHS-SS-biotin), a biotin-labeled cell impermeable reagent.

Assessment of internalized VE-cadherin (endocytosis). Cell monolayers were incubated with sulfo-NHS-SS-biotin at $0^{\circ} \mathrm{C}$ for $1 \mathrm{~h}$ followed by washing with a blocking reagent for sulfo-NHS-SS-biotin at $4^{\circ} \mathrm{C}$ for $10 \mathrm{~min}$ to quench free sulfo-NHS-SS-biotin. Cells were cultured in MCDB at $37^{\circ} \mathrm{C}$ for 30 min and treated with $\mathrm{S} 1 \mathrm{P}$. Endocytosis was stimulated by increasing temperature to $37^{\circ} \mathrm{C}$, by lowering extracellular $\mathrm{Ca}^{2+}$ with EGTA, or by treatment with VEGF (15). After endocytosis, cell monolayers were washed $2 x$ for 20 min each with a glutathione solution at $4^{\circ} \mathrm{C}$ to remove cell surface biotin. Internalized biotinylated proteins were protected from glutathione stripping. Cells were lysed in RIPA buffer with protease inhibitors. Equal amount of proteins was incubated with streptavidin beads and resolved by SDS-PAGE. Internalized, biotinylated VEcadherin was identified with an anti-VE-cadherin antibody to the extracellular domain.

Assessment of cell surface VE-cadherin. Endocytosis was induced by EGTA, and cells were treated with VEGF or S1P, then incubated at $0^{\circ} \mathrm{C}$ with the biotin-labeled cell impermeable reagent. Cell lysates were processed as described above and assessed only for cell surface, actually recovered cell surface, VE-cadherin.

Co-immunoprecipitation. Cells were lysed in RIPA buffer with phosphatase and protease inhibitors, and lysates were centrifuged at $14,000 \mathrm{rpm}$ for $10 \mathrm{~min}$ at $4^{\circ} \mathrm{C}$ to clear debris. About $2 \mathrm{mg}$ of protein was incubated with a rabbit anti-human VEcadherin antibody for $2 \mathrm{~h}$ at $4^{\circ} \mathrm{C}$ after preclearing with $50 \mu$ of protein $A / G$ beads for $1 \mathrm{~h}$. Protein A/G beads were added and incubated for additional hour to pull down antibody- 
bound proteins. Beads were washed with RIPA buffer several times and boiled in $3 x$ sample buffer. Proteins were resolved and analyzed by Western blotting.

Statistics. All values are means \pm SE. A minimum of six experiments was conducted for ECIS experiments and three experiments for the biotinylation assay and microscopy. Data on electrical resistance were analyzed with a 2-way analysis of variance with repeated measures (40). Statistical significance was set at $P<0.05$. 


\section{RESULTS}

S1P increased junctional localization of VE-cadherin and p120. Within $10 \mathrm{~min}$ of treatment, $1 \mu \mathrm{M}$ S1P increased the immunofluorescent staining of VE-cadherin and p120 at intercellular junctions (Fig. 1). S1P also increased N-cadherin at intercellular junctions (data not shown) but did not appear to affect junctional $\beta$-catenin. This increase in junctional VE-cadherin was also observed using the $\mathrm{Ca}^{2+}$-switch protocol (Fig. 2a), whereby $\mathrm{Ca}^{2+}$ dependent, homophilic VE-cadherin binding was disrupted with addition of EGTA, then restored with addition of fresh MCDB. Administration of EGTA resulted in a loss of VE-cadherin at cell-cell contacts and an increase in cytoplasmic vesicles stained for VE-cadherin. Upon restoration of extracellular $\mathrm{Ca}^{2+}$ with $\mathrm{MCDB}$, VE-cadherin was present at intercellular junctions by $10 \mathrm{~min}$, but to a greater extent when also treated with S1P+MCDB (Fig. 2a).

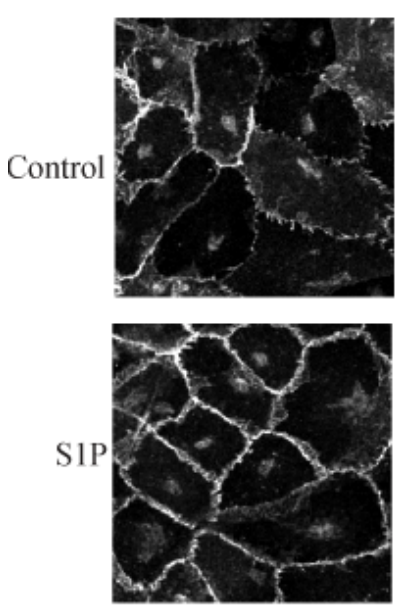

VE-cadherin
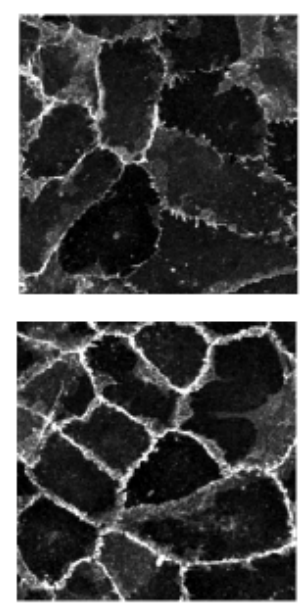

p120
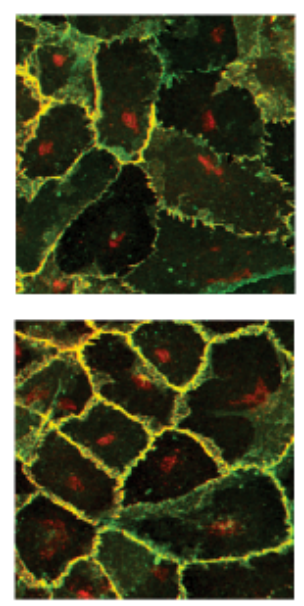

VE-cadherin + p120
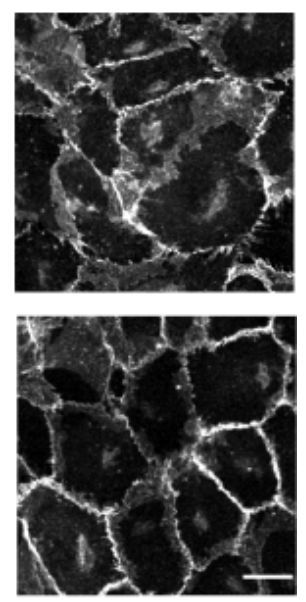

$\beta$-catenin

Figure 1. Sphingosine 1-phosphate (S1P) increased VE-cadherin and p120 at cell-cell contacts. Endothelial cell monolayers derived from human umbilical veins (HUVEC) and seeded on glass coverslips were treated with S1P $(1 \mu \mathrm{M})$ for $10 \mathrm{~min}$. VE-cadherin was visualized by incubation with a mouse anti-human VE-cadherin primary antibody (Cad 5) and an Alexa Fluor 594-labeled goat anti-mouse secondary antibody. p120 and $\beta$-catenin were viewed, respectively, by a polyclonal or monoclonal antibody. Column 3 depicts the merged image of VE-cadherin and p120. Scale bar, $20 \mu \mathrm{m}$. 


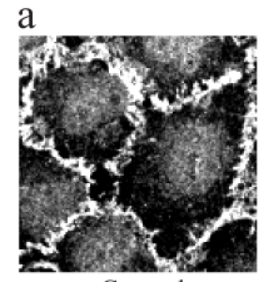

Control

b Cell surface VE-cadherin

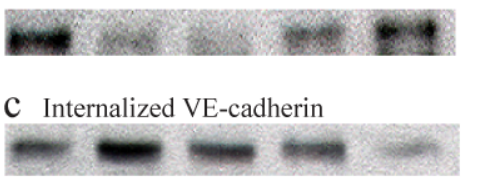

Total cell lysate VE-cadherin

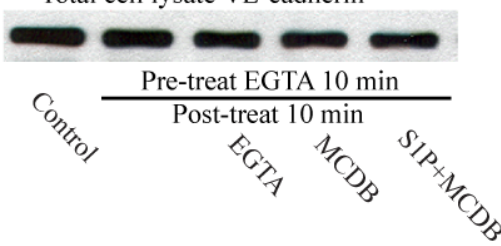

e Temperature-induced internalization of VE-cadherin

Internalized VE-cadherin

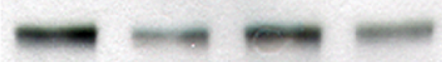

Total cell lysate VE-cadherin

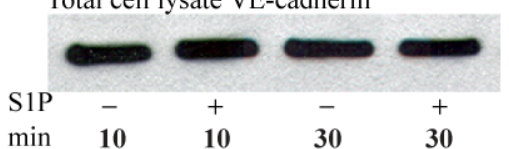

Figure 2. S1P influenced trafficking of VE-cadherin. Endocytosis of VE-cadherin in HUVEC monolayers was induced by EGTA ( $2 \mathrm{mM}$, a) or by increasing temperature (e). a) VE-cadherin was visualized by incubation with a rabbit anti-human antibody against the extracellular domain followed by Alexa Fluor488-labeled secondary antibody. b) Recovery of cell surface VEcadherin. HUVEC monolayers were incubated with EGTA for $10 \mathrm{~min}$ at $37^{\circ} \mathrm{C}$ to induce endocytosis followed by an additional 10 min of EGTA (post-treatment control group) or treatment with MCDB or $\mathrm{S} 1 \mathrm{P}+\mathrm{MCDB}$ for an additional $10 \mathrm{~min}$. Cells were then incubated at $0^{\circ} \mathrm{C}$ with cell impermeable marker, sulfo-NHS-SS-biotin, for $1 \mathrm{~h}$. Cell lysed in RIPA buffer with protease inhibitors, and equal amount of protein was incubated with streptavidin beads to complex biotin-labeled proteins. Proteins were resolved on SDS-PAGE and VE-cadherin identified with a rabbit anti-human antibody against its extracellular domain. VE-cadherin in total cell lysate was used as loading control. c) Cells were pre-incubated at $0^{\circ} \mathrm{C}$ with sulfo-NHS-SSbiotin, administered EGTA at $37^{\circ} \mathrm{C}$, then treated as described in (b). Cell surface biotin-labeled proteins were removed by two, 20 min washed with glutathione at $0^{\circ} \mathrm{C}$, leaving internalized biotinylated proteins resistant to glutathione. Cell lysates were processed as decribed in (b). d) Quantification of three immunoblots shown as ratio of individually treated group to control group. e) Cells were incubated at $0^{\circ} \mathrm{C}$ with sulfo-NHS-SS-biotin for $1 \mathrm{~h}$, and then temperature was increased from $0^{\circ} \mathrm{C}$ to $37^{\circ} \mathrm{C}$ and treated with S1P. Cell lysates were processed as described in (b). b,c,d) Note that S1P decreased endocytosis and increased recovery of VE-cadherin in comparison with MCDB. *P $<0.05$ vs. MCDB group, ${ }^{\#} P<0.05$ vs. EGTA groups. Scale bar, 10 $\mu \mathrm{m}$. 
S1P decreased endocytosis of VE-cadherin and increased recovery of cell surface VE-cadherin. Internalized and cell surface VE-cadherin were visualized by immunofluorescence microscopy and quantified by the biotinylation assay. Addition of EGTA for 10 and $20 \mathrm{~min}$ (the latter used as the control group for post-treatments) induced the endocytosis of VE-cadherin (Fig. 2a, c, d). Post-treatment with MCDB for 10 min reduced the amount of internalized VE-cadherin. Post-treatment with S1P further decreased the immunofluorescent localization of VE-cadherin in the cytoplasm (Fig. 2a) and significantly reduced the amount of internalized, biotin-labeled VEcadherin in comparison with the EGTA- and MCDB-treated groups (Fig. 2, c and d, internalized). Endocytosis was also induced by increasing temperature from $0^{\circ} \mathrm{C}$, temperature at which cell surface proteins were labeled with sulfo-NHS-SS-biotin, to $37^{\circ} \mathrm{C}$. S1P decreased the temperature-induced endocytosis of VE-cadherin at 10 and 30 min of treatment (Fig. 2e). Opposite results were obtained for the recovery of cell surface VE-cadherin. Administration of EGTA dramatically decreased cell surface VEcadherin in the initial 10-min and post-10-min treatment (Fig. 2, b and d, cell surface). Post-treatment for 10 min with MCDB slightly increased cell surface VE-cadherin; whereas, S1P significantly increased the amount of cell surface VE-cadherin as viewed by immunofluorescent staining (Fig. 2a) and quantification by the biotin assay (Fig. 2,b and $d$, cell surface). Quantification of three immunoblots depicts the statistically significant effects of S1P on endocytosis and recovery of cell surface VE-cadherin using the biotinylation assay (Fig. 2d). These results demonstrate that S1P influences VEcadherin trafficking.

S1P decreased and reversed VEGF effects on endothelial electrical resistance, VE-cadherin trafficking, and interaction with $\beta$-arrestin2. Next, it was determined if S1P could affect the trafficking of VE-cadherin by the physiologically relevant mediator, VEGF (15). For these experiments, it was necessary to switch to BPAEC monolayers, because VEGF mimicked the effects of S1P on increasing endothelial electrical resistance and decreasing the endocytosis of VE-cadherin in HUVEC monolayers. In BPAEC monolayers, S1P prevented and reversed the decrease in endothelial electrical resistance induced by VEGF (Fig. 3a). The effect of VEGF on internalization of VE- 
cadherin was viewed by immunofluorescence microscopy (Fig. 3b) and quantified by the biotinylation assay (Figs. 3, c and d). Immunofluorescent localization of VEcadherin at intercellular junctions was observed by incubation with an antibody to the $\mathrm{N}$ terminus of VE-cadherin. VEGF decreased the junctional staining of VE-cadherin and increased the number of endocytic vesicles containing VE-cadherin (Fig. 3b, top row). Co-treatment of S1P+VEGF blocked the VEGF effect resulting in the maintenance of cell-surface VE-cadherin (Fig. 3b, top row). An acid wash was applied to remove all cell surface antibodies enabling identification only of acid-resistant, internalized VE-cadherin (Fig. 3b, bottom row). This technique revealed a lesser amount of internalized VEcadherin in the cell monolayers co-treated with VEGF+S1P versus treatment with VEGF alone. Using the biotinylation assay, it was demonstrated that VEGF increased the internalization of VE-cadherin (Fig. 3, c and d, internalized) and much less biotinylated VE-cadherin was recovered at the cell surface (Fig. 3, c and d, cell surface). S1P induced the opposite effects. Furthermore, S1P prevented and reversed these effects of VEGF when co-treated or post-treated for $30 \mathrm{~min}$ following the initial 30-min treatment with VEGF. These data demonstrate that S1P can block the VEGF-induced endocytosis of VE-cadherin.

It was previously demonstrated that the increased endocytosis of VE-cadherin induced by VEGF requires an enhanced interaction of $\beta$-arrestin2 with VE-cadherin (15). I confirmed this finding in BPAEC monolayers and extended this finding to show that S1P induced the opposite effect within $30 \mathrm{~min}$ of treatment (Fig 3 , e and f). Furthermore, both co-treatment and post-treatment with S1P decreased and reversed the VEGF-induced interaction of $\beta$-arrestin2 with VE-cadherin. 
a

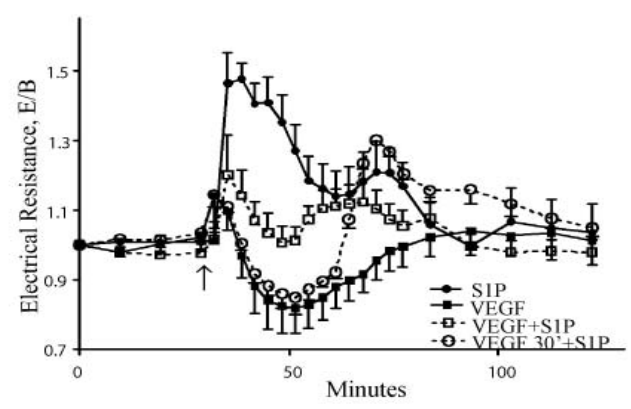

b

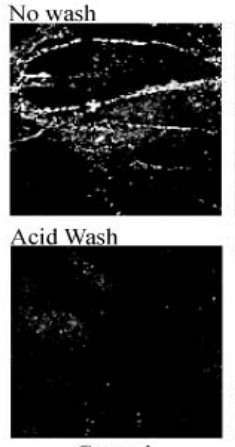

Control
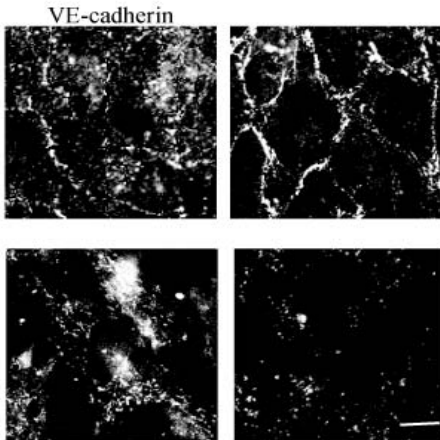

VEGF

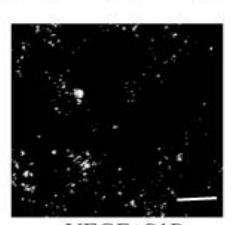

VEGF+SIP

c
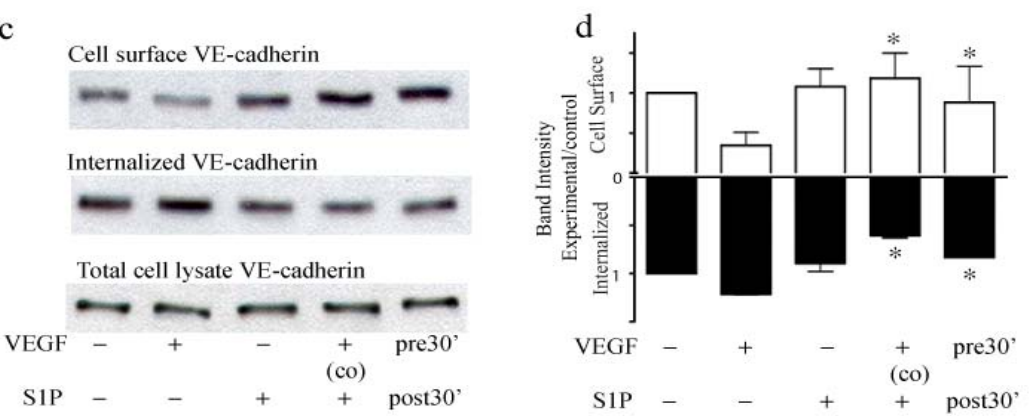

$\mathrm{e}$
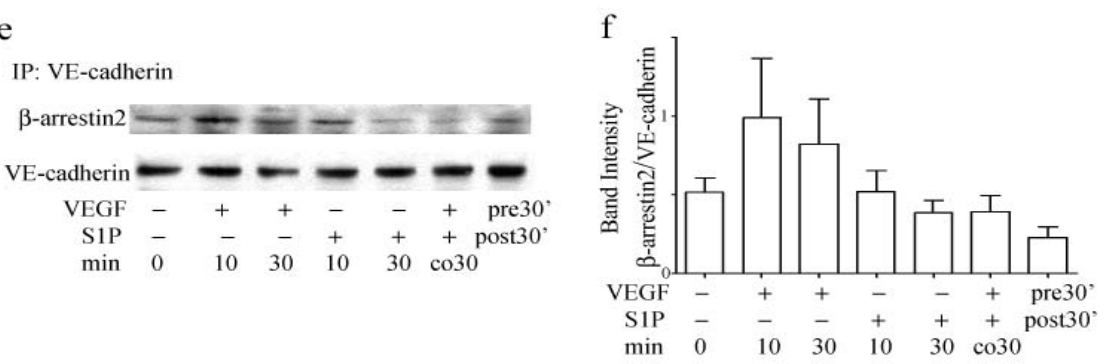

Figure 3. S1P decreased and reversed effects of VEGF. Endothelial cell monolayers derived from bovine pulmonary arteries (BPAEC) were treated individually with S1P or VEGF or in combination or pretreated for 30 min with VEGF then post-treated for 30 min with S1P. a) Cell monolayers $(n=5)$ were monitored continuously for changes in endothelial electrical resistance. b) Cell monolayers were pre-incubated with a monoclonal VEcadherin antibody (cad 5) against its extracellular domain at $4^{\circ} \mathrm{C}$ for $1 \mathrm{~h}$ following treatments at $37^{\circ} \mathrm{C}$. Cells were either washed with mild acid to remove VE-cadherin antibody to better visualize internalized VE-cadherin (second row) or not washed to view cell surface and internalized VE-cadherin antibody, and then processed for immunofluorescent staining of VE-cadherin. c) Cells were incubated with sulfo-NIH-SS-biotin for assessment of internalized and cell surface VE-cadherin (see Fig. 2 and Methods for details). VE-cadherin in total cell lysate was used as loading control. d) Quantification of three immunoblots shown as a ratio of individually treated group to control group. e) Interaction of VE-cadherin with $\beta$-arrestin2. Cell lysates were immunoprecipitated with a rabbit anti-human VEcadherin antibody and immunoblotted for $\beta$-arrestin2 and VE-cadherin. (f) Quantification of three immunoblots as normalized to VE-cadherin blots. Note that S1P opposed these effects of VEGF and also blocked and reversed effects of VEGF when co- or post-treated. ${ }^{*} \mathrm{P}<0.05$ vs. VEGF groups. Scale bar, $10 \mu \mathrm{m}$. 
S1P increased co-localization of Rab11 with VE-cadherin. Exocytosis (or recycling) also contributes to trafficking. Therefore, it was determined if VE-cadherin is
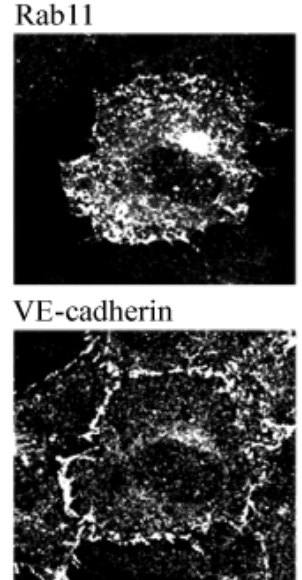

Merge

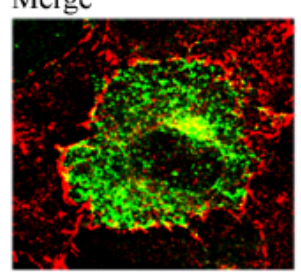

Control
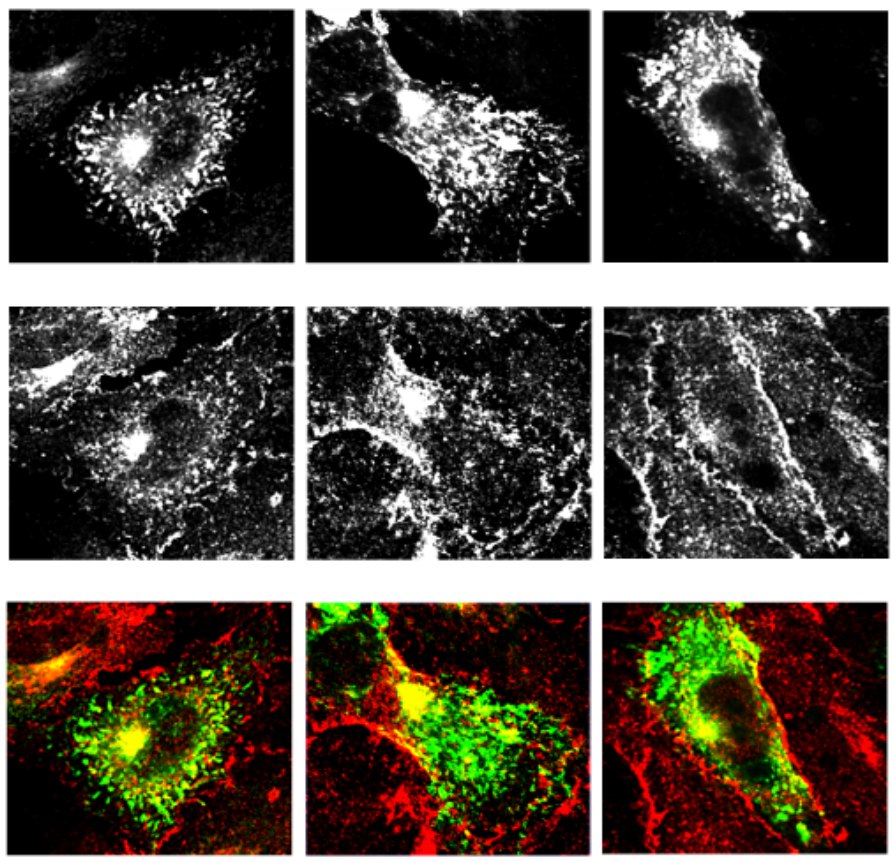

Pre-treat EGTA $10 \mathrm{~min}$

SIP+MCDB $5 \mathrm{~min}$ Post-treat

S1P+MCDB $10 \mathrm{~min}$
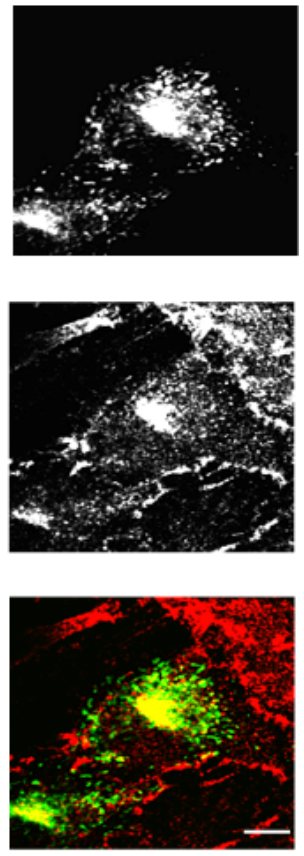

MCDB $5 \mathrm{~min}$

Figure 4. S1P increased co-localization of Rab11 with VE-cadherin. Enhanced green fluorescent protein (EGFP) tagged Rab11, a marker of recycling endosomes, was transiently transfected by electroporation into HUVECs. After $48 \mathrm{~h}$, endocytosis was induced with EGTA followed by treatment with S1P+MCDB or MCDB alone. VE-cadherin was visualized by incubation with monoclonal antibody (Cad 5) and Alexa Fluor 594labeled secondary antibody. Note that VE-cadherin co-localized with EGFP-Rab11 prominently in perinuclear recycling endosome (columns 2, 3, and 5) and also co-localized adjacent to the plasma membrane (columns 3 and 4) after treatment with S1P. Scale bar, $5 \mu \mathrm{m}$.

associated with Rab11, a marker of recycling endosomes. EGFP-tagged Rab11 was transiently transfected by electroporation into HUVECs, and cells were visualized by immunofluorescence microscopy during the $\mathrm{Ca}^{2+}$-switch protocol. Figure 4 shows that the expressed EGFP-Rab11 distributed throughout the cell but localized primarily in an area that could be considered the perinuclear, recycling endosome (top row). VEcadherin localized at cell junctions in the control setting and after treatment with S1P for 
10 min (columns 1 and 4). As expected, administration of EGTA for 10 min triggered the internalization of VE-cadherin, that was observed throughout the cell but predominantly in the perinuclear, recycling endosome where VE-cadherin was colocalized with Rab11 (merge row, columns 2, 3 and 5). After treatment with S1P for 5 min, VE-cadherin remained co-localized with Rab11 in the perinuclear, recycling endosome but was also distributed with Rab11 adjacent to the plasma membrane (column 3). Upon treatment with S1P for $10 \mathrm{~min}$, less VE-cadherin was co-localized with Rab11 in the recycling endosome and at the cell surface, and VE-cadherin once again outlined the cell (column 4). With MCDB treatment, VE-cadherin co-localized with Rab11 only in the perinuclear, recycling endosome (column 5).

S1P increased recycling of VE-cadherin. Dependency on a recycling pathway for the S1P-induced increase in junctional localization of VE-cadherin demonstrated in Figure 1 was further demonstrated using the recycling inhibitor, bafilomycin A1. Bafilomycin A1 blocks the ATP-dependent proton pump that results in the inhibition of acidification of endosomes (20). It has been suggested that endosome acidification plays a crucial role in the recycling of internalized vesicles back to the plasma membrane. Pre-treatment with $1 \mu \mathrm{M}$ bafilomycin $\mathrm{A} 1$ for $1 \mathrm{~h}$ prevented the S1P-induced increase in junctional VE-cadherin (Fig. 5a). Bafilomycin A1 also blocked (Fig. 5b, lanes 5 and 6 , and c) the S1P-induced increase in biotin-labeled, cell surface VEcadherin at 10 and 60 min (Fig. 5 b, lanes 2 and 3, and c) as assessed by the biotinylation assay. S1P also increased biotin-labeled, cell surface p120 at 10 and 60 min (Fig. 5b, lanes 2 and 3, and d); however, bafilomycin A1 did not inhibit the S1Pinduced increase in cell surface p120 at 10 and $60 \mathrm{~min}$ (Fig. 5b, lanes 5 and 6, and d). 


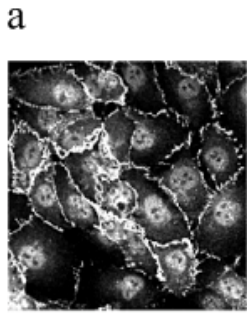

DMSO Control

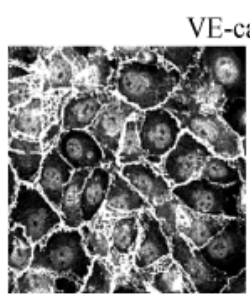

S1P
VE-cadherin

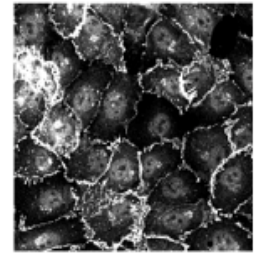

Bafilomycin A1

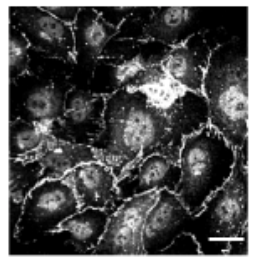

Bafilomycin A1+S1P

b

IP: Biotin (Cell Surface)

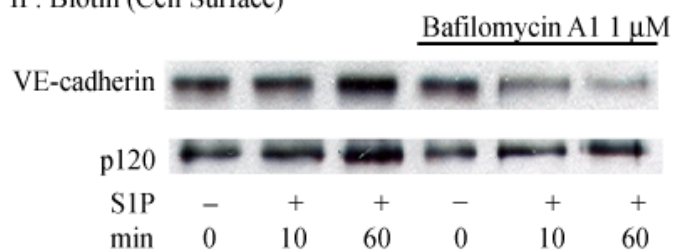

$\mathrm{c}$

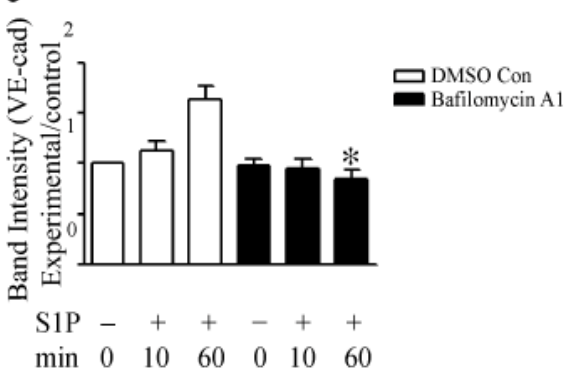

IP: Biotin (Cell Surface) d

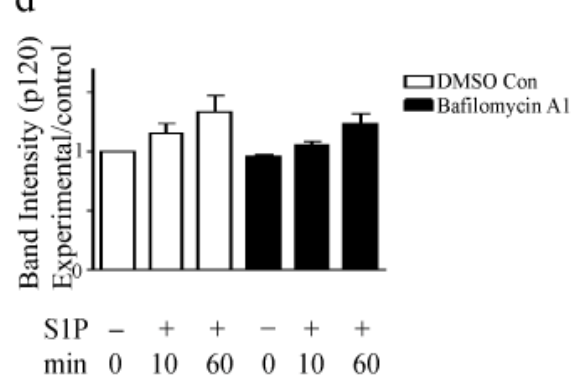

$\min \quad 0 \quad 10 \quad 60 \quad 0 \quad 10 \quad 60$

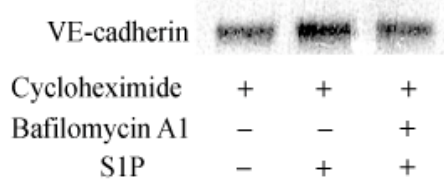

Figure 5. S1P augmented recycling of VE-cadherin. HUVEC monolayers were pretreated for 60 min with bafilomycin $A 1(1 \mu \mathrm{M})$, dissolved in dimethyl sulfoxide (DMSO), to inhibit recycling of VE-cadherin. Cell surface VE-cadherin was identified either by immunofluorescence microscopy (a) or by immunoprecipitation of biotin-labeled proteins with streptavidin beads and immunoblotting with VE-cadherin (b). The latter method was also used to identify cell surface p120 (b). c,d) Quantification of three immunoblots of VEcadherin or p120. e) HUVEC monolayers were pretreated with cycloheximide, or cotreated with cycloheximide and bafilomycin A1, followed by addition of S1P. Cell surface VE-cadherin was visualized by biotinylation. ${ }^{*} \mathrm{P}<0.05$ vs. DMSO control groups at the same time course. Scale bar, $20 \mu \mathrm{m}$. 
a

b

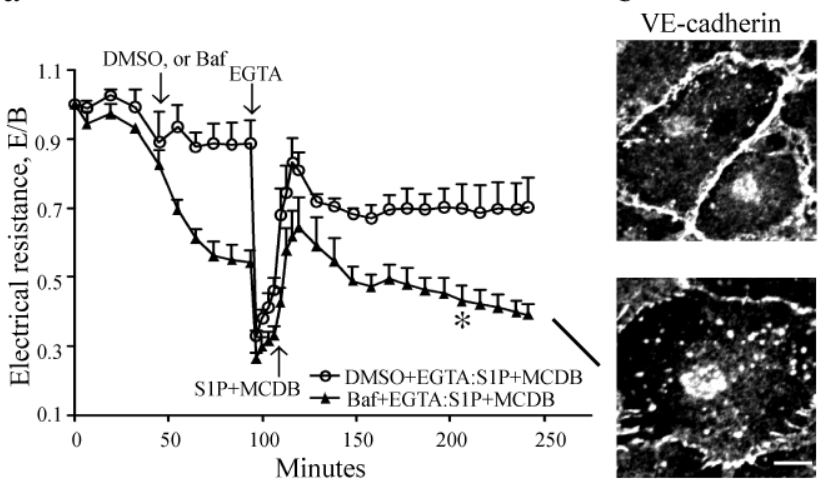

$\mathrm{c}$

d

IP: Biotin (Cell surface)

Cell surface VE-cadherin $\underline{\text { Bafilomycin A1 }}$

Total cell lysate VE-cadherin
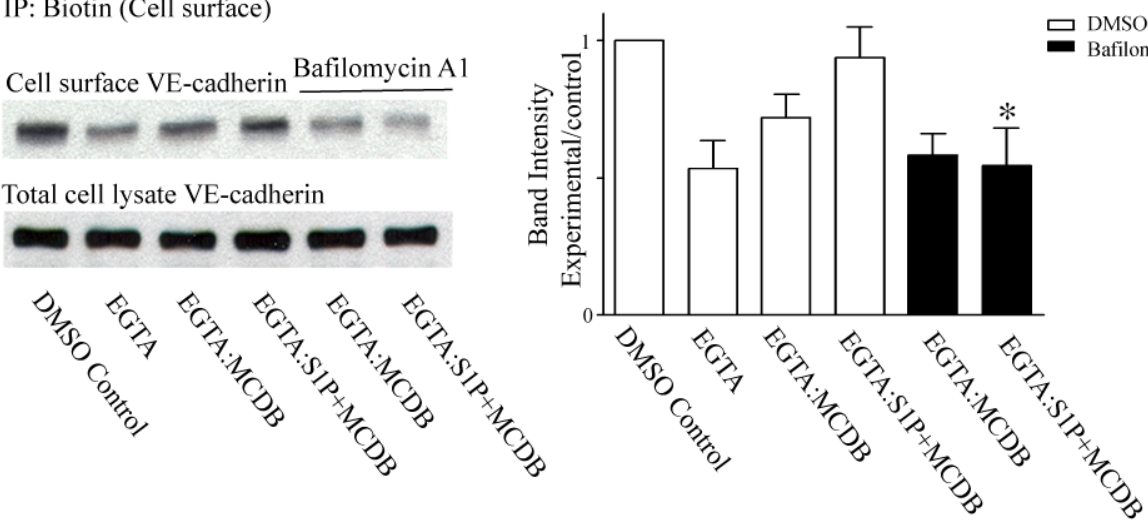

Figure 6. Inhibition of recycling blocked sustained activity of S1P and recovery of cell surface VE-cadherin. S1P-induced recycling of VE-cadherin was highlighted using $\mathrm{Ca}^{2+}$-switch protocol. a) Endothelial electrical resistance was continuously recorded in HUVEC monolayers pretreated with DMSO or bafilomycin A1, administered EGTA, and then post-treated with S1P+MCDB. b) At completion of experiment (240 min), cells seeded directly on ECIS wells were visualized for VE-cadherin by incubation with a rabbit anti-human VE-cadherin antibody. c) Representative immunoblot of cell monolayers incubated with sulfo-NHS-SS-biotin to assess cell surface VEcadherin without or with bafilomycin A1. VE-cadherin in total cell lysate was used as loading control. d) Quantification of four immunoblots in (c). Note that bafilomycin A1 decreased basal, electrical resistance and blocked sustained increase in electrical resistance and also inhibited increased recovery of cell surface VE-cadherin induced by S1P. ${ }^{*} \mathrm{P}<0.05$ vs. same treated group in DMSO control. Scale bar, $5 \mu \mathrm{m}$.

To test whether or not the S1P-induced increase in cell surface VE-cadherin is related to the bio-synthesis of VE-cadherin. HUVEC monolayers were pretreated for 2 h with $10 \mu \mathrm{g} / \mathrm{ml}$ of cycloheximide, an inhibitor of protein syntheses, or co-treated with cycloheximide and bafilomycin A1 followed by administration of S1P for $1 \mathrm{~h}$. Cycloheximide interferes with the translocation step in protein synthesis thus blocking 
translational elongation. Cycloheximide alone failed to block the S1P-induced increase in biotin-labeled, cell surface VE-cadherin (Fig. 5e). However, co-treatment with cycloheximide and bafilomycin A1 blocked the effect of S1P. These data indicate that the increase in cell surface of VE-cadherin by S1P is not due to an increase in biosynthesis of VE-cadherin.

Further indication that S1P augmented the recycling of VE-cadherin was demonstrated by incorporation of bafilomycin A1 with the $\mathrm{Ca}^{2+}$-switch protocol (Fig. 6). Pretreatment with bafilomycin A1 decreased basal, endothelial electrical resistance, suggesting that constitutive recycling of VE-cadherin contributes to the maintenance of baseline barrier function (Fig. 6a). Following the precipitous drop in electrical resistance with administration of EGTA, treatment with S1P+MCDB induced a rapid increase in endothelial electrical that was sustained for the 3-h duration of the experiment. Bafilomycin A1 blocked the sustained increase in endothelial electrical resistance (Fig. 6a). These results indicate that basal resistance and the sustained increase in endothelial electrical resistance induced by S1P were dependent on recycling. At completion of the electrical resistance experiment, cells seeded on the ECIS wells were processed for the immunofluorescent staining of VE-cadherin. Junctional VE-cadherin was present at $3 \mathrm{~h}$ after treatment with S1P but was reduced in appearance in cell monolayers pretreated with bafilomycin A1 (Fig. 6b). The biotinylation assay confirmed these findings (Fig. 6, c and d). S1P increased the recovery of cell surface, biotinylated VE-cadherin to a greater extent than MCDB (Fig. 6c, lane 4 vs. 3, and d) following the initial reduction by EGTA. And pretreatment with bafilomycin A1 blocked the S1P- as well as the MCDB-induced increase in biotinylated VE-cadherin at the cell surface (Fig. $6 \mathrm{c}$, lanes 5 and 6 vs. lanes 3 and 4 , and d).

S1P decreased EGTA-triggered endocytosis of VE-cadherin. Trafficking of VEcadherin is a dynamic process involving endocytosis and recycling, as well as degradation. To determine if S1P directly affected the endocytosis of VE-cadherin, recycling was inhibited with bafilomycin $A 1$ and degradation was inhibited by chloroquine which inhibits the lysosomal pathway of protein degradation. Before 
labeling cell surface proteins with sulfo-NHS-SS-biotin, cell monolayers were pretreated for $1 \mathrm{~h}$ with bafilomycin $\mathrm{A} 1(1 \mu \mathrm{M})$ and the lysosomal inhibitor chloroquine (100 $\mu \mathrm{M})$. Bafilomycin A1 caused an increase in biotinylated VE-cadherin in the cytoplasm (Fig. 7a, lane 2), and S1P blocked this increase (lane 3), indicating that S1P decreased the constitutive endocytosis of VE-cadherin. In the presence of bafilomycin A1 and chloroquine, endocytosis of VE-cadherin was artificially triggered by EGTA following pretreatment with Tris (as vehicle control) or S1P for $30 \mathrm{~min}$. Pretreatment of S1P decreased the EGTA-induced endocytosis of VE-cadherin (lane 5 vs. lane 4). The decrease in endocytosis by S1P was also observed with immunofluorescence microscopy (Fig. 7b). Within 2 min of EGTA administration, cells were separated and strands extended between adjacent cells. In addition, internalized VE-cadherin localized predominantly to the sub-plasma membrane. Administration of EGTA for 5 and 10 min facilitated the endocytotic process, and internalized VE-cadherin was distributed throughout the cytoplasm (Fig. 7b, top row). Pretreatment with S1P for 30 min reduced the internalization of VE-cadherin by EGTA, and VE-cadherin was observed predominantly at intercellular junctions throughout the 2-10 min-administration of EGTA (Fig. 7b, bottom row).

Figure 7 also demonstrates that internalized VE-cadherin resided in early endosomes identified with the early endosome antigen 1, EEA1. In the control setting, VE-cadherin localized to intercellular junctions and EEA1 to cytoplasmic vesicles. Upon administration of EGTA, VE-cadherin co-localized with EEA1 in cytoplasmic vesicles when cells were pretreated with the Tris vehicle (Fig. 7c, column 2, merge row). In contrast, pretreatment with S1P blocked this co-localization (column 3, merge row), and VE-cadherin appeared prominently at intercellular junctions. 
a

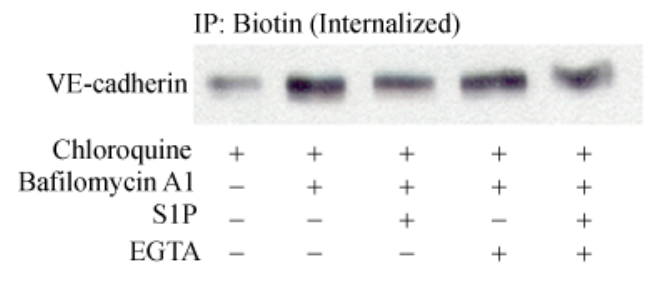

b

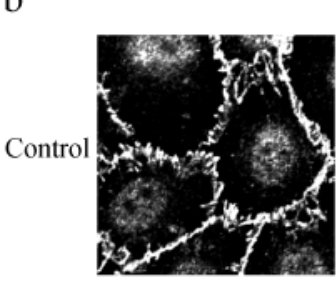

Pre-treat SIP

Control

Control

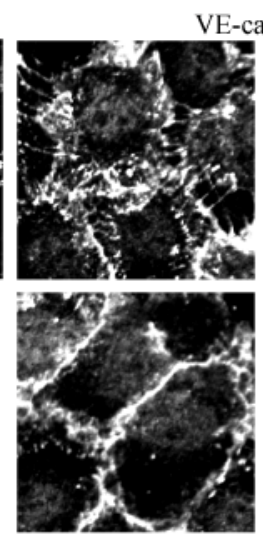

EGTA 2 min

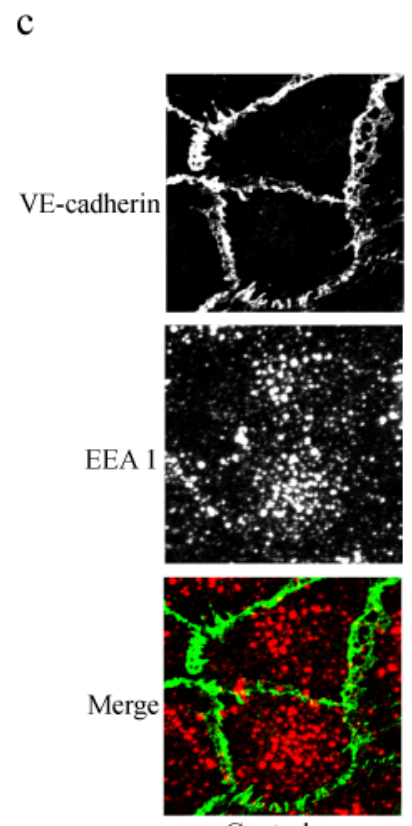

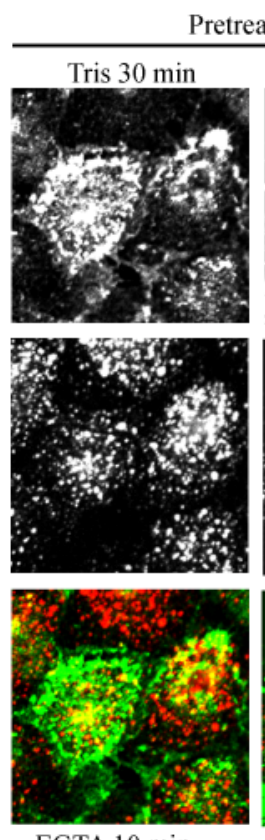

EGTA 10 min

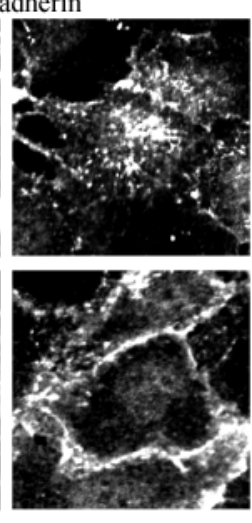

EGTA 5 min

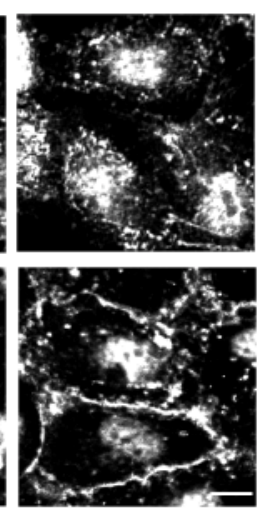

EGTA 10 min
Pretreatment
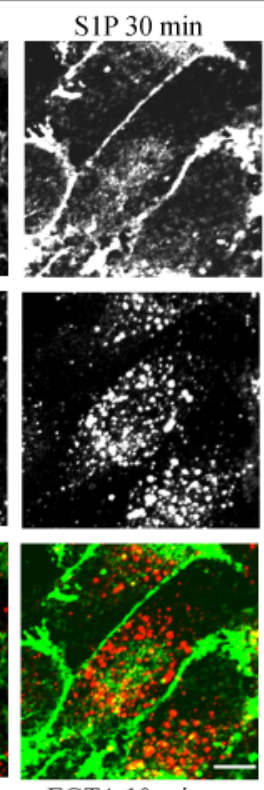

EGTA $10 \mathrm{~min}$
Figure 7. S1P decreased endocytosis of VE-cadherin and blocked increase in colocalization of VE-cadherin with EEA 1. The process of endocytosis was separated from recycling and degradation in HUVEC monolayers by using inhibitors of the latter two (a) and by pretreatment with S1P before induction of endocytosis by EGTA ( $a, b$ and c). a) Cells were incubated with sulfo$\mathrm{NIH}-\mathrm{SS}-$ biotin at $0^{\circ} \mathrm{C}$ for $1 \mathrm{~h}$, and pretreated for $1 \mathrm{~h}$ with chloroquine to inhibit degradation and bafilomycin A1 to inhibit recycling. Cells were pretreated with S1P to determine its effects on internalization of VE-cadherin followed by addition of EGTA for $10 \mathrm{~min}$ to induce endocytosis. b and c) Cells were pretreated for $30 \mathrm{~min}$ with Tris or S1P followed by administration of EGTA for 2, 5 , and $10 \mathrm{~min}$ (b) and $10 \mathrm{~min}$ only (c) to trigger endocytosis. VE-cadherin was visualized by incubation with a rabbit anti-human VE-cadherin antibody and an Alexa Fluor488-labeled secondary antibody, and EEA1 by incubation with a monoclonal EEA 1 antibody and Alexa Fluor594-labeled secondary antibody. Scale bar (b and c), $10 \mu \mathrm{m}$. 
Microtubule inhibitors blocked S1P effects. Microtubules provide the tracks for the exocytosis of endocytic vesicles $(16,44)$. Thus, the involvement of microtubules was tested by pretreatment for $1 \mathrm{~h}$ with either taxol to inhibit depolymerization (taxol binds to $\beta$-subunit of tubulin on microtubules that locks the tubulin from disassembly) or colchicine to inhibit polymerization of microtubules (colchicine binds to free tubulins that results in blocking the nucleation of tubulins) followed by the $\mathrm{Ca}^{2+}$-switch protocol. Both taxol and colchicine blocked the sustained increase in electrical resistance induced by S1P in a dose-dependent manner (Fig. 8, a and b). As stated above, the sustained endothelial electrical resistance induced by S1P was related to the restoration of junctional VE-cadherin (Fig. 6b, 8c, DMSO control). Immunofluorescent staining showed that the recovery of junctional VE-cadherin by S1P+MCDB, following induced endocytosis by EGTA, was attenuated by taxol and colchicine (Fig. 8c). These two inhibitors of microtubules, however, did not prevent the EGTA-induced internalization of VE-cadherin. These data demonstrate that the recycling of VE-cadherin induced by S1P transported via microtubules. 
a

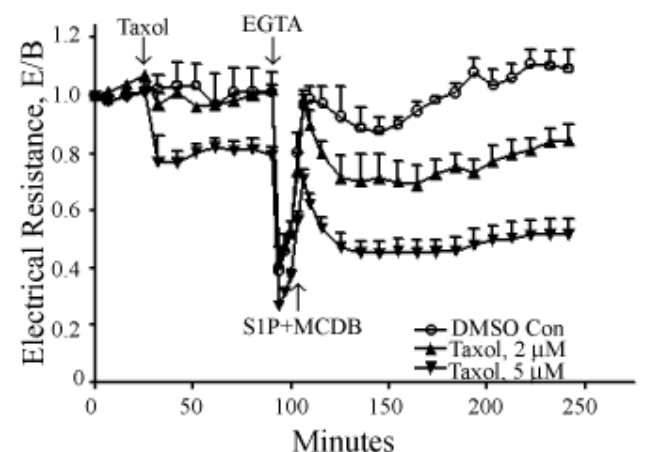

b

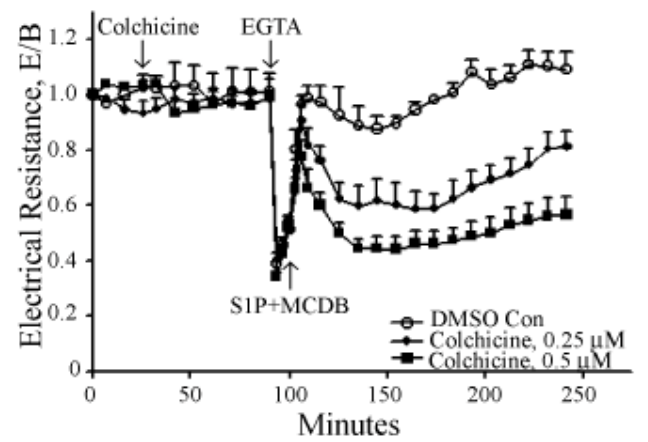

c
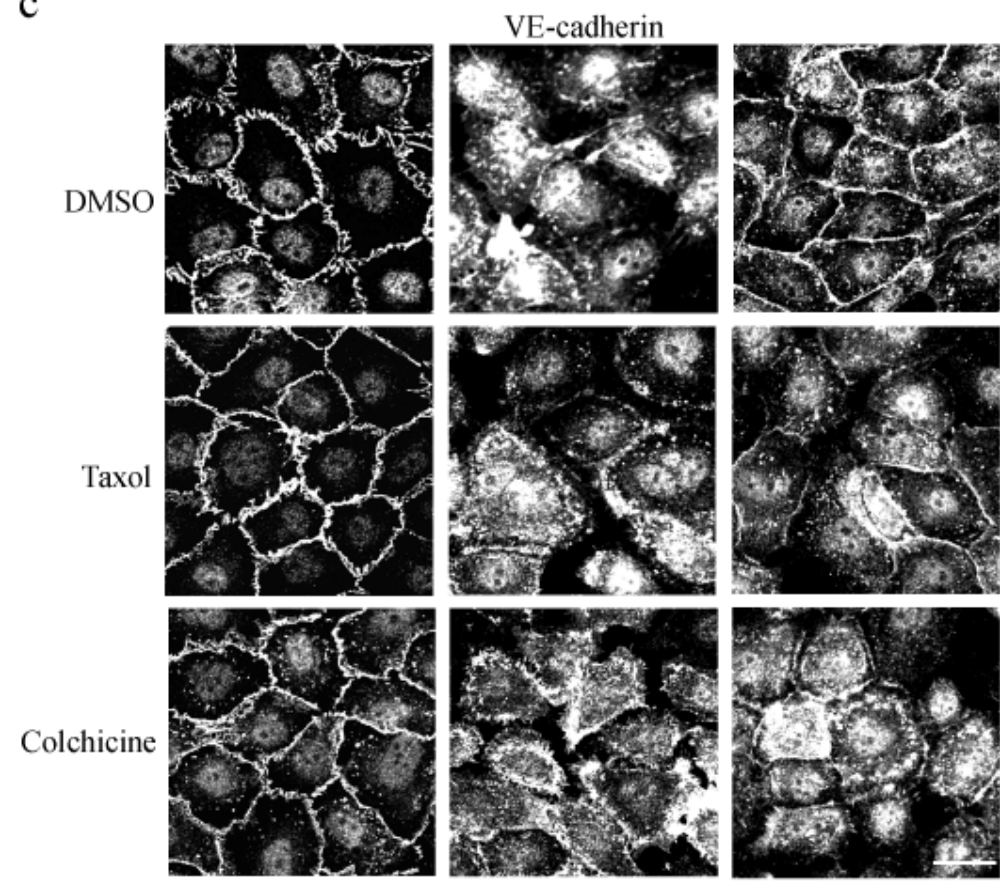

Control
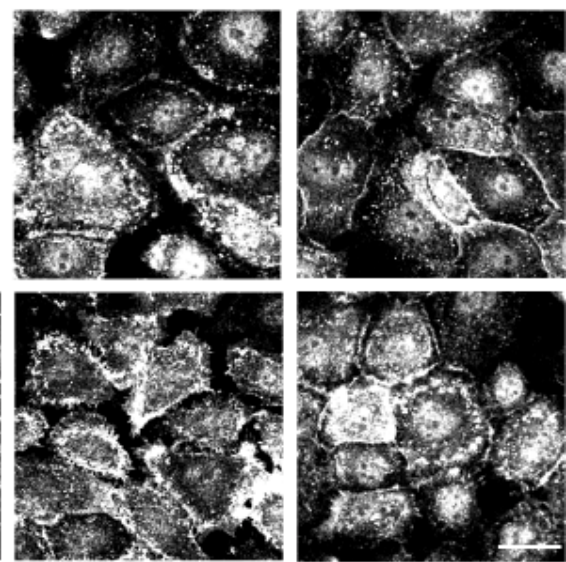

EGTA

EGTA:S1P+MCDB 
Figure 8. Microtubule inhibitors blocked effects of S1P. HUVEC monolayers were subjected to the $\mathrm{Ca}^{2+}$-switch protocol and were either monitored continuously for endothelial electrical resistance (a) or viewed for VE-cadherin by immunofluorescence microscopy (b). Cells were pretreated for $1 \mathrm{~h}$ with DMSO vehicle, or taxol or colchicine to inhibit microtubules. EGTA was added to induce endocytosis of VE-cadherin followed by treatment with S1P+MCDB. a and b) Endothelial electrical resistance was monitored continuously. c) VE-cadherin was visualized by incubation with a rabbit anti-human antibody. Note that sustained increase in electrical resistance and increased recovery of junctional VE-cadherin induced by S1P were blocked by taxol and colchicines. Scale bar, $20 \mu \mathrm{m}$. 


\section{DISCUSSION}

The objective of this study was to demonstrate the cellular mechanism(s) for the increase in junctional VE-cadherin induced by S1P within 10 min of treatment. I determined using immunofluorescence microscopy and a quantitative biotinylation assay that S1P decreased the endocytosis and increased the recovery of cell surface VE-cadherin induced by EGTA and VEGF. Furthermore, S1P increased the colocalization of internalized VE-cadherin with Rab11 and blocked and reversed the VEGF-induced interaction of VE-cadherin with $\beta$-arrestin2. Finally, inhibitors of the recycling process or microtubules blocked the S1P-induced increase in junctional appearance of VE-cadherin. I conclude that S1P rapidly increases junctional VEcadherin by decreasing the endocytosis and increasing the recycling of VE-cadherin.

Synthesis and degradation and in the case of a membrane protein such as VEcadherin movement in and out of the cell can determine the amount and cellular localization of a protein. The increase in junctional VE-cadherin induced by S1P does not appear to involve synthesis because it can occur within 10 min of treatment. Further, inhibition of protein synthesis with cycloheximide had no effect. Therefore, I focused on membrane trafficking of VE-cadherin involving the endocytosis of the protein from the cell surface to intracellular endosomes and recycling back to the cell surface through recycling endosomes. Herein, I demonstrated that S1P opposed the effects of VEGF as well as EGTA on decreasing endothelial electrical resistance, reducing VE-cadherin at intercellular junctions, increasing the endocytosis of VE-cadherin, and increasing the interaction of $\beta$-arrestin2 with VE-cadherin. Previous studies have demonstrated that VE-cadherin constitutively internalizes via a clathrin-dependent pathway (42). Trafficking of E-cadherin has been extensively studied by Stow et al. (4). Using the biotinylation assay, these investigators found that $13 \%$ of cell surface E-cadherin is constitutively internalized and recycled back to the cell surface (20), and that this process is mediated by protein kinase $C$ and Rac1 $(1,19)$. Trafficking of E-cadherin appears to regulate cell-cell adhesion, morphogenesis and signaling downstream of the active fibroblast growth factor receptor $1(1,4,5)$. VE-cadherin also appears to 
constitutively undergo endocytosis and recycling (43), and trafficking of VE-cadherin has been postulated to be involved in angiogenesis and regulation of endothelial barrier function $(42,43)$. Endocytosis induced by VEGF has been hypothesized as the cellular mechanism for the permeability-increasing activity of VEGF (15). The binding of VEGF to its VEGF2 receptor initiates the activation of Src leading to a sequence of events including activation of Vav2 (a guanosine exchange factor for the Rho family of GTPases), Rac1, and $\mathrm{p}^{21}$-activated kinase (PAK). Active PAK induces the phosphorylation of Ser665 on VE-cadherin providing a signaling site for the interaction with beta-arrestin2 (endocytic adaptor protein) and allowing for subsequent internalization of VE-cadherin via a clathrin-dependent pathway $(15,42)$. Interestingly, S1P like VEGF activates Rac1 and PAK (14), and inhibition of Rac1 diminishes the immunofluorescent staining of VE-cadherin at intercellular junctions (28).

Stow et al. $(4,20)$ showed that most of the endocytic vesicles containing $\mathrm{E}$ cadherin were recycled back to the cell membrane and were not targeted for degradation, and that recycling of E-cadherin to the cell surface predominated over degradation, promoting stabilization of the barrier. This was evident when cells were treated with bafilomycin A1, an inhibitor of recycling endosomes. Furthermore, Ecadherin present in endocytic vesicles co-stained with rab5, a marker of early endosomes, but did not co-localize with the late endosomal marker rab7 (20). Rab11 locates at recycling endosomes and acts as an intermediate compartment for the postGolgi trafficking of E-cadherin (23). In the present study, S1P increased the recycling of internalized VE-cadherin back to the cell surface, as assessed by immunofluorescence microscopy and the biotinylation assay. The recycling inhibitor, bafilomycin A1, prevented the S1P-induced increase in junctional VE-cadherin under normal conditions and during the $\mathrm{Ca}^{2+}$-switch protocol.

Endocytosed vesicles first sort into early-endosomes, and then either go through late endosomes, lysosomes to be degraded, or transport back to cell membrane via recycling endosomes. Early, recycling, and late endosomes are populated by specific Rab GTPases that cluster in these distinct domains with their effectors (37). Rab 
proteins, in their active form, assemble with their effectors in responsible for vesicle budding, cytoskeletal transport, and target membrane fusion (38). Internalized VEcadherin and E-cadherin co-localize with Rab5 found in early endosomes and EEA1, an effector of Rab5 $(15,20)$. But, internalized E-cadherin induced by increasing temperature did not localize with Rab7, a marker of late endosomes (20). In the present study, VE-cadherin containing vesicles were initially localized to the subplasma membrane after 2 min of EGTA administration. With longer administration of EGTA (5$10 \mathrm{~min}$ ), these vesicles distributed throughout the cells coinciding with EEA1. S1P blocked the co-localization of internalized VE-cadherin and EEA1.

Rab4 and Rab11 cluster in recycling endosomes and comprise the machinery that recycles proteins to the cell surface $(33,38)$. Expression of a Rab11 mutant deficient in GTP binding significantly slowed transferrin-receptor recycling back to the cell membrane (30). For $\beta_{2}$-adrenergic receptors, Rab11 regulates recycling and targeting to lysosomes. Further, Rab11 acts as an intermediate compartment to regulate the post-Golgi trafficking and exocytosis of E-cadherin (23). Recycling endosomes distribute throughout the cell but also localize prominently in a cluster called the perinuclear recycling endosome. Following treatment with EGTA for $10 \mathrm{~min}$, internalized VE-cadherin was distributed throughout the cell in coincidence with expressed EGFP-Rab11 but was prominently clustered with EGFP-Rab11 in perinuclear recycling endosomes. Within 5-min of treatment with S1P, co-localization was apparent at the subplasma membrane. After 10-min of treatment, VE-cadherin appeared to a lesser degree in the perinuclear recycling endosome, still resided with Rab11 at the subplasma membrane, and reappeared at the cell periphery. In contrast, internalized VE-cadherin co-localized with Rab11 only in the perinuclear recycling endosomes in MCDB-treated group. These data suggest that S1P enhanced the recycling of VE-cadherin via the Rab11 GTPase.

It was reported that S1P triggered exocytosis in bovine chromaffin cells (32), increased glutamate secretion in neurons (18), and also facilitated the endothelial exocytosis of Weibel-Palade bodies in part by activating of phospholipase C (PLC)- $\gamma$ 
pathways (25). Transportation of intracellular vesicles to cell membrane is a kind of exocytosis that involves the recycling process, and elevated intracellular $\mathrm{Ca}^{2+}$ level plays a role in exocytosis. Interestingly, S1P rapidly increases the intracellular level of $\mathrm{Ca}^{2+}$ in many cell types $(32,35,46)$.

Endocytosis, recycling, and degradation are dynamic processes making it difficult to separate the effects of S1P on these three processes. The bafilomycin A1 experiments clearly implicate recycling in the increased junctional localization of VEcadherin induced by S1P. In the attempt to separate the effects of S1P on endocytosis, recycling and degradation were inhibited, respectively, by bafilomycin $A 1$ and chloroquine. Also, S1P was pretreated for 30 min before administration of EGTA for 2, 5 , and $10 \mathrm{~min}$. Immunofluorescence microscopy and the quantitative biotinylation assay demonstrated that S1P decreased the endocytosis of VE-cadherin. I conclude that S1P can regulate both endocytosis and the recycling processes of VE-cadherin that result in the increased presence of junctional VE-cadherin and stabilization of the endothelial barrier.

S1P was reported to increase microtubule polymerization (31). Microtubule cytoskeletons, together with the microtubule-based motor proteins, kinesin and dynein, have been shown to play important roles in membrane trafficking events involved in endocytosis and transcytosis $(6,22,44)$. The cadherin-catenin complex and $\mathrm{N}$-cadherin were shown to transport to the intercellular junctions along microtubule cytoskeletons and driven by kinesin $(24,31)$. To further prove that the S1P-enhanced junctional VEcadherin is through regulation of vesicle trafficking via microtubules, cells were treated with microtubules inhibitors, taxol and colchicine. Taxol and colchicine stabilize microtubules by inhibiting depolymerization or polymerization, respectively. Sokolova et al. (36) reported that depolymerization of microtubules has no effects on EGF internalization, and I also found that both taxol and colchicines have no influence on the EGTA-induced endocytosis of VE-cadherin. However, taxol and colchicine blocked the restoration of immunofluorescent localization of VE-cadherin at cell junctions and 
prevented the S1P-induced maintenance of electrical resistance which is associated with junctional VE-cadherin, as originally demonstrated in our previous study (45).

With respect to endocytosis and recovery of cell surface VE-cadherin, S1P and VEGF induced opposite responses. Interestingly, when VEGF and S1P were co-treated or when VEGF was pretreated for 30 min followed by post-treatment for 30 min with $\mathrm{S} 1 \mathrm{P}$, the end results favored the effects of S1P. This complementary response would implicate a transactivation event involving a receptor tyrosine kinase and a G-proteincoupled receptor (GPCR). S1P triggers intracellular signaling via binding to G-proteincoupled receptors, i.e. Edg receptors. Likewise, VEGF up-regulates the expression of S1P1 receptors in bovine aortic endothelial cells, which was associated with enhanced intracellular signaling responses to S1P and the potentiation of S1P-mediated vasorelaxation (17). Tanimoto et al. (39) reported that S1P activates not only S1P receptors but also activates the VEGF receptor Flk-1/KDR faster than VEGF stimulation. Endo et al. (12) proved that S1P induces membrane ruffling of human umbilical vein endothelial cells (HUVECs) via the vascular endothelial growth factor receptor (VEGFR), Src family tyrosine kinase(s), and the Crkll adaptor protein. Similarly epithelial growth factor (EGF) receptor, platelet derived growth factor (PDGF) receptor and insulin-like growth factor in response to activation of G-protein-coupled receptor (GPCR) has been reported $(10,11)$. VEGF binds to VEGF R2 that results in increases in permeability and endocytosis of VE-cadherin (15). In this paper, VEGF decreased the endothelial electrical resistance and increased the endocytosis of VE-cadherin, and S1P induced the opposite effects. In view of that, S1P protects endothelial barrier from the effects of VEGF via regulating VE-cadherin trafficking, and possibly involving the crosstalk between receptors of S1P and VEGF.

Going over the main points in this paper, I demonstrated that S1P enhances the endothelial barrier by regulating VE-cadherin trafficking via decreases in endocytosis and increases in recycling of VE-cadherin. The recycling of VE-cadherin transports along microtubules. 


\section{REFERENCES}

Reference List

1. Akhtar $\mathbf{N}$ and Hotchin NA. RAC1 regulates adherens junctions through endocytosis of E-cadherin. Mol Biol Cell 12: 847-862, 2001.

2. Alexander JS, Alexander BC, Eppihimer LA, Goodyear N, Haque R, Davis CP, Kalogeris TJ, Carden DL, Zhu YN and Kevil CG. Inflammatory mediators induce sequestration of VE-cadherin in cultured human endothelial cells. Inflammation 24: 99-113, 2000.

3. Bobryshev YV, Cherian SM, Inder SJ and Lord RS. Neovascular expression of VE-cadherin in human atherosclerotic arteries and its relation to intimal inflammation. Cardiovasc Res 43: 1003-1017, 1999.

4. Bryant DM and Stow JL. The ins and outs of E-cadherin trafficking. Trends Cell Biol 14: 427-434, 2004.

5. Bryant DM, Wylie FG and Stow JL. Regulation of endocytosis, nuclear translocation, and signaling of fibroblast growth factor receptor 1 by E-cadherin. Mol Biol Cell 16: 14-23, 2005.

6. Cole NB and Lippincott-Schwartz J. Organization of organelles and membrane traffic by microtubules. Curr Opin Cell Biol 7: 55-64, 1995.

7. Corada M, Liao F, Lindgren M, Lampugnani MG, Breviario F, Frank R, Muller WA, Hicklin DJ, Bohlen P and Dejana E. Monoclonal antibodies directed to different regions of vascular endothelial cadherin extracellular domain affect 
adhesion and clustering of the protein and modulate endothelial permeability. Blood 97: 1679-1684, 2001.

8. Corada M, Mariotti M, Thurston G, Smith K, Kunkel R, Brockhaus M, Lampugnani MG, Martin-Padura I, Stoppacciaro A, Ruco L, McDonald DM, Ward PA and Dejana E. Vascular endothelial-cadherin is an important determinant of microvascular integrity in vivo. Proc Natl Acad Sci U S A 96: 9815-9820, 1999.

9. Corada M, Zanetta L, Orsenigo F, Breviario F, Lampugnani MG, Bernasconi S, Liao F, Hicklin DJ, Bohlen P and Dejana E. A monoclonal antibody to vascular endothelial-cadherin inhibits tumor angiogenesis without side effects on endothelial permeability 11. Blood 100: 905-911, 2002.

10. Daub H, Wallasch C, Lankenau A, Herrlich A and Ullrich A. Signal characteristics of $G$ protein-transactivated EGF receptor. EMBO J 16: 70327044, 1997.

11. Daub H, Weiss FU, Wallasch $\mathbf{C}$ and Ullrich A. Role of transactivation of the EGF receptor in signalling by G-protein-coupled receptors. Nature 379: 557-560, 1996.

12. Endo A, Nagashima K, Kurose H, Mochizuki S, Matsuda M and Mochizuki N. Sphingosine 1-phosphate induces membrane ruffling and increases motility of human umbilical vein endothelial cells via vascular endothelial growth factor receptor and Crkll

33. J Biol Chem 277: 23747-23754, 2002. 
13. Frid MG, Kale VA and Stenmark KR. Mature vascular endothelium can give rise to smooth muscle cells via endothelial-mesenchymal transdifferentiation: in vitro analysis. Circ Res 90: 1189-1196, 2002.

14. Garcia JG, Liu F, Verin AD, Birukova A, Dechert MA, Gerthoffer WT, Bamberg JR and English D. Sphingosine 1-phosphate promotes endothelial cell barrier integrity by Edg-dependent cytoskeletal rearrangement 10. J Clin Invest 108: 689-701, 2001.

15. Gavard J and Gutkind JS. VEGF controls endothelial-cell permeability by promoting the beta-arrestin-dependent endocytosis of VE-cadherin. Nat Cell Biol 8: 1223-1234, 2006.

16. Hamm-Alvarez SF and Sheetz MP. Microtubule-dependent vesicle transport: modulation of channel and transporter activity in liver and kidney 69. Physiol Rev 78: 1109-1129, 1998.

17. Igarashi J, Erwin PA, Dantas AP, Chen H and Michel T. VEGF induces S1P1 receptors in endothelial cells: Implications for cross-talk between sphingolipid and growth factor receptors. Proc Natl Acad Sci U S A 100: 10664-10669, 2003.

18. Kajimoto T, Okada T, Yu H, Goparaju SK, Jahangeer S and Nakamura S. Involvement of sphingosine-1-phosphate in glutamate secretion in hippocampal neurons. Mol Cell Biol 27: 3429-3440, 2007.

19. Le TL, Joseph SR, Yap AS and Stow JL. Protein kinase $C$ regulates endocytosis and recycling of E-cadherin. Am J Physiol Cell Physiol 283: C489C499, 2002. 
20. Le TL, Yap AS and Stow JL. Recycling of E-cadherin: a potential mechanism for regulating cadherin dynamics. J Cell Biol 146: 219-232, 1999.

21. Liao F, Li Y, O'Connor W, Zanetta L, Bassi R, Santiago A, Overholser J, Hooper A, Mignatti P, Dejana E, Hicklin DJ and Bohlen P. Monoclonal antibody to vascular endothelial-cadherin is a potent inhibitor of angiogenesis, tumor growth, and metastasis. Cancer Res 60: 6805-6810, 2000.

22. Lippincott-Schwartz $\mathbf{J}$ and Cole NB. Roles for microtubules and kinesin in membrane traffic between the endoplasmic reticulum and the Golgi complex. Biochem Soc Trans 23: 544-548, 1995.

23. Lock JG and Stow JL. Rab11 in recycling endosomes regulates the sorting and basolateral transport of E-cadherin 5. Mol Biol Cell 16: 1744-1755, 2005.

24. Mary S, Charrasse S, Meriane M, Comunale F, Travo P, Blangy A and Gauthier-Rouviere C. Biogenesis of N-cadherin-dependent cell-cell contacts in living fibroblasts is a microtubule-dependent kinesin-driven mechanism. Mol Biol Cell 13: 285-301, 2002.

25. Matsushita K, Morrell CN and Lowenstein CJ. Sphingosine 1-phosphate activates Weibel-Palade body exocytosis. Proc Natl Acad Sci U S A 101: 1148311487, 2004.

26. McVerry BJ and Garcia JG. Endothelial cell barrier regulation by sphingosine 1phosphate. J Cell Biochem 92: 1075-1085, 2004. 
27. McVerry BJ and Garcia JG. In vitro and in vivo modulation of vascular barrier integrity by sphingosine 1-phosphate: mechanistic insights. Cell Signal 17: 131139, 2005.

28. Mehta D, Konstantoulaki M, Ahmmed GU and Malik AB. Sphingosine 1phosphate-induced mobilization of intracellular $\mathrm{Ca} 2+$ mediates rac activation and adherens junction assembly in endothelial cells. J Biol Chem 280: 17320-17328, 2005.

29. Minnear FL, Zhu L and He P. Sphingosine 1-phosphate prevents plateletactivating factor-induced increase in hydraulic conductivity in rat mesenteric venules: pertussis toxin sensitive. Am J Physiol Heart Circ Physiol 289: H840H844, 2005.

30. Moore RH, Millman EE, pizar-Foster E, Dai W and Knoll BJ. Rab11 regulates the recycling and lysosome targeting of beta2-adrenergic receptors. J Cell Sci 117: 3107-3117, 2004.

31. Paik JH, Skoura A, Chae SS, Cowan AE, Han DK, Proia RL and Hla T. Sphingosine 1-phosphate receptor regulation of $\mathrm{N}$-cadherin mediates vascular stabilization

1. Genes Dev 18: 2392-2403, 2004.

32. Pan CY, Lee $\mathbf{H}$ and Chen CL. Lysophospholipids elevate [Ca2+]i and trigger exocytosis in bovine chromaffin cells. Neuropharmacology 51: 18-26, 2006.

33. Peden AA, Schonteich E, Chun J, Junutula JR, Scheller RH and Prekeris R. The RCP-Rab11 complex regulates endocytic protein sorting. Mol Biol Cell 15: 3530-3541, 2004. 
34. Peng X, Hassoun PM, Sammani S, McVerry BJ, Burne MJ, Rabb H, Pearse D, Tuder RM and Garcia JG. Protective effects of sphingosine 1-phosphate in murine endotoxin-induced inflammatory lung injury 1. Am J Respir Crit Care Med 169: 1245-1251, 2004.

35. Rapizzi E, Donati C, Cencetti F, Pinton P, Rizzuto R and Bruni P. Sphingosine 1-phosphate receptors modulate intracellular $\mathrm{Ca} 2+$ homeostasis. Biochem Biophys Res Commun 353: 268-274, 2007.

36. Sokolova IP, Arnautov AM, Blagoveshchenskaia AD, Nikol'skii NN and Kornilova ES. [Effect of nocodazole on endocytosis of epidermal growth factor receptor]. Tsitologiia 40: 855-861, 1998.

37. Somsel RJ and Wandinger-Ness A. Rab GTPases coordinate endocytosis 4. J Cell Sci 113 Pt 2: 183-192, 2000.

38. Stein MP, Dong J and Wandinger-Ness A. Rab proteins and endocytic trafficking: potential targets for therapeutic intervention 1. Adv Drug Deliv Rev 55: 1421-1437, 2003.

39. Tanimoto T, Jin ZG and Berk BC. Transactivation of vascular endothelial growth factor (VEGF) receptor Flk-1/KDR is involved in sphingosine 1phosphate-stimulated phosphorylation of Akt and endothelial nitric-oxide synthase (eNOS)

2. J Biol Chem 277: 42997-43001, 2002.

40. Wallenstein S, Zucker CL and Fleiss JL. Some statistical methods useful in circulation research. Circ Res 47: 1-9, 1980. 
41. Xiao K, Allison DF, Buckley KM, Kottke MD, Vincent PA, Faundez V and Kowalczyk AP. Cellular levels of p120 catenin function as a set point for cadherin expression levels in microvascular endothelial cells 5. J Cell Biol 163: 535-545, 2003.

42. Xiao K, Garner J, Buckley KM, Vincent PA, Chiasson CM, Dejana E, Faundez V and Kowalczyk AP. p120-Catenin regulates clathrin-dependent endocytosis of VE-cadherin. Mol Biol Cell 16: 5141-5151, 2005.

43. Xiao K, Oas RG, Chiasson CM and Kowalczyk AP. Role of p120-catenin in cadherin trafficking. Biochim Biophys Acta 1773: 8-16, 2007.

44. Xie J, Qian L, Wang Y, Hamm-Alvarez SF and Mircheff AK. Role of the microtubule cytoskeleton in traffic of EGF through the lacrimal acinar cell endomembrane network 2. Exp Eye Res 78: 1093-1106, 2004.

45. Xu M, Waters CL, Hu C, Wysolmerski RB, Vincent PA and Minnear FL. Sphingosine 1-phosphate rapidly increases endothelial barrier function independently of VE-cadherin but requires cell spreading and Rho kinase. Am J Physiol Cell Physiol 293: C1309-C1318, 2007.

46. Young KW and Nahorski SR. Sphingosine 1-phosphate: a Ca2+ release mediator in the balance 5. Cell Calcium 32: 335-341, 2002. 


\section{Study 3}

\section{p120 is potentially involved in the regulated VE-cadherin trafficking by S1P}

Keywords: kinesin, microtubule, Rab11, recycling endosome, human umbilical vein endothelial cell. 


\section{ABSTRACT}

My previous studies demonstrated that S1P regulates VE-cadherin trafficking by decreasing endocytosis and increasing recycling of VE-cadherin. However, what mechanisms contribute to these regulatory effects of S1P are still unclear. In this study, I found that under normal conditions (without EGTA), S1P increased the interaction of VE-cadherin with p120 and augmented the co-localization of VE-cadherin with p120 at cell-cell junctions; furthermore, S1P enhanced the association of p120 with biotinylated, cell surface VE-cadherin. After administration of EGTA to induce endocytosis of VEcadherin, association of $\mathrm{p} 120$ with VE-cadherin was increased by S1P as compared to the control treatment (MCDB) in HUVECs. S1P enhanced the co-localization of p120 with Rab11, a marker of recycling endosomes, and the interaction of p120 with kinesin, a motor protein moving along microtubules. In contrast, VEGF, previously demonstrated to induce endocytosis of VE-cadherin via increased interaction of VE-cadherin with $\beta$ arrestin2 (12), decreased the interaction of VE-cadherin with p120 in BPAEC monolayers. In addition, co-treatment of S1P with VEGF or post-treatment with S1P following pretreatment with VEGF blocked or reversed, respectively, the VEGF-induced effects. I conclude that the regulatory effects of S1P on VE-cadherin trafficking potentially occur through the increased interaction of VE-cadherin with p120, and the interaction of $\mathrm{p} 120$ with kinesin. 


\section{INTRODUCTION}

In my previous studies, I demonstrated that sphingosine 1-phosphate (S1P) enhances the endothelial barrier through regulation of VE-cadherin trafficking, i. e. decreasing endocytosis and increasing recycling of VE-cadherin. What cellular mechanisms contribute to this regulatory effects of S1P, however, are unclear. VEcadherin, a main protein of adherens junctions, stabilizes the endothelial barrier through homophilic binding of its extracellular region $(5,15)$. The cytoplasmic tail of VE-cadherin interacts with $\beta$-catenin and plakoglobin ( $\gamma$-catenin) which bind to $\alpha$-catenin. $\alpha$-Catenin in turn directly interacts with actin filaments. This sequential linkage, however, is controversial as one study has reported that $\alpha$-catenin does not bind simultaneously to actin and $\beta$-catenin (37). p120 catenin (p120) is the fourth catenin at the adherens junction. p120 binds to the cytoplasmic tail of VE-cadherin at the juxtamembrane domain and plays a crucial role to stabilize VE-cadherin. p120 also regulates adherens junctions indirectly through its functional connections with Rho GTPases $(2,3,14,28)$.

p120, a member of the armadillo family of proteins, consists of an $\mathrm{NH}_{2}$-terminal head domain, an ARM domain with 10 ARM repeats which is involved in the interaction of p120 with cadherin, and a short $\mathrm{COOH}$-terminal domain $(4,30)$. p120 was first described as a substrate of Src and other tyrosine kinases, but p120 is constantly found having multiple roles in cellular activities, well known as a stabilizer of cadherin $(4,10$, 16). Interaction of $\mathrm{p} 120$ with VE-cadherin regulates the expression of VE-cadherin which influences the regulation of the endothelial barrier. Gene silencing of p120 or mutation of the juxtamembrane domain on p120 binding site of VE-cadherin decreased the level of VE-cadherin, which was accompanied with internalization and degradation of VE-cadherin $(17,34,35)$. Whereas increasing or overexpression of p120 enhanced the level of VE-caderin. Decreases in the p120 level caused a loss of barrier function, however, overexpression of p120 also disrupted endothelial barrier (17). Hence, p120 plays an important role in regulating endothelial barrier function. p120 regulates not only VE-cadherin but also other cadherins. Gene silencing of p120 in cells expressing epithelial (E-), placental ( $\mathrm{P}-$ ) and neuronal $(\mathrm{N}-)$ cadherin induced rapid degradation of 
each cadherin, as well as $\alpha$ - and $\beta$-catenin, that resulted in the loss of adherens junctions (10).

In addition to interacting with cadherins, p120 associates with cortactin via the cortactin $\mathrm{N}$-terminal region to regulate lamellipodial dynamics and cell adhesion (6). Interestingly, Anastasiadis et al. (38) reported that p120 can traffic along microtubules via the direct interaction of its $\mathrm{N}$-terminal region with the kinesin heavy chain. Kinesin is a motor protein and transports vesicles from minus end to plus end (cell membrane) along microtubules $(21,24,25)$. p120 recruits and interacts with kinesin, this interaction regulates not only localization and function of $\mathrm{p} 120$, but also facilitates the transport of cadherin-catenin complexes to intercellular junctions $(8,38)$.

In my second study, I demonstrated that S1P-induced recycling of VE-cadherin traffics along microtubules. Mary et al. (26) reported that microtubules and kinesin are crucial for the transport of $\mathrm{N}$-cadherin to intercellular junctions. Furthermore, Paik et al. (29) showed that S1P induced microtubule polymerization, regulated the phosphorylation of $\mathrm{N}$-cadherin and $\mathrm{p} 120$, and mediated trafficking of $\mathrm{N}$-cadherin to the polarized plasma membrane. Here, I provide evidence that p120 potentially is involved in the effects of S1P on the regulation of VE-cadherin trafficking. Enhanced interaction of p120 with VE-cadherin by S1P in normal or $\mathrm{Ca}^{2+}$-switch experiments was investigated by using co-immunoprecipitation and biotinylation methods and visualized by confocal immunofluorescence microscopy. EGFP-tagged Rab11, a marker of the recycling endosome, was transfected into HUVECs to investigate the co-localization of p120 with recycling endosomes. The increased interaction of $p 120$ with kinesin by S1P was investigated by co-immunoprecipitation. 


\section{MATERIALS AND METHODS}

Materials. S1P was purchased from Avanti Polar Lipids (Alabaster, AL). Bovine pulmonary artery endothelial cells were purchased from Vec Technologies, Inc. (Rensselaer, NY). Gentamicin sulfate was from ICN Biomedicals, Inc. (Aurora, OH). Newborn calf serum and bovine brain extract were from Cambrex Corporation (East Rutherford, NJ). Sulfosuccinimidyl 2-(biotinamido) ethyl-dithioproprionate (sulfo-NHSSS-biotin) was purchased from Pierce (Rockford, IL). Recombinant human VEGF 165 was purchased from R\&D systems, Inc. (Minneapolis, MN). Prolong Gold anti-fade reagent and Alexa Fluor-labeled secondary antibodies were from Invitrogen Molecular Probes (Eugene, OR). VE-cadherin antibodies were purchased from Axxora (San Diego, CA) and Beckman Coulter Company (Marseille Cedex, France). Beta-catenin antibody was from BD Bioscience (San Jose, CA). p120-catenin antibody and protein A/G beads were from Santa Cruz Biotechnology (San Diego, CA). Horseradish peroxidase conjugated secondary antibodies and mouse anti-kinesin heavy chain antibody (clone 2) were purchased from Chemicon International (Temecula, CA). Nitrocellulose membranes and ECL (enhanced chemiluminescence) Western blotting detection reagents were purchased from Amersham Biosciences (Buckinghamshire, England). EGFP-tagged Rab11 was a gift from Dr. Karen Martin. All other chemicals were from Sigma-Aldrich (St. Louis, MO).

Cell culture. Human umbilical vein endothelial cells (HUVEC) were isolated from fresh human placentas by $1 \mathrm{mg} / \mathrm{ml}$ of type I collagenase and grown in MCDB-131 (MCDB) culture medium containing $5 \%(\mathrm{v} / \mathrm{v})$ human serum, $20 \%(\mathrm{v} / \mathrm{v})$ newborn calf serum, 7.5 $\mu \mathrm{g} / \mathrm{ml}$ of endothelial cell growth supplement, $4.5 \mu \mathrm{g} / \mathrm{ml}$ of bovine brain extract, $25 \mu \mathrm{g} / \mathrm{ml}$ of porcine intestinal heparin, and $50 \mu \mathrm{g} / \mathrm{ml}$ of gentamicin sulfate at $37^{\circ} \mathrm{C}$ in $5 \% \mathrm{CO}_{2}$. HUVECs were used between passages 2 and 8 . Before treatments, HUVEC monolayers were serum-starved for $2 \mathrm{~h}$. Bovine pulmonary artery endothelial cells (BPAEC, passages 3-18) were cultured in MCDB medium containing 10\% fetal bovine serum and $50 \mu \mathrm{g} / \mathrm{ml}$ of gentamicin sulfate. BPAEC monolayers were serum-starved for 
$4 \mathrm{~h}$ before treatments. HUVECs were used for all experiments except for experiments with VEGF.

$\mathrm{Ca}^{2+}$-switch protocol. Cell monolayers were treated with $2 \mathrm{mM}$ EGTA (ethylene glycolbis(2-amino-ethylether)-N,N,N',N'-tetra-acetic acid) for $10 \mathrm{~min}$ to chelate extracellular $\mathrm{Ca}^{2+}$, followed by (1) adding nothing, (2) adding fresh MCDB containing $1.6 \mathrm{mM} \mathrm{Ca}^{2+}$ to restore extracellular $\mathrm{Ca}^{2+}$, or (3) adding $1 \mu \mathrm{M}$ S1P and fresh MCDB.

Immunofluorescence microscopy. After treatments, cell monolayers were rinsed quickly with phosphate-buffered saline containing $\mathrm{Ca}^{2+}$ and $\mathrm{Mg}^{2+}(\mathrm{PBS}+/+)$. Cells were fixed, permeabilized, and incubated with 5\% BSA. Cells were then incubated with primary antibodies, followed by Alexa Fluor-labeled secondary antibodies, and rinsed several times with PBS+/+. Cells were mounted with Prolong Gold anti-fade reagent. Images were generated by confocal laser scanning with a Zeiss LSM 510 confocal microscope. For the same group of images, the fluorescent signals were measured at emission wavelengths of 488 and $594 \mathrm{~nm}$ with the same pinhole (less than $1 \mu \mathrm{m}$ ), the same detector gain, and the same amplifier offset.

Transfection. Enhanced GFP (EGFP)-tagged Rab11 was transfected into HUVECs by electroporation with the Nucleofector I device (Amaxa Biosystems, Berlin, Germany). Briefly, 90\% confluent HUVEC monolayers were trypsinized and counted. After centrifugation, $1.0 \times 10^{6}$ cells were resuspended in $100 \mu \mathrm{l}$ of Nucleofector solution $(7.25$ mM ATP, $12 \mathrm{mM} \mathrm{MgCl}_{2} \cdot 6 \mathrm{H}_{2} \mathrm{O}, 88 \mathrm{mM} \mathrm{KH}_{2} \mathrm{PO}_{4}, 14 \mathrm{mM} \mathrm{NaHCO}_{3}$, and $2 \mathrm{mM}$ glucose at $\mathrm{pH}$ 7.4) with EGFP-tagged Rab11 and transferred immediately to a cuvette and electroporated in the Nucleofector apparatus, using program U-001. Transfected cells were recovered with fresh medium at $37^{\circ} \mathrm{C}$ for $5 \mathrm{~min}$ and seeded on gelatin-coated glass cover-slips. Cells were placed in a humidified environment and maintained at $37^{\circ} \mathrm{C}$ and $5 \% \mathrm{CO}_{2}$ for $2 \mathrm{~d}$ until used for experimentation.

Immunoblotting. Cells were washed $2 x$ in ice-cold PBS, lysed in RIPA buffer (15 mM $\mathrm{NaCl}, 50 \mathrm{mM}$ Tris, $1 \% \mathrm{NP}-40,0.5 \%$ sodium deoxycholate) containing $2 \mathrm{mM}$ EGTA, 1 
$\mathrm{mM}$ sodium vanadate, $1 \mathrm{mM}$ phenylmethanesulfonyl fluoride (PMSF), $5 \mu \mathrm{g} / \mathrm{ml}$ of aprotinin, and $2 \mu \mathrm{g} / \mathrm{ml}$ of leupeptin. Samples were clarified by centrifugation at 14,000 rpm for $10 \mathrm{~min}$ at $4^{\circ} \mathrm{C}$. Proteins were resolved by sodium dodecyl sulfatepolyacrylamide gel electrophoresis (SDS-PAGE) and transferred to Nitrocellulose membrane using a mini-Protean electrophoresis system. Protein blots were probed with indicated primary antibodies, followed by the appropriate horseradish peroxidaseconjugated secondary antibody, and developed by enhanced chemiluminescence.

Biotinylation assay for assessment of cell surface VE-cadherin. Cell surface VEcadherin and membrane protein-bound p120 were quantified by using a biotinylation assay $(7,22)$. Cell surface proteins were covalently labeled with $1.0 \mathrm{mg} / \mathrm{ml}$ of sulfosuccinimidyl 2-(biotinamido) ethyl-dithioproprionate (sulfo-NHS-SS-biotin), a biotinlabeled cell impermeable reagent. Briefly, after indicated treatments, cells were incubated at $0^{\circ} \mathrm{C}$ with the sulfo-NHS-SS-biotin for $1 \mathrm{~h}$, followed by washing with blocking buffer to quench free biotin. Cells were lysed in RIPA buffer with protease inhibitors. Equal amounts of proteins were incubated with streptavidin beads and resolved by SDS-PAGE. Biotinylated, cell surface VE-cadherin was identified with an anti-VEcadherin antibody to the extracellular domain. p120 immunoprecipitated in biotin was identified with a rabbit anti-p120 antibody.

Co-immunoprecipitation. Cells were lysed in RIPA buffer with phosphatase and protease inhibitors, and lysates were centrifuged at $14,000 \mathrm{rpm}$ for $10 \mathrm{~min}$ at $4^{\circ} \mathrm{C}$ to clear debris. About $2 \mathrm{mg}$ of protein was incubated with a rabbit anti-human VEcadherin antibody or mouse anti-bovine kinesin heavy chain antibody for $2 \mathrm{~h}$ at $4^{\circ} \mathrm{C}$ after preclearing with $50 \mu \mathrm{l}$ of protein $A / G$ beads for $1 \mathrm{~h}$. Protein $A / G$ beads were added and incubated for additional hour to pull down antibody-bound proteins. Beads were washed with RIPA buffer several times and boiled in 3x sample buffer. Proteins were resolved and analyzed by Western blotting.

Statistics. All values are means \pm SE and were obtained in at least four separate experiments. 


\section{RESULTS}

S1P increased interaction of VE-cadherin with p120. Within 10 min of treatment,

a
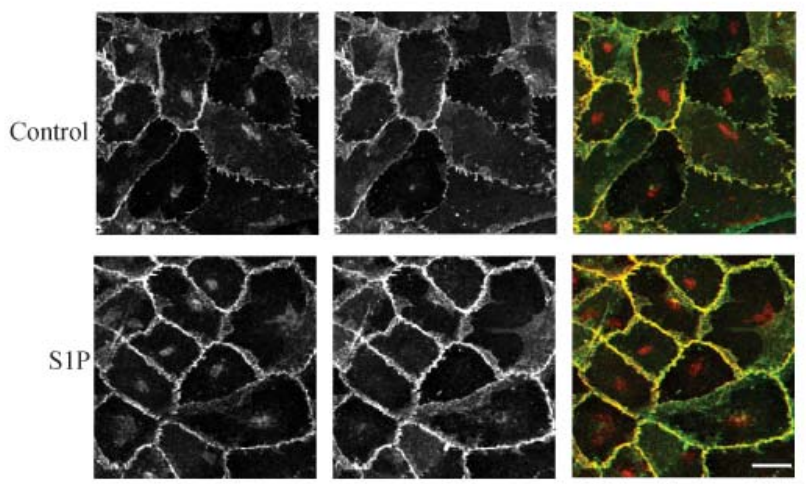

pl20

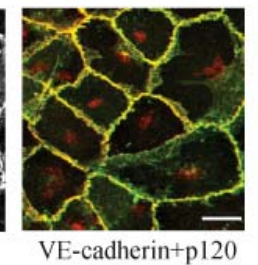

b

c

IP: VE-cadherin

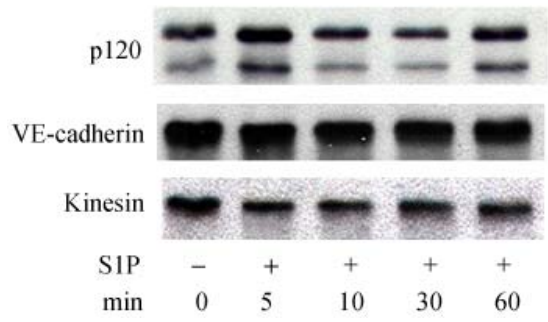

IP: Biotin (Cell surafce)

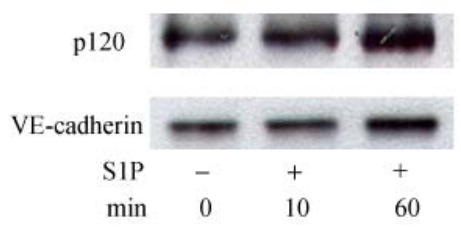

Figure 1. S1P increased interaction of VE-cadherin with p120. HUVEC monolayers were treated with $1 \mu \mathrm{M} \mathrm{S1P}$, and co-localization and interaction of VE-cadherin with p120 were determined by immunofluorescence microscopy (a), immunoprecipitation (b) and cell surface biotinylation (c). (a) Cells were treated with S1P for $10 \mathrm{mim}$, then stained by mouse anti-human VE-cadherin and rabbit anti-mouse p120 antibodies. (b) Cell lysates were immunoprecipitated with a rabbit anti-human VE-cadherin antibody against $\mathrm{N}$-terminal domain to pull down VE-cadherin-bound proteins and resolved on SDS-PAGE. p120, kinesin and VE-cadherin were identified by $\mathrm{p} 120$, VE-cadherin or mouse anti-bovine kinesin heavy chain antibodies. (c) Cell surface proteins were incubated with sulfo-NHS-SS-biotin at $0^{\circ} \mathrm{C}$ after S1P treatments, and equal amount of protein was incubated with streptavidin beads to complex biotin-labeled proteins. VE-cadherin and p120 were identified by the antibodies used in (b). Blot is representative of 3 separate experiments. Scale bar, $10 \mu \mathrm{m}$.

$1 \mu \mathrm{M}$ S1P increased the co-localization of immunofluorescent staining of VE-cadherin and p120 at intercellular junctions (Fig. 1a). This increased association of VE-cadherin 
with p120 was also demonstrated by co-immunoprecipitation and biotinylation (Fig. 1b, c). S1P enhanced the interaction of VE-cadherin with p120 at 5 min (Fig. $1 \mathrm{~b}$, top bands). Interestingly, the interaction of VE-cadherin with kinesin did not increase until 30 min (Fig. 1b bottom bands). S1P increased biotinylated, cell surface VE-cadherin at
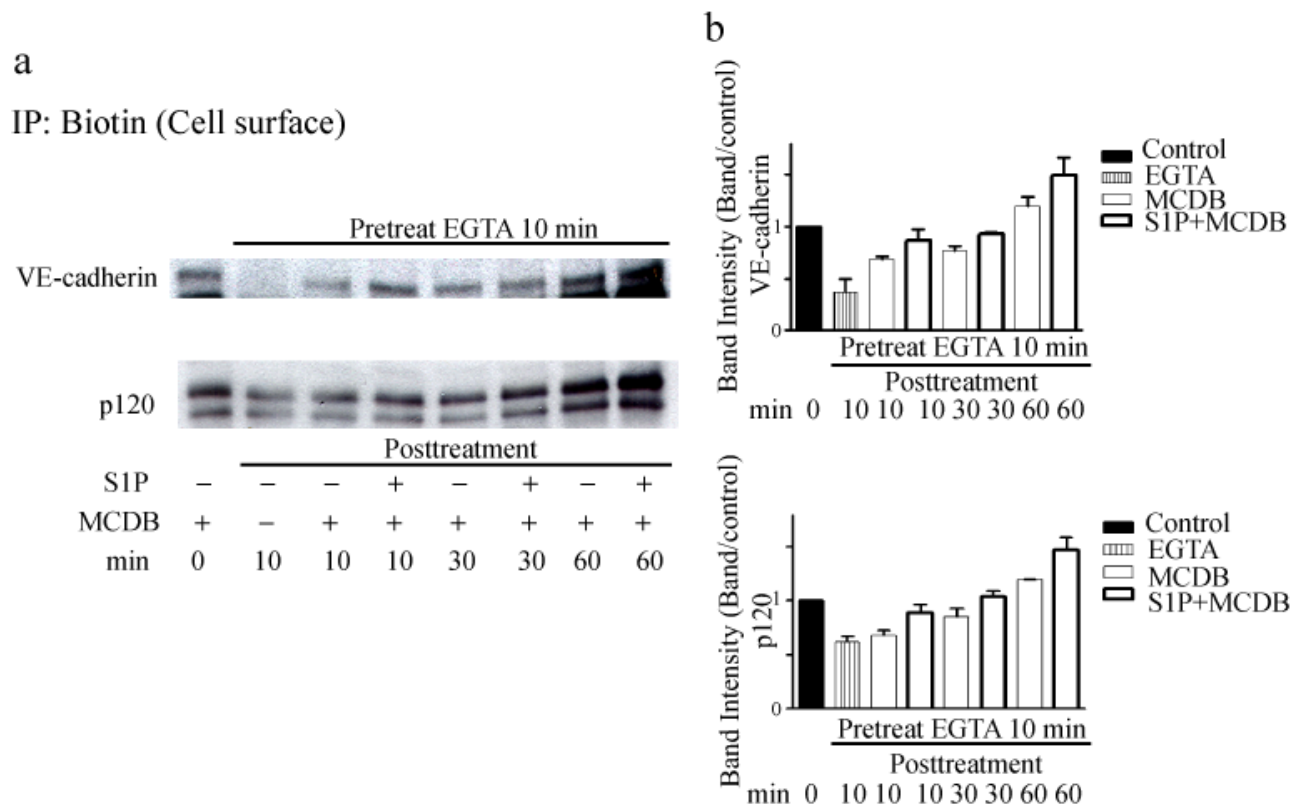

Figure 2. S1P enhanced the interaction of p120 with recycled, cell surface VE-cadherin. Interaction of p120 with recycled VE-cadherin was performed by pretreatment with $2 \mathrm{mM}$ EGTA to reduce cell surface VE-cadherin and post-treatment with or without S1P. (a) Cell surface VE-cadherin and p120 were assessed by the biotinylation method. (b) Quantification of four immunoblots shown as a ratio of individual band to control band.

10 and 60 min (also demontrated in study 2) (Fig. 1c, top bands), and also biotinylated, cell surface protein-bound p120 (Fig. 2c, bottom bands).

S1P enhanced the interaction of p120 with recycled VE-cadherin. Quantitative measurement of the interaction of cell surface protein-bound p120 with cell surface VEcadherin was highlighted by using the $\mathrm{Ca}^{2+}$-switch protocol. Administration of $2 \mathrm{mM}$ EGTA decreased most of biotinylated, cell surface VE-cadherin (Fig. 2a, top band/second lane), but just partially decreased the level of p120 (Fig. 2a, bottom band/second lane). Subsequently, HUVEC monolayers were post-treated with MCDB to restore extracellular $\mathrm{Ca}^{2+}$ with or without S1P. Post-treatment with S1P plus MCDB 
recovered cell surface VE-cadherin to a greater extent than those post-treatments
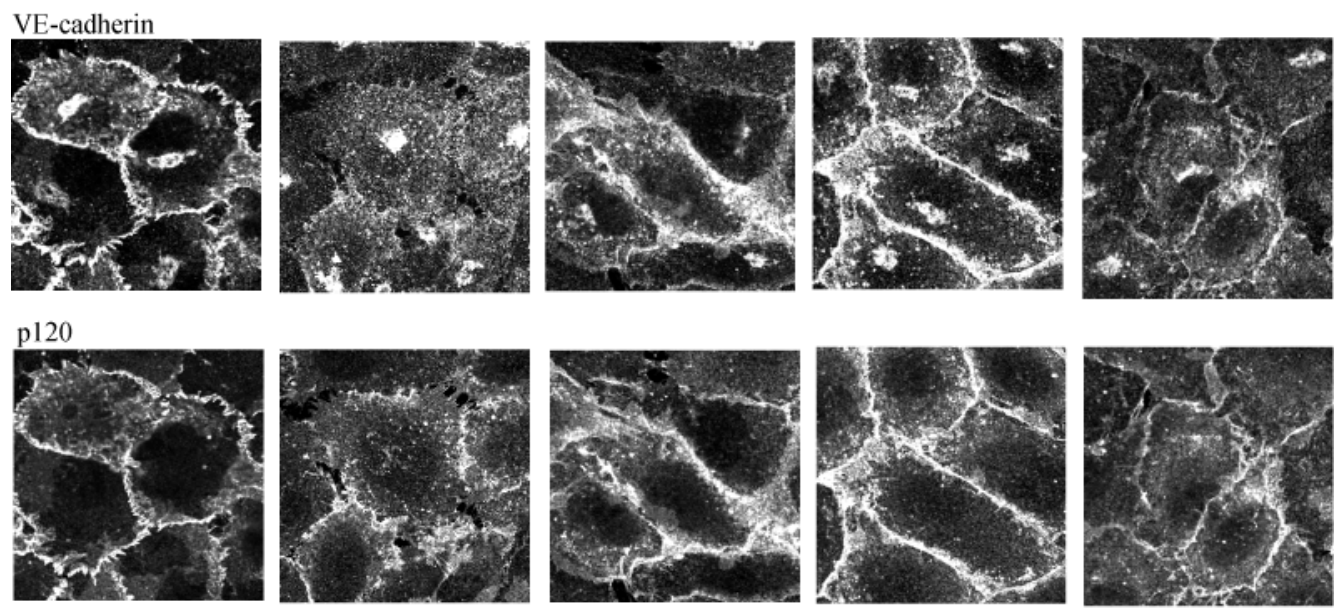

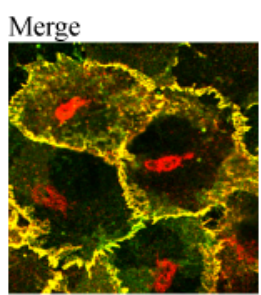

Control

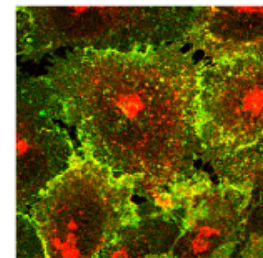

EGTA $10 \mathrm{~min}$
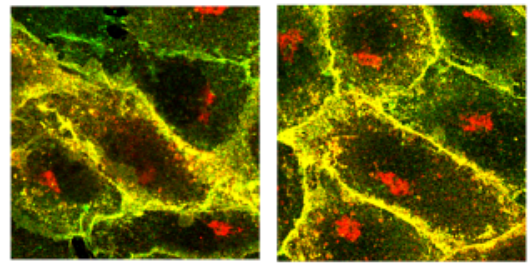

Pretreat EGTA $10 \mathrm{~min}$

Posttreatment

$\mathrm{S} 1 \mathrm{P}+\mathrm{MCDB} 10 \mathrm{~min}$

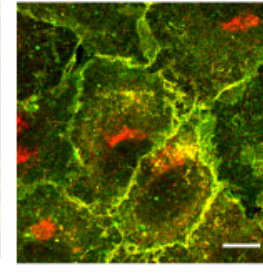

MCDB $10 \mathrm{~min}$

Figure 3. S1P increased the co-localization of p120 with recycled VE-cadherin. HUVEC monolayers were pretreated with $2 \mathrm{mM}$ EGTA to reduce cell surface and increase internalized VE-cadherin followed by post-treated with or without S1P. VE-cadherin was visualized by incubation with a mouse anti-human VE-cadherin primary antibody (Cad 5) and an Alexa Fluor 594-labeled goat anti-mouse secondary antibody. p120 was visualized by incubation with a rabbit anti-mouse p120 antibody and an Alexa Fluor488-labeled goat anti-rabbit secondary antibody. Note that p120 co-localized with VE-cadherin at the peripheral region in the groups treated with S1P for $5 \mathrm{~min}$, and co-localized with VEcadherin at both peripheral and junctional area in the groups treated with S1P for 10 min. Scale bar, $10 \mu \mathrm{m}$.

without S1P (Fig. 2a, b, top bands/bar, $4^{\text {th }}, 6^{\text {th }}$ and $8^{\text {th }}$ lane/bar vs. $3^{\text {rd }}, 5^{\text {th }}$ and $7^{\text {th }}$ lane/bar). Accompanied increase of p120 with increased recycled, cell surface VEcadherin was observed (Fig. 2a, b, bottom bands/bar). In addition, the interaction of p120 with VE-cadherin was higher in the S1P-treated groups compared with the MCDB groups (Fig. $2 \mathrm{a}, \mathrm{b}$, bottom bands/bars, $4^{\text {th }}, 6^{\text {th }}$ and $8^{\text {th }}$ lane/bar vs. $3^{\text {rd }}, 5^{\text {th }}$ and $7^{\text {th }}$ lane/bar). 
The increased interaction of $\mathrm{p} 120$ with recycled VE-cadherin by S1P was confirmed by immunofluorescent staining (Fig. 3). VE-cadherin co-localized with p120 at the intercellular junctions observed in the control setting (Fig. 3, control column). Administration of EGTA caused decreases in junctional VE-cadherin and p120, a reduction of the co-localization of VE-cadherin with $\mathrm{p} 120$, and induced internalization of VE-cadherin and p120 from the junction to cytoplasm (Fig. $3,2^{\text {nd }}$ column). p120 disassociated from internalized VE-cadherin and did not co-localize with it (Fig. 3, merge row, $2^{\text {nd }}$ column). However, post-treatment with S1P for 5 min facilitated the transport of internalized VE-cadherin and p120 to the cell peripheral area (Fig. 3, top and middle row, $3^{\text {rd }}$ column) and increased the co-localization of p120 with VE-cadherin at these regions (Fig. 3, merge row, $3^{\text {rd }}$ column). At $10 \mathrm{~min}$, there was an obvious codistribution of junctional VE-cadherin and p120 (Fig. 3, $4^{\text {th }}$ column). There was no colocalization of p120 with VE-cadherin after post-treatment with MCDB for $5 \mathrm{~min}$ and limited co-localization was observed at $10 \mathrm{~min}$ (Fig. 3, merge row, $5^{\text {th }}$ column). These data suggest that S1P increases the transport of VE-cadherin and p120 to adherens junctions.

S1P increased co-localization of p120 with Rab11. To test if $\mathrm{p} 120$ plays a role during the S1P-facilitated recycling process, enhanced GFP-tagged Rab11 was transiently electroporated into HUVECs, and cells were visualized by confocal microscopy. p120 was reduced at cell junctions by administration of EGTA (Fig. 3 and 4). Post-treatment of S1P for 5 min induced co-localization of p120 with Rab11 at the subplasma membrane and at the intercellular junction (Fig. 4, $3^{\text {rd }}$ column). No interaction of p120 with Rab11 was observed in the MCDB-treated group (Fig. $4,4^{\text {th }}$ column). 

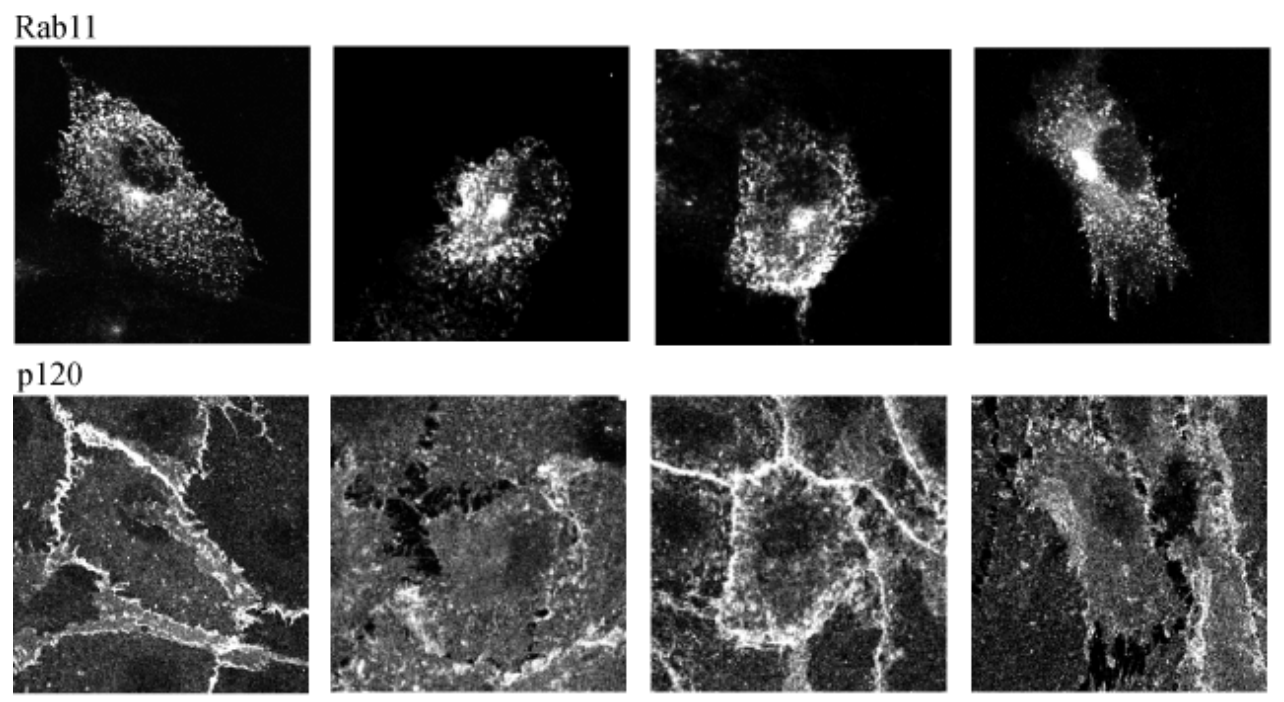

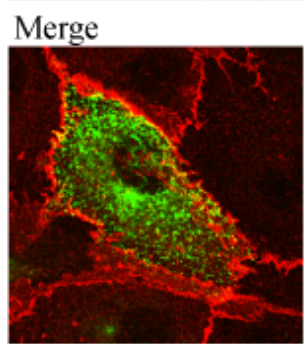

Control

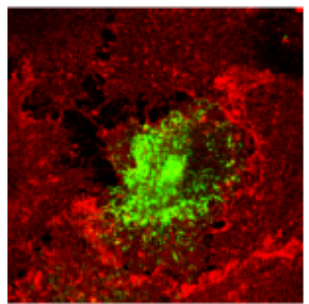

EGTA $10 \mathrm{~min}$
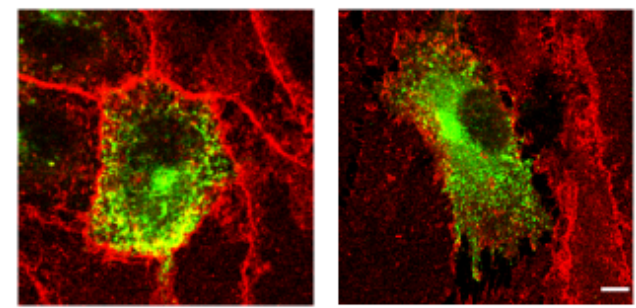

Pretreat EGTA $10 \mathrm{~min}$

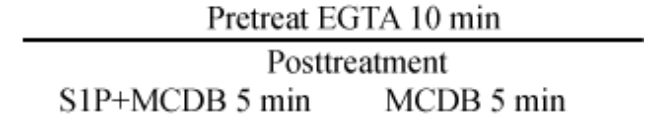

Figure 4. S1P increased co-localization of p120 with Rab11. EGFP-tagged Rab11 was transiently transfected into HUVECs by electroporation. After $48 \mathrm{~h}$, cell monolayers were treated with or without S1P following pretreatment with EGTA. p120 was visualized by incubation with a rabbit anti-mouse p120 antibody and an Alexa Fluor 594-labeled goat antirabbit secondary antibody. Note that p120 co-localized with Rab11 at the peripheral area within 5 min in S1P treated group. Scale bar, $5 \mu \mathrm{m}$.

S1P increased interaction of p120 with kinesin. Data in study 2 demonstrated that S1P facilitated recycling of VE-cadherin through microtubules (study 2, Fig. 9). Kinesin, a plus-end directed motor protein, facilitates transport of vesicles along microtubules $(24,25)$. Interestingly, p120 was reported to associate with kinesin and facilitate transport of cadherin-catenin complexes to intercellular junctions (8). Herein, I tested how p120 is involved in the effects of S1P to facilitate the transport of VEcadherin. The $\mathrm{Ca}^{2+}$-switch protocol was applied to induce endocytosis of VE-cadherin followed by post-treatment with or without S1P to restore cell surface VE-cadherin. The 
interaction of p120 with kinesin was assessed by co-immunoprecipitation. Posttreatment with S1P dramatically enhanced the interaction of p120 with kinesin within 5 and $10 \mathrm{~min}$ of treatment compared to post-treatment with MCDB alone (Fig. 5). Together the data in Figures 2 and 3 suggest that S1P increases recycling of VEcadherin back to cell surface by increasing the interaction of recycling VE-cadherin with p120 and recruiting kinesin to the complex and facilitating recycling of VE-cadherin.

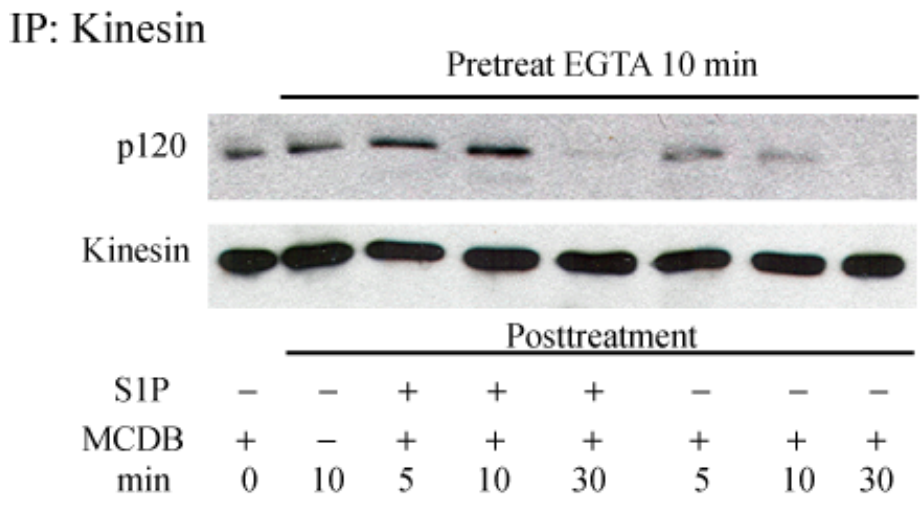

Figure 5. S1P increased interaction of $p 120$ with kinesin. HUVEC monolayers were posttreated with or without S1P for 5, 10 and 30 min following pretreatment with EGTA. Cell lysates were incubated with a mouse anti-bovine kinesin heavy chain antibody (clone 2) to complex kinesin-bound proteins and immunoblotted for p120 and kinesin. Blot is representative of 4 separate experiments. Note that S1P increased interaction of $p 120$ with kinesin compared to MCDB group.

S1P inhibited and reversed decreased interaction of VE-cadherin with p120 by VEGF. Since EGTA, used to induce endocytosis of VE-cadherin, is not a physiological reagent, I next studied the effects of S1P on the interaction of VE-cadherin with p120 in BPAEC monolayers using the physiological mediator VEGF. VEGF decreased the interaction of VE-cadherin with p120 in a time-dependent manner (Fig. 6, lane 2 and 3), but S1P increased this interaction in the same temperal manner (Fig. 6, lane 4 and 5). Furthermore, co-treatment of S1P with VEGF and post-treatment with S1P after pretreatment with VEGF for 30 min blocked and reversed, respectively, the VEGF-induced decrease in interaction of VE-cadherin with p120 (lane 6 and 7). These data suggest 
that the cellular mechanism of S1P protection from the vascular barrier effects of VEGF may occur through regulation of the interaction of p120 with VE-cadherin.

IP: VE-cadherin (in BPAECs)

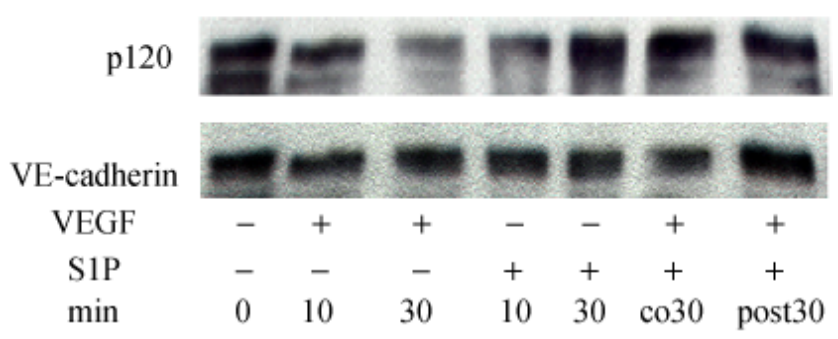

Figure 6. S1P inhibited and reversed decreased interaction of VE-cadherin with $p 120$ by VEGF. Endothelial cell monolayers derived from bovine pulmonary arteries (BPAEC) were treated individually with S1P or VEGF or in combination or pretreated for $30 \mathrm{~min}$ with VEGF then post-treated for $30 \mathrm{~min}$ with S1P. Cell lysates were immunoprecipitated with a rabbit anti-human VE-cadherin antibody and immunoblotted for p120 and VE-cadherin. Note that VEGF decreased the interaction of VE-cadherin with $\mathrm{p} 120, \mathrm{~S} 1 \mathrm{P}$ increased it and co-treatment or post-treatment with S1P blocked and reversed VEGF effects. Blot is representative of 3 separate experiments. 


\section{DISCUSSION}

In this study, the role of $\mathrm{p} 120$ in the S1P effects on regulation of VE-cadherin trafficking were investigated. Xiao et al. $(10,34-36)$ reported that p120 is crucial for regulating expression and trafficking of VE-cadherin. Paik et al. (29) showed that p120 was involved in N-cadherin trafficking mediated by S1P. Here, I demonstrated that S1P increased co-localization and interaction of p120 with VE-cadherin in whole cell lysate and at the cell surface. EGTA or VEGF were applied to highlight the study of S1P effects on the trafficking of VE-cadherin. S1P increased recycling of VE-cadherin to a greater extent and faster than MCDB (also demonstrated in study 2), and this increase was accompanied with an increased interaction and co-localization of p120 with recycled, cell surface VE-cadherin, as well as with Rab11. Interestingly, S1P also enhanced the interaction of $\mathrm{p} 120$ with kinesin. Furthermore, S1P blocked and reversed the VEGF-induced decrease in interaction of VE-cadherin with $\mathrm{p} 120$. I conclude that S1P increases VE-cadherin trafficking through enhanced interaction of p120 with VEcadherin and with kinesin to facilitate this transport.

Interaction of p120 with VE-cadherin is important for maintenance of endothelial barrier function (17), and this is a dual interactions: one, p120 interacts with cell surface VE-cadherin to stabilize junctional VE-cadherin; two, p120 interacts with recycled VEcadherin in the cytoplasm. In the first case, Xiao et al. $(35,36)$ reported that p120 works as a cap to interact with the cytoplasmic tail of VE-cadherin and inhibits the endocytosis of VE-cadherin. I found that S1P increased the association of $\mathrm{p} 120$ with cell surface VEcadherin and inhibited the dynamic endocytosis of VE-cadherin (demonstrated in study 2). Hence, during the normal situation, S1P enhances junctional VE-cadherin via an increase in the interaction of p120 with cell surface VE-cadherin. However, it is unclear if p120 also interacts with internalized VE-cadherin, I did not see any co-localization of p120 with cytoplasmic VE-cadherin in the control group (Fig. 1a), but this may be due to the small amount of VE-cadherin that dynamically internalizes. Interestingly, p120 was reported to facilitate transport of itself and cadherin-catenin complex to cell-cell junctions $(8,38)$, so the interaction of cytosolic p120 with recycling cadherin may 
influence the recycling process. EGTA or VEGF was added to augment the internalization of VE-cadherin. During the initial endocytosis process, p120 disassociated from internalized VE-cadherin and no-co-localization was observed as previously reported by Xiao et al. (35). When S1P was added to launch the recycling process of VE-cadherin (demonstrated in study 2), p120 interacted primarily with recycled VE-cadherin and coincidently with Rab11, a marker and pivotal protein of recycling endosomes. p120 also interacted with cell surface VE-cadherin following the recovery process. So far, the role of the small GTPase, Rab11, in the transport of VEcadherin facilitated by $\mathrm{p} 120$ is not characterized. In summary, S1P facilitated the recycling of VE-cadherin possibly through an enhanced interaction of p120 with recycled cell surface VE-cadherin.

The role of p120 in S1P effects may also involve the Rho family of GTPases. Rho family GTPases, such as Rac1, RhoA and Cdc42 are important for regulation of the endothelial barrier, actin cytoskeleton, cell spreading and migration, as well as cadherin trafficking $(1,18-20,31-33)$. S1P activates Rac1, Cdc42, as well as RhoA and remodels the actin cytoskeleton $(9,13,23,27)$. p120 was reported to bind to the Rho family exchange factor Vav2 to activate Rac and Cdc42 (28) and even directly to Rho A through its Arm domain (11). Therefore, the sequence and linkage among S1P, Rho family GTPases and p120 with regard to VE-cadherin trafficking need further investigation.

Interaction of $\beta$-arrestin2 with VE-cadherin triggers internalization of VE-cadherin. VEGF was reported to induce endocytosis of VE-cadherin through a $\beta$-arrestin2dependent pathway (12). In study 2, I found that S1P had the opposite effect. S1P suppressed and reversed the VEGF-induced interaction of VE-cadherin with $\beta$-arrestin2. Moreover, the present study identified that VEGF decreased the interaction of p120 with VE-cadherin. In contrast, S1P increased this interaction and co-treatment or posttreatment with S1P suppressed or reversed the VEGF effects. $\beta$-arrestin2 binds to a conserved, phosphorylated Ser-Val-Arg (SVR) motif on the intracellular domain of VEcadherin where the SVR motif is just adjacent to the p120 binding region (12). The 
increased interaction of $\mathrm{p} 120$ with VE-cadherin by S1P may cap the intracellular domain of VE-cadherin and inhibit the binding of $\beta$-arrestin2 to VE-cadherin. S1P may also regulate the phosphorylation level of the SVR motif, which in turn blocks VE-cadherin endocytosis. All of these hypotheses need to be studied in the future.

Microtubules together with kinesin play a crucial role in the transport of $\mathrm{N}$ cadherin to cell-cell junctions $(26,29)$. p120 can directly associate with kinesin and microtubules (11). The interaction of p120 with kinesin facilitates the transport of $p 120$ and the cadherin-catenin complex $(8,38)$. In study 2 , I demonstrated that S1P regulated VE-cadherin trafficking via microtubules (study 2, Fig. 8). The present study revealed that S1P increased the interaction of p120 with kinesin and with VE-cadherin. However, it is unclear whether or not VE-cadherin can directly bind to kinesin or bind through p120 because kinesin was pulled down by immunoprecipitation with the VE-cadherin antibody not by a p120 antibody. Thus, p120 may work as a scaffold to link VE-cadherin and kinesin. Interestingly during normal conditions, S1P increased the interaction of p120 with kinesin (through immunoprecipitation of VE-cadherin) within $30 \mathrm{~min}$ of treatment. But during the recycling process induced by EGTA, this increased interaction by S1P occurred as early as $5 \mathrm{~min}$. These data provide evidence to support that S1P has a dual role in VE-cadherin trafficking: one is inhibition of endocytosis; another is the enhancement of recycling. p120 may be involved in both processes. 


\section{REFERENCES}

Reference List

1. Adamson RH, Curry FE, Adamson G, Liu B, Jiang Y, Aktories K, Barth H, Daigeler A, Golenhofen N, Ness W and Drenckhahn D. Rho and rho kinase modulation of barrier properties: cultured endothelial cells and intact microvessels of rats and mice. J Physiol 539: 295-308, 2002.

2. Anastasiadis PZ. p120-ctn: A nexus for contextual signaling via Rho GTPases. Biochim Biophys Acta 1773: 34-46, 2007.

3. Anastasiadis PZ, Moon SY, Thoreson MA, Mariner DJ, Crawford HC, Zheng $\mathrm{Y}$ and Reynolds AB. Inhibition of RhoA by p120 catenin. Nat Cell Biol 2: 637$644,2000$.

4. Anastasiadis $\mathbf{P Z}$ and Reynolds $\mathbf{A B}$. The $\mathrm{p} 120$ catenin family: complex roles in adhesion, signaling and cancer. J Cell Sci 113 ( Pt 8): 1319-1334, 2000.

5. Bazzoni G and Dejana E. Endothelial cell-to-cell junctions: molecular organization and role in vascular homeostasis. Physiol Rev 84: 869-901, 2004.

6. Boguslavsky S, Grosheva I, Landau E, Shtutman M, Cohen M, Arnold K, Feinstein E, Geiger B and Bershadsky A. p120 catenin regulates lamellipodial dynamics and cell adhesion in cooperation with cortactin. Proc Natl Acad Sci U S A 104: 10882-10887, 2007. 
7. Bryant DM, Wylie FG and Stow JL. Regulation of endocytosis, nuclear translocation, and signaling of fibroblast growth factor receptor 1 by E-cadherin. Mol Biol Cell 16: 14-23, 2005.

8. Chen X, Kojima S, Borisy GG and Green KJ. p120 catenin associates with kinesin and facilitates the transport of cadherin-catenin complexes to intercellular junctions. J Cell Biol 163: 547-557, 2003.

9. Czeloth N, Bernhardt G, Hofmann F, Genth H and Forster R. Sphingosine-1phosphate mediates migration of mature dendritic cells. J Immunol 175: 29602967, 2005.

10. Davis MA, Ireton RC and Reynolds AB. A core function for p120-catenin in cadherin turnover

5. J Cell Biol 163: 525-534, 2003.

11. Franz CM and Ridley AJ. p120 catenin associates with microtubules: inverse relationship between microtubule binding and Rho GTPase regulation. J Biol Chem 279: 6588-6594, 2004.

12. Gavard J and Gutkind JS. VEGF controls endothelial-cell permeability by promoting the beta-arrestin-dependent endocytosis of VE-cadherin. Nat Cell Biol 8: 1223-1234, 2006.

13. Gonzalez E, Kou R and Michel T. Rac1 modulates sphingosine 1-phosphatemediated activation of phosphoinositide 3-kinase/Akt signaling pathways in vascular endothelial cells. J Biol Chem 281: 3210-3216, 2006.

14. Grosheva I, Shtutman M, Elbaum M and Bershadsky AD. p120 catenin affects cell motility via modulation of activity of Rho-family GTPases: a link between cell- 
cell contact formation and regulation of cell locomotion. J Cell Sci 114: 695-707, 2001.

15. Huber $\mathbf{O}$, Kemler $\mathbf{R}$ and Langosch $\mathbf{D}$. Mutations affecting transmembrane segment interactions impair adhesiveness of E-cadherin. J Cell Sci 112 ( Pt 23): 4415-4423, 1999.

16. Ireton RC, Davis MA, van HJ, Mariner DJ, Barnes K, Thoreson MA, Anastasiadis PZ, Matrisian L, Bundy LM, Sealy L, Gilbert B, van RF and Reynolds AB. A novel role for p120 catenin in E-cadherin function. J Cell Biol 159: 465-476, 2002.

17. lyer S, Ferreri DM, DeCocco NC, Minnear FL and Vincent PA. VE-cadherinp120 interaction is required for maintenance of endothelial barrier function 4. Am J Physiol Lung Cell Mol Physiol 286: L1143-L1153, 2004.

18. Izumi G, Sakisaka T, Baba T, Tanaka S, Morimoto K and Takai Y. Endocytosis of E-cadherin regulated by Rac and Cdc42 small G proteins through IQGAP1 and actin filaments. J Cell Biol 166: 237-248, 2004.

19. Kamei T, Matozaki T, Sakisaka T, Kodama A, Yokoyama S, Peng YF, Nakano K, Takaishi K and Takai Y. Coendocytosis of cadherin and c-Met coupled to disruption of cell-cell adhesion in MDCK cells--regulation by Rho, Rac and Rab small $G$ proteins 5. Oncogene 18: 6776-6784, 1999.

20. Katoh $\mathbf{H}$, Hiramoto $\mathrm{K}$ and Negishi M. Activation of Rac1 by RhoG regulates cell migration. J Cell Sci 119: 56-65, 2006. 
21. Kumar J, Yu H and Sheetz MP. Kinectin, an essential anchor for kinesin-driven vesicle motility

84. Science 267: 1834-1837, 1995.

22. Le TL, Yap AS and Stow JL. Recycling of E-cadherin: a potential mechanism for regulating cadherin dynamics. J Cell Biol 146: 219-232, 1999.

23. Lee JF, Ozaki H, Zhan X, Wang E, Hla T and Lee MJ. Sphingosine-1phosphate signaling regulates lamellipodia localization of cortactin complexes in endothelial cells

4. Histochem Cell Biol 126: 297-304, 2006.

24. Lippincott-Schwartz $\mathbf{J}$ and Cole NB. Roles for microtubules and kinesin in membrane traffic between the endoplasmic reticulum and the Golgi complex. Biochem Soc Trans 23: 544-548, 1995.

25. Lippincott-Schwartz J, Cole NB, Marotta A, Conrad PA and Bloom GS. Kinesin is the motor for microtubule-mediated Golgi-to-ER membrane traffic 4. J Cell Biol 128: 293-306, 1995.

26. Mary S, Charrasse S, Meriane M, Comunale F, Travo P, Blangy A and Gauthier-Rouviere C. Biogenesis of N-cadherin-dependent cell-cell contacts in living fibroblasts is a microtubule-dependent kinesin-driven mechanism 2. Mol Biol Cell 13: 285-301, 2002.

27. McVerry BJ and Garcia JG. In vitro and in vivo modulation of vascular barrier integrity by sphingosine 1-phosphate: mechanistic insights. Cell Signal 17: 131139, 2005. 
28. Noren NK, Liu BP, Burridge $\mathrm{K}$ and Kreft B. p120 catenin regulates the actin cytoskeleton via Rho family GTPases. J Cell Biol 150: 567-580, 2000.

29. Paik JH, Skoura A, Chae SS, Cowan AE, Han DK, Proia RL and Hla T. Sphingosine 1-phosphate receptor regulation of $\mathrm{N}$-cadherin mediates vascular stabilization

1. Genes Dev 18: 2392-2403, 2004.

30. Reynolds AB, Daniel JM, Mo YY, Wu J and Zhang Z. The novel catenin p120cas binds classical cadherins and induces an unusual morphological phenotype in NIH3T3 fibroblasts. Exp Cell Res 225: 328-337, 1996.

31. Waschke J, Burger S, Curry FR, Drenckhahn D and Adamson RH. Activation of Rac-1 and Cdc42 stabilizes the microvascular endothelial barrier. Histochem Cell Biol 125: 397-406, 2006.

32. Wojciak-Stothard B, Potempa S, Eichholtz T and Ridley AJ. Rho and Rac but not Cdc42 regulate endothelial cell permeability. J Cell Sci 114: 1343-1355, 2001.

33. Wojciak-Stothard B and Ridley AJ. Rho GTPases and the regulation of endothelial permeability. Vascul Pharmacol 39: 187-199, 2002.

34. Xiao K, Allison DF, Buckley KM, Kottke MD, Vincent PA, Faundez V and Kowalczyk AP. Cellular levels of p120 catenin function as a set point for cadherin expression levels in microvascular endothelial cells. J Cell Biol 163: 535-545, 2003. 
35. Xiao K, Garner J, Buckley KM, Vincent PA, Chiasson CM, Dejana E, Faundez V and Kowalczyk AP. p120-Catenin regulates clathrin-dependent endocytosis of VE-cadherin. Mol Biol Cell 16: 5141-5151, 2005.

36. Xiao K, Oas RG, Chiasson CM and Kowalczyk AP. Role of p120-catenin in cadherin trafficking. Biochim Biophys Acta 1773: 8-16, 2007.

37. Yamada S, Pokutta S, Drees F, Weis WI and Nelson WJ. Deconstructing the cadherin-catenin-actin complex. Cell 123: 889-901, 2005.

38. Yanagisawa M, Kaverina IN, Wang A, Fujita $Y$, Reynolds $A B$ and Anastasiadis PZ. A novel interaction between kinesin and p120 modulates p120 localization and function. J Biol Chem 279: 9512-9521, 2004. 


\section{GENERAL REFERENCES}

\section{Reference List}

1. Alexander JS, Alexander BC, Eppihimer LA, Goodyear N, Haque R, Davis CP, Kalogeris TJ, Carden DL, Zhu YN and Kevil CG. Inflammatory mediators induce sequestration of VE-cadherin in cultured human endothelial cells. Inflammation 24: 99-113, 2000.

2. Alexander JS, Jackson SA, Chaney E, Kevil CG and Haselton FR. The role of cadherin endocytosis in endothelial barrier regulation: involvement of protein kinase C and actin-cadherin interactions. Inflammation 22: 419-433, 1998.

3. Anastasiadis $\mathbf{P Z}$ and Reynolds $\mathbf{A B}$. The $\mathrm{p} 120$ catenin family: complex roles in adhesion, signaling and cancer. J Cell Sci 113 ( Pt 8): 1319-1334, 2000.

4. Argraves KM and Argraves WS. HDL serves as a S1P signaling platform mediating a multitude of cardiovascular effects. J Lipid Res 48: 2325-2333, 2007.

5. Bazzoni G and Dejana E. Endothelial cell-to-cell junctions: molecular organization and role in vascular homeostasis. Physiol Rev 84: 869-901, 2004.

6. Bazzoni G, Martinez EO and Dejana E. Molecular structure and functional role of vascular tight junctions. Trends Cardiovasc Med 9: 147-152, 1999.

7. Bobryshev YV, Cherian SM, Inder SJ and Lord RS. Neovascular expression of VE-cadherin in human atherosclerotic arteries and its relation to intimal inflammation

1. Cardiovasc Res 43: 1003-1017, 1999. 
8. Bryant DM and Stow JL. The ins and outs of E-cadherin trafficking. Trends Cell Biol 14: 427-434, 2004.

9. Bryant DM, Wylie FG and Stow JL. Regulation of endocytosis, nuclear translocation, and signaling of fibroblast growth factor receptor 1 by E-cadherin. Mol Biol Cell 16: 14-23, 2005.

10. Cavallaro U, Liebner S and Dejana E. Endothelial cadherins and tumor angiogenesis. Exp Cell Res 312: 659-667, 2006.

11. Charrier L, Yan Y, Nguyen HT, Dalmasso G, Laboisse CL, Gewirtz AT, Sitaraman SV and Merlin D. ADAM-15/metargidin mediates homotypic aggregation of human $T$ lymphocytes and heterotypic interactions of $\mathrm{T}$ lymphocytes with intestinal epithelial cells. J Biol Chem 282: 16948-16958, 2007.

12. Chen X, Kojima S, Borisy GG and Green KJ. p120 catenin associates with kinesin and facilitates the transport of cadherin-catenin complexes to intercellular junctions

5. J Cell Biol 163: 547-557, 2003.

13. Corada M, Liao F, Lindgren M, Lampugnani MG, Breviario F, Frank R, Muller WA, Hicklin DJ, Bohlen P and Dejana E. Monoclonal antibodies directed to different regions of vascular endothelial cadherin extracellular domain affect adhesion and clustering of the protein and modulate endothelial permeability. Blood 97: 1679-1684, 2001.

14. Corada M, Zanetta L, Orsenigo F, Breviario F, Lampugnani MG, Bernasconi S, Liao F, Hicklin DJ, Bohlen P and Dejana E. A monoclonal antibody to vascular endothelial-cadherin inhibits tumor angiogenesis without side effects on 
endothelial permeability

11. Blood 100: 905-911, 2002.

15. Davis MA, Ireton RC and Reynolds AB. A core function for p120-catenin in cadherin turnover

5. J Cell Biol 163: 525-534, 2003.

16. Dejana E. Endothelial cell-cell junctions: happy together. Nat Rev Mol Cell Biol 5: 261-270, 2004.

17. Dejana E, Bazzoni G and Lampugnani MG. Vascular endothelial (VE)cadherin: only an intercellular glue? Exp Cell Res 252: 13-19, 1999.

18. Dejana E, Spagnuolo R and Bazzoni G. Interendothelial junctions and their role in the control of angiogenesis, vascular permeability and leukocyte transmigration. Thromb Haemost 86: 308-315, 2001.

19. Frid MG, Kale VA and Stenmark KR. Mature vascular endothelium can give rise to smooth muscle cells via endothelial-mesenchymal transdifferentiation: in vitro analysis

1. Circ Res 90: 1189-1196, 2002.

20. Garcia JG, Liu F, Verin AD, Birukova A, Dechert MA, Gerthoffer WT, Bamberg JR and English D. Sphingosine 1-phosphate promotes endothelial cell barrier integrity by Edg-dependent cytoskeletal rearrangement 10. J Clin Invest 108: 689-701, 2001.

21. Gavard J and Gutkind JS. VEGF controls endothelial-cell permeability by promoting the beta-arrestin-dependent endocytosis of VE-cadherin. Nat Cell Biol 8: 1223-1234, 2006. 
22. Gonzalez E, Kou R and Michel T. Rac1 modulates sphingosine 1-phosphatemediated activation of phosphoinositide 3-kinase/Akt signaling pathways in vascular endothelial cells. J Biol Chem 281: 3210-3216, 2006.

23. Hadjout N, Laevsky G, Knecht DA and Lynes MA. Automated real-time measurement of chemotactic cell motility. Biotechniques 31: 1130-1138, 2001.

24. Hadjout N, Yin X, Knecht DA and Lynes MA. Automated real-time measurements of leukocyte chemotaxis. J Immunol Methods 320: 70-80, 2007.

25. Hamm-Alvarez SF and Sheetz MP. Microtubule-dependent vesicle transport: modulation of channel and transporter activity in liver and kidney 69. Physiol Rev 78: 1109-1129, 1998.

26. Hla T, Lee MJ, Ancellin N, Thangada S, Liu CH, Kluk M, Chae SS and Wu MT. Sphingosine-1-phosphate signaling via the EDG-1 family of G-proteincoupled receptors

3. Ann N Y Acad Sci 905: 16-24, 2000.

27. Ito K, Anada Y, Tani M, Ikeda M, Sano T, Kihara A and Igarashi Y. Lack of sphingosine 1-phosphate-degrading enzymes in erythrocytes

1. Biochem Biophys Res Commun 357: 212-217, 2007.

28. lyer S, Ferreri DM, DeCocco NC, Minnear FL and Vincent PA. VE-cadherinp120 interaction is required for maintenance of endothelial barrier function 4. Am J Physiol Lung Cell Mol Physiol 286: L1143-L1153, 2004.

29. Kajimoto T, Okada T, Yu H, Goparaju SK, Jahangeer S and Nakamura S. Involvement of sphingosine-1-phosphate in glutamate secretion in hippocampal neurons. Mol Cell Biol 27: 3429-3440, 2007. 
30. Koch T, Duncker HP, Rosenkranz S, Neuhof H and Van AK. Alterations of filtration coefficients in pulmonary edema of different pathogenesis. J Appl Physiol 73: 2396-2402, 1992.

31. Lampugnani MG, Caveda L, Breviario F, Del MA and Dejana E. Endothelial cell-to-cell junctions. Structural characteristics and functional role in the regulation of vascular permeability and leukocyte extravasation. Baillieres Clin Haematol 6: 539-558, 1993.

32. Lampugnani MG, Orsenigo F, Gagliani MC, Tacchetti $C$ and Dejana E. Vascular endothelial cadherin controls VEGFR-2 internalization and signaling from intracellular compartments. J Cell Biol 174: 593-604, 2006.

33. Le TL, Joseph SR, Yap AS and Stow JL. Protein kinase C regulates endocytosis and recycling of E-cadherin. Am J Physiol Cell Physiol 283: C489C499, 2002.

34. Le TL, Yap AS and Stow JL. Recycling of E-cadherin: a potential mechanism for regulating cadherin dynamics. J Cell Biol 146: 219-232, 1999.

35. Lee JF, Ozaki H, Zhan X, Wang E, Hla T and Lee MJ. Sphingosine-1phosphate signaling regulates lamellipodia localization of cortactin complexes in endothelial cells

4. Histochem Cell Biol 126: 297-304, 2006.

36. Lee MJ, Thangada S, Claffey KP, Ancellin N, Liu CH, Kluk M, Volpi M, Sha'afi RI and Hla T. Vascular endothelial cell adherens junction assembly and morphogenesis induced by sphingosine-1-phosphate

4. Cell 99: 301-312, 1999. 
37. Lee MJ, Van B, Jr., Thangada S, Liu CH, Hand AR, Menzeleev R, Spiegel S and Hla T. Sphingosine-1-phosphate as a ligand for the G protein-coupled receptor EDG-1

9. Science 279: 1552-1555, 1998.

38. Liao F, Li Y, O'Connor W, Zanetta L, Bassi R, Santiago A, Overholser J, Hooper A, Mignatti P, Dejana E, Hicklin DJ and Bohlen P. Monoclonal antibody to vascular endothelial-cadherin is a potent inhibitor of angiogenesis, tumor growth, and metastasis. Cancer Res 60: 6805-6810, 2000.

39. Lippincott-Schwartz $\mathbf{J}$ and Cole NB. Roles for microtubules and kinesin in membrane traffic between the endoplasmic reticulum and the Golgi complex. Biochem Soc Trans 23: 544-548, 1995.

40. Lippincott-Schwartz J, Cole NB, Marotta A, Conrad PA and Bloom GS. Kinesin is the motor for microtubule-mediated Golgi-to-ER membrane traffic 4. J Cell Biol 128: 293-306, 1995.

41. Lock JG and Stow JL. Rab11 in recycling endosomes regulates the sorting and basolateral transport of E-cadherin

5. Mol Biol Cell 16: 1744-1755, 2005.

42. Lum $\mathbf{H}$ and Malik AB. Mechanisms of increased endothelial permeability 13. Can J Physiol Pharmacol 74: 787-800, 1996.

43. Mary S, Charrasse S, Meriane M, Comunale F, Travo P, Blangy A and Gauthier-Rouviere C. Biogenesis of N-cadherin-dependent cell-cell contacts in living fibroblasts is a microtubule-dependent kinesin-driven mechanism 2. Mol Biol Cell 13: 285-301, 2002. 
44. Matsushita K, Morrell CN and Lowenstein CJ. Sphingosine 1-phosphate activates Weibel-Palade body exocytosis. Proc Natl Acad Sci U S A 101: 1148311487, 2004.

45. McVerry BJ and Garcia JG. Endothelial cell barrier regulation by sphingosine 1phosphate. J Cell Biochem 92: 1075-1085, 2004.

46. McVerry BJ and Garcia JG. In vitro and in vivo modulation of vascular barrier integrity by sphingosine 1-phosphate: mechanistic insights. Cell Signal 17: 131139, 2005.

47. Mehta D, Konstantoulaki M, Ahmmed GU and Malik AB. Sphingosine 1phosphate-induced mobilization of intracellular $\mathrm{Ca} 2+$ mediates rac activation and adherens junction assembly in endothelial cells. J Biol Chem 280: 17320-17328, 2005.

48. Moore RH, Millman EE, pizar-Foster E, Dai W and Knoll BJ. Rab11 regulates the recycling and lysosome targeting of beta2-adrenergic receptors. J Cell Sci 117: 3107-3117, 2004.

49. Neco P, Giner D, del Mar FM, Viniegra S and Gutierrez LM. Differential participation of actin- and tubulin-based vesicle transport systems during secretion in bovine chromaffin cells 14. Eur J Neurosci 18: 733-742, 2003.

50. Olson AL, Trumbly AR and Gibson GV. Insulin-mediated GLUT4 translocation is dependent on the microtubule network 22. J Biol Chem 276: 10706-10714, 2001. 
51. Paik JH, Chae S, Lee MJ, Thangada S and Hla T. Sphingosine 1-phosphateinduced endothelial cell migration requires the expression of EDG-1 and EDG-3 receptors and Rho-dependent activation of alpha vbeta3- and beta1-containing integrins

30. J Biol Chem 276: 11830-11837, 2001.

52. Paik JH, Skoura A, Chae SS, Cowan AE, Han DK, Proia RL and Hla T. Sphingosine 1-phosphate receptor regulation of $\mathrm{N}$-cadherin mediates vascular stabilization

1. Genes Dev 18: 2392-2403, 2004.

53. Prekeris R. Rabs, Rips, FIPs, and endocytic membrane traffic 2. ScientificWorldJournal 3: 870-880, 2003.

54. Ren J, Xiao YJ, Singh LS, Zhao X, Zhao Z, Feng L, Rose TM, Prestwich GD and $\mathrm{Xu} Y$ Y. Lysophosphatidic acid is constitutively produced by human peritoneal mesothelial cells and enhances adhesion, migration, and invasion of ovarian cancer cells. Cancer Res 66: 3006-3014, 2006.

55. Saba JD and Hla T. Point-counterpoint of sphingosine 1-phosphate metabolism 8. Circ Res 94: 724-734, 2004.

56. Saxena NK, Sharma D, Ding X, Lin S, Marra F, Merlin D and Anania FA. Concomitant activation of the JAK/STAT, PI3K/AKT, and ERK signaling is involved in leptin-mediated promotion of invasion and migration of hepatocellular carcinoma cells. Cancer Res 67: 2497-2507, 2007.

57. Schaphorst KL, Chiang E, Jacobs KN, Zaiman A, Natarajan V, Wigley F and Garcia JG. Role of sphingosine-1 phosphate in the enhancement of endothelial 
barrier integrity by platelet-released products. Am J Physiol Lung Cell Mol Physiol 285: L258-L267, 2003.

58. Shikata Y, Birukov KG and Garcia JG. S1P induces FA remodeling in human pulmonary endothelial cells: role of Rac, GIT1, FAK, and paxillin 25. J Appl Physiol 94: 1193-1203, 2003.

59. Somsel RJ and Wandinger-Ness A. Rab GTPases coordinate endocytosis 4. J Cell Sci 113 Pt 2: 183-192, 2000.

60. Stein MP, Dong J and Wandinger-Ness A. Rab proteins and endocytic trafficking: potential targets for therapeutic intervention 1. Adv Drug Deliv Rev 55: 1421-1437, 2003.

61. Stevens T, Garcia JG, Shasby DM, Bhattacharya J and Malik AB. Mechanisms regulating endothelial cell barrier function 11. Am J Physiol Lung Cell Mol Physiol 279: L419-L422, 2000.

62. Vincent PA, Xiao K, Buckley KM and Kowalczyk AP. VE-cadherin: adhesion at arm's length. Am J Physiol Cell Physiol 286: C987-C997, 2004.

63. Xiao K, Allison DF, Buckley KM, Kottke MD, Vincent PA, Faundez V and Kowalczyk AP. Cellular levels of p120 catenin function as a set point for cadherin expression levels in microvascular endothelial cells. J Cell Biol 163: 535-545, 2003.

64. Xiao K, Garner J, Buckley KM, Vincent PA, Chiasson CM, Dejana E, Faundez V and Kowalczyk AP. p120-Catenin regulates clathrin-dependent endocytosis of VE-cadherin. Mol Biol Cell 16: 5141-5151, 2005. 
65. Xiao K, Oas RG, Chiasson CM and Kowalczyk AP. Role of p120-catenin in cadherin trafficking. Biochim Biophys Acta 1773: 8-16, 2007.

66. Xie J, Qian L, Wang Y, Hamm-Alvarez SF and Mircheff AK. Role of the microtubule cytoskeleton in traffic of EGF through the lacrimal acinar cell endomembrane network

2. Exp Eye Res 78: 1093-1106, 2004.

67. Yanagisawa M, Kaverina IN, Wang A, Fujita $Y$, Reynolds $A B$ and Anastasiadis PZ. A novel interaction between kinesin and p120 modulates p120 localization and function

4. J Biol Chem 279: 9512-9521, 2004.

68. Zerial $\mathbf{M}$ and $\mathbf{M c B r i d e} \mathbf{H}$. Rab proteins as membrane organizers. Nat Rev $\mathrm{Mol}$ Cell Biol 2: 107-117, 2001. 